Florida International University FIU Digital Commons

FIU Electronic Theses and Dissertations

University Graduate School

7-19-2010

\title{
Employee Engagement: An Examination of Antecedent and Outcome Variables
}

Michael B. Shuck

Florida International University, brad.shuck@gmail.com

DOI: $10.25148 /$ etd.FI10080415

Follow this and additional works at: https:// digitalcommons.fiu.edu/etd

Part of the Human Resources Management Commons

\section{Recommended Citation}

Shuck, Michael B., "Employee Engagement: An Examination of Antecedent and Outcome Variables" (2010). FIU Electronic Theses and Dissertations. 235.

https://digitalcommons.fiu.edu/etd/235

This work is brought to you for free and open access by the University Graduate School at FIU Digital Commons. It has been accepted for inclusion in FIU Electronic Theses and Dissertations by an authorized administrator of FIU Digital Commons. For more information, please contact dcc@fiu.edu. 


\section{FLORIDA INTERNATIONAL UNIVERSITY}

Miami, Florida

\section{EMPLOYEE ENGAGEMENT: AN EXAMINATION OF ANTECEDENT AND OUTCOME VARIABLES}

A dissertation submitted in partial fulfillment of the

requirements for the degree of

DOCTOR OF EDUCATION

in

ADULT EDUCATION

AND

HUMAN RESOURCE DEVELOPMENT

by

Michael Bradley Shuck

2010 
To: Interim Dean Delia C. Garcia

College of Education

This dissertation, written by Michael Bradley Shuck, and entitled Employee Engagement: An Examination of Antecedent and Outcome Variables, having been approved in respect to style and intellectual content, is referred to you for judgment.

We have read this dissertation and recommend that it be approved.

Keith Revell

Tonette S. Rocco

Delia C. Garcia

Thomas G. Reio Jr., Major Professor

Date of Defense: July 19, 2010

The dissertation of Michael Bradley Shuck is approved.

Interim Dean Delia C. Garcia College of Education

Interim Dean Kevin O'Shea University Graduate School

Florida International University, 2010 
(C) Copyright 2010 by Michael Bradley Shuck

All rights reserved. 


\section{DEDICATION}

To our daughter, Madalyn Grace. We loved you before you were born. 


\section{ACKNOWLEDGMENTS}

It can be said that no one completes a dissertation alone, and for me this could not be a more true statement. First, I owe special gratitude to Dr. Thomas G. Reio, Jr., my major professor and dissertation chair. His guidance, mentorship, and belief in this project were critical to its completion. There is no doubt, his dedication to service is unparalleled and unmatched. Additionally, a very special thank you to Dr. Tonette S. Rocco, Dr. Delia C. Garcia, and Dr. Keith Revell who in addition to my chair, agreed to serve on my committee and provide guidance for this process. Thank you all for your assistance, teaching, and reading as well as for the many comments you provided over the past few years. Without you, this project may have never gotten off the ground. Additionally, I would like to acknowledge support from the Dissertation Evidence Acquisition Fellowship, prestigiously provided by the University Graduate School at Florida International University, toward the completion of this research project.

To my family who always believed in me, especially to my mom and dad who shaped a young man's character at an early age. Your unwavering love for me is a cornerstone for the man you see today. Thank you for always encouraging my curiosity. To my lovely wife, who supportively agreed to so many short weekends and calls of "ten more minutes" over the past few years. Angie, you were always with me, encouraging me to take it one step at a time, believing that we could do this together. Your love, support, and friendship are the most important elements of my life. I look so forward to the next chapter of our lives together. I love you with everything that I am. 
To friends and mentors near and far, and to whom many without this process we may have never met. Thank you for reading the many drafts and providing such wonderful encouragement and feedback. Most of all, thank you for your support.

To my Heavenly Father. My God, I am so very blessed. My cup runneth over with your grace, mercy, and love. To you be the glory and through you, all things are possible. 


\title{
ABSTRACT OF THE DISSERTATION \\ EMPLOYEE ENGAGEMENT: AN EXAMINATION OF ANTECEDENT AND OUTCOME VARIABLES \\ by
}

\author{
Michael Bradley Shuck
}

Florida International University, 2010

Miami, Florida

Professor Thomas G. Reio, Jr., Major Professor

This nonexperimental, correlational study $(N=283)$ examined the relation among job fit, affective commitment, psychological climate, discretionary effort, intention to turnover, and employee engagement. An internet-based self-report survey battery of six scales were administered to a heterogeneous sampling of organizations from the fields of service, technology, healthcare, retail, banking, nonprofit, and hospitality. Hypotheses were tested through correlational and hierarchical regression analytic procedures.

Job fit, affective commitment, and psychological climate were all significantly related to employee engagement and employee engagement was significantly related to both discretionary effort and intention to turnover. For the discretionary effort model, the hierarchical regression analysis results suggested that the employees who reported experiencing a positive psychological climate were more likely to report higher levels of discretionary effort. As for the intention to turnover model, the hierarchical regression analysis results indicated that affective commitment and employee engagement predicted lower levels of an employee's intention to turnover. 
The regression beta weights ranged from to .43 to .78 , supporting the theoretical, empirical, and practical relevance of understanding the impact of employee engagement on organizational outcomes. Implications for HRD theory, research, and practice are highlighted as possible strategic leverage points for creating conditions that facilitate the development of employee engagement as a means for improving organizational performance. 


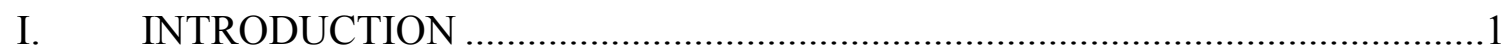

Background to the Problem ............................................................................

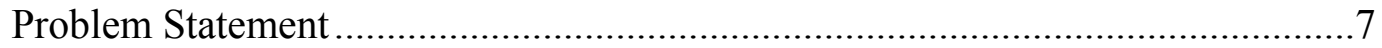

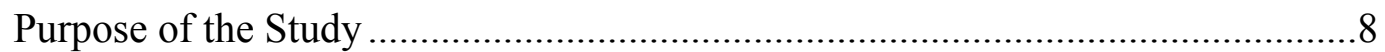

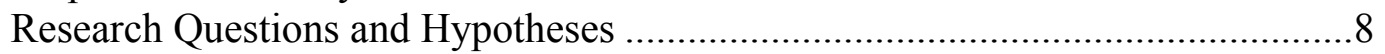

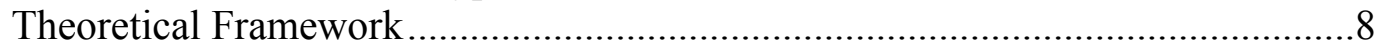

Antecedent Variables ..................................................................................

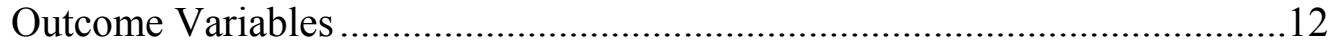

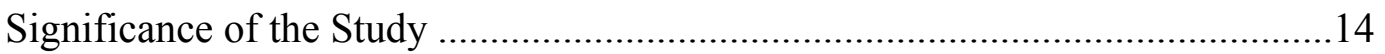

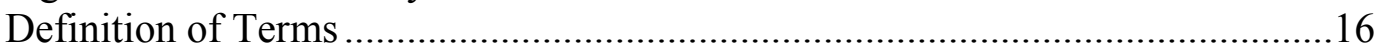

Assumptions and Delimitations of the Study …………...................................17

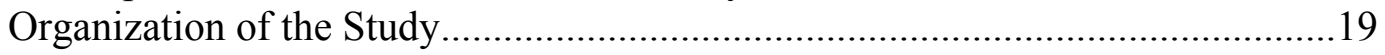

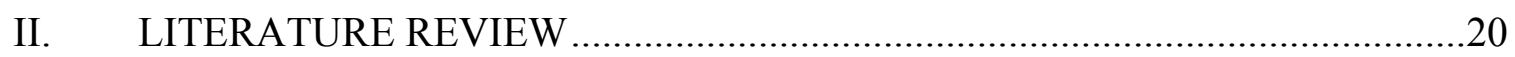

Employee Engagement: Situating the Concept ...................................................20

Review of the Academic Perspective of Employee Engagement ......................... 23

Summary of the Employee Engagement Literature ……………………................37

Potential Demographic and Personality Variables that Effect Employee

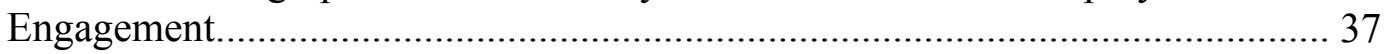

Race and Employee Engagement ...................................................................38

Age and Employee Engagement ………………………............................38

Gender and Employee Engagement …………………....................................39

Workplace Location and Employee Engagement ...........................................39

Personality Variables and Employee Engagement.............................................40

Antecedents of Employee Engagement..............................................................

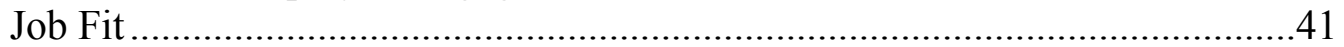

Affective Commitment ..............................................................................45

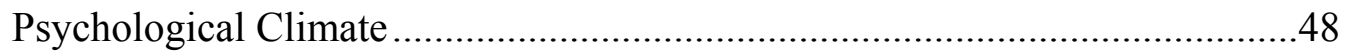

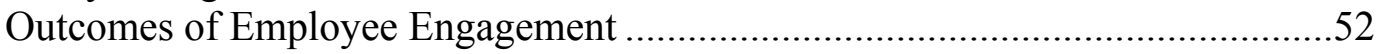

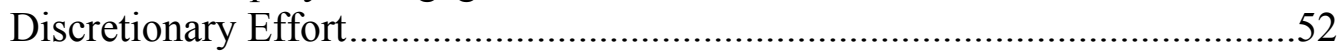

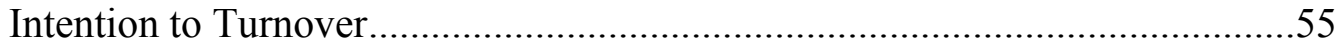

Proposed Employee Engagement Model ………………..................................56

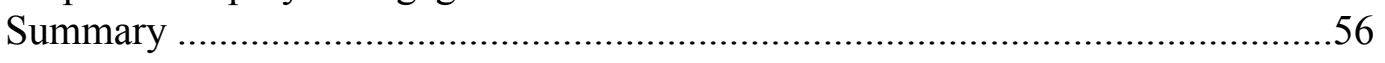

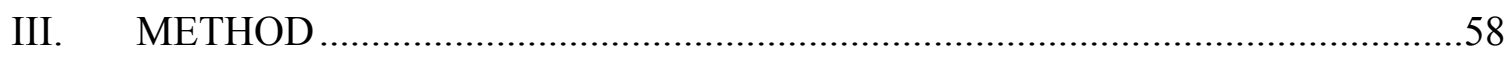

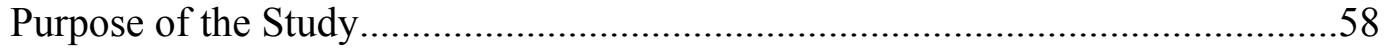

Research Questions and Hypotheses ................................................................ 58

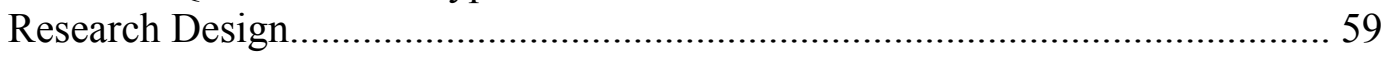

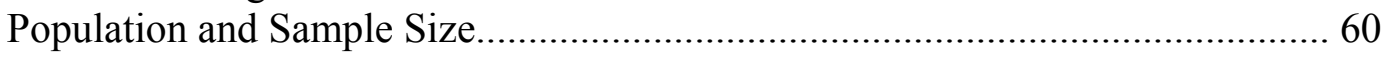

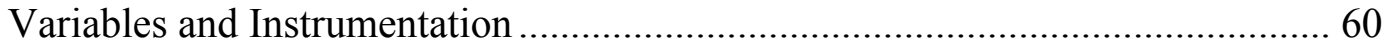




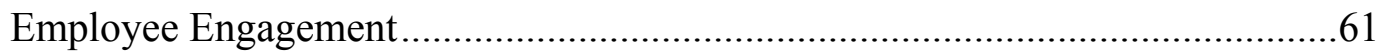

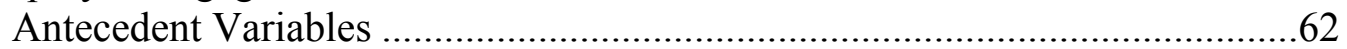

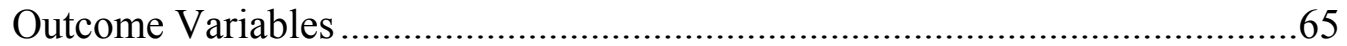

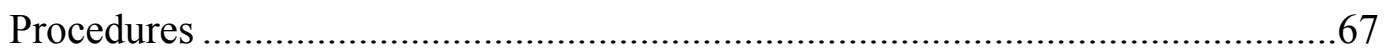

Internet Survey Research...........................................................................67

Internet-Based Self-Report Surveys ............................................................68

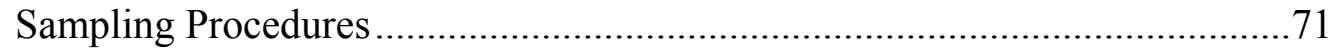

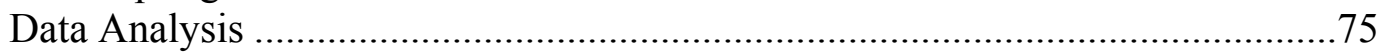

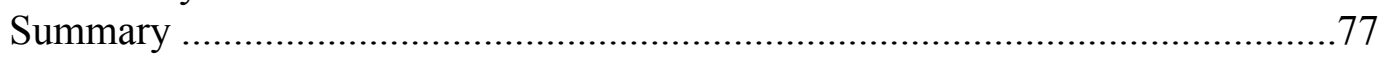

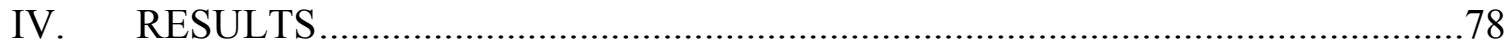

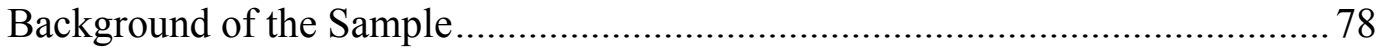

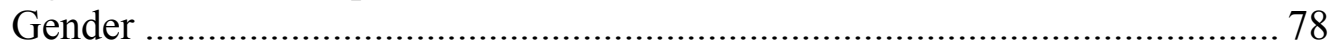

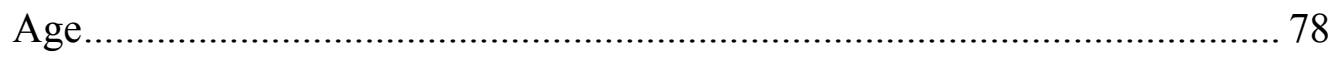

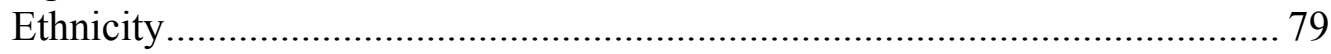

Highest Level of Education Completed......................................................... 79

Position within Organization .................................................................... 79

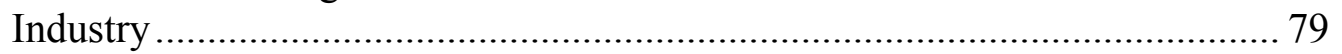

Cross Tabulation of Background Demographic Variables ............................... 82

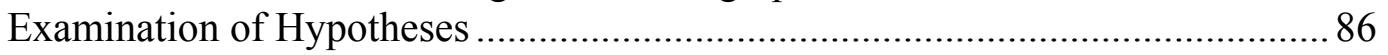

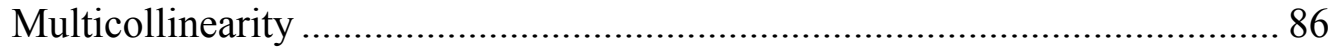

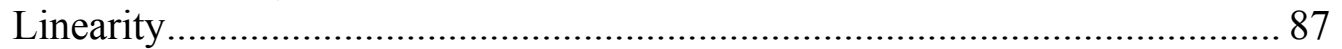

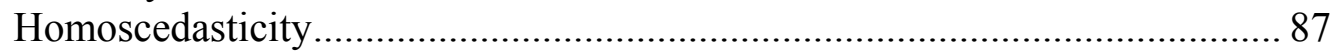

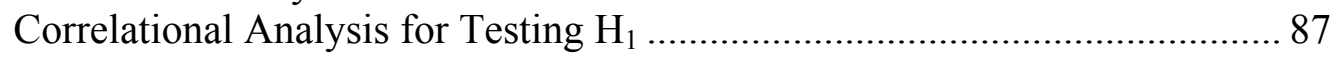

Correlational Analysis for Testing $\mathrm{H}_{2}$..................................................... 92

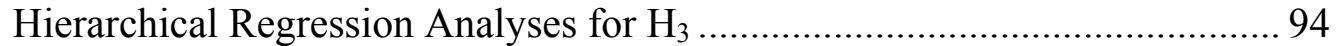

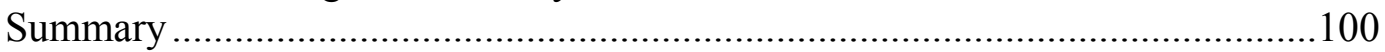

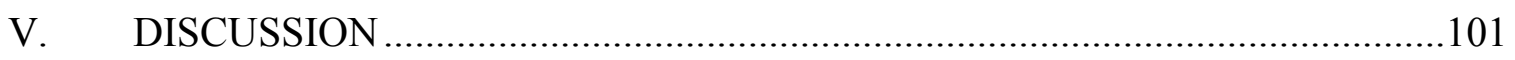

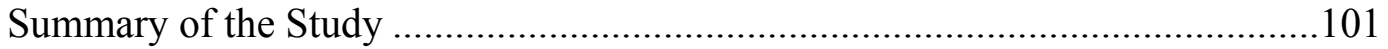

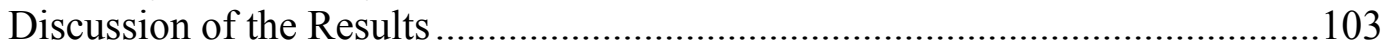

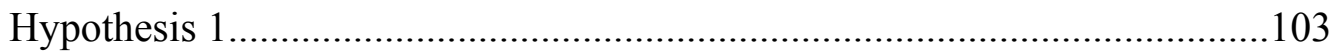

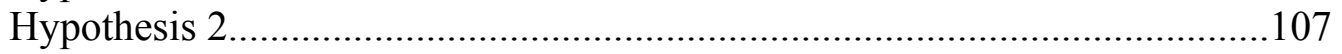

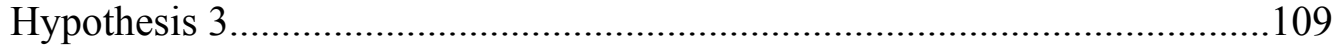

Implications for Theory, Research, and Practice .............................................116

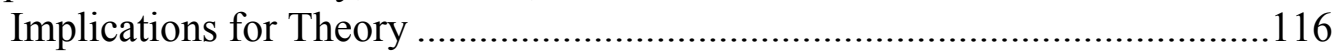

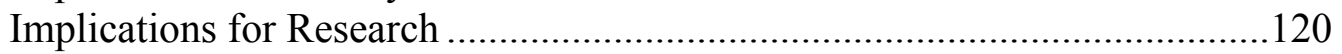

Implications for Practice ......................................................................122

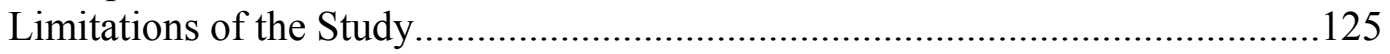

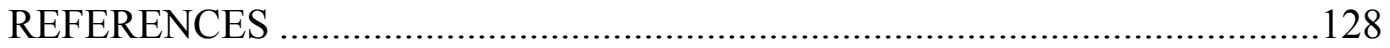

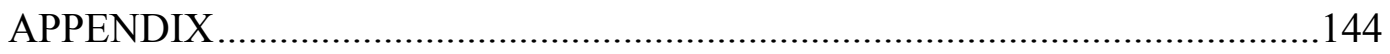

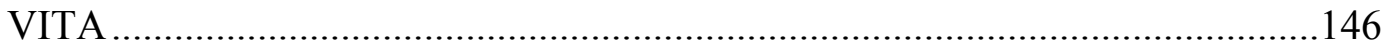




\section{LIST OF TABLES}

TABLE

PAGE

1. Summary of Needs-Satisfying (Kahn, 1990) Literature ............................................25

2. Summary of Burnout-Antithesis (Maslach et al., 2001) Literature ..............................28

3. Summary of Satisfaction-Engagement (Harter et al., 2002) Literature .......................... 32

4. Summary of Multidimensional (Saks, 2006) Engagement Literature ...........................36

5. O'Neil and Arendt (2008) Correlations for Psychological Climate and Outcome

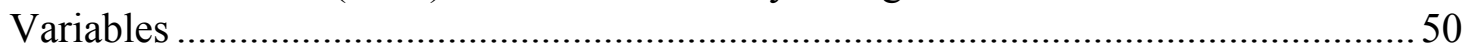

6. Steps in Dillman et al.'s (2009) Tailored Design Method ........................................... 72

7. Scheduling Framework: Based on Dillman et al.'s (2009) Tailored Design

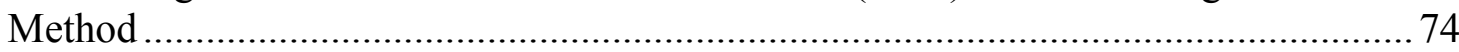

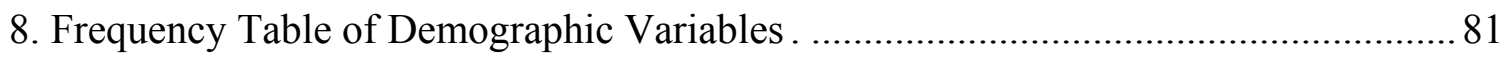

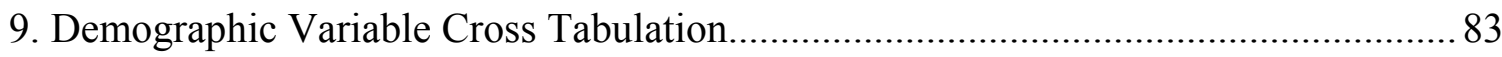

10. Zero-Order Correlation Coefficients for Employee Engagement, Job Fit, Affective Commitment, and Psychological Climate Scales ......................................... 91

11. Zero-Order Correlation Coefficients for Employee Engagement, Discretionary Effort, and Intention to Turnover.

12. Summary Hierarchical Regression Analysis with Psychological Climate, Affective Commitment, Job Fit, and Employee Engagement Predicting Discretionary Effort

13. Summary Hierarchical Regression Analysis with Psychological Climate, Affective Commitment, Job Fit, and Employee Engagement Predicting Intention to Turnover. 


\section{LIST OF FIGURES}

FIGURE

PAGE

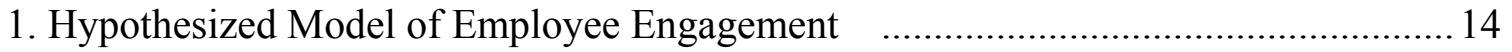

2. Job Fit Approach to Employee Engagement .......................................................... 45

3. Affective Commitment Approach to Employee Engagement .................................. 48

4. Psychological Climate Approach to Employee Engagement ................................... 51

5. Employee Engagement Approach to Discretionary Effort ..................................... 54

6. Employee Engagement Approach to Intention to Turnover .....................................56

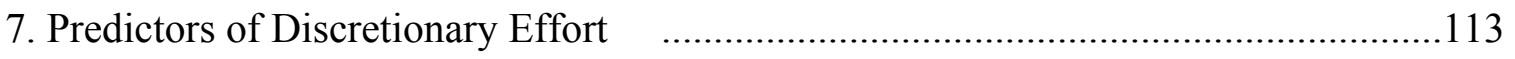

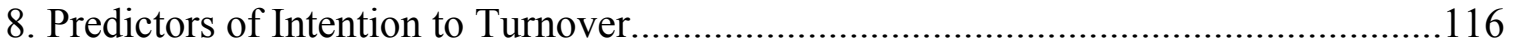




\section{CHAPTER I}

\section{INTRODUCTION}

The chapter begins with the background to the problem, followed by the problem statement, purpose of the study, and theoretical framework. Next, the significance of the study, definition of terms, assumptions, delimitations, and organization of the study are discussed.

\section{Background to the Problem}

In the United States, 145 million people go to work everyday (Bureau of Labor Statistics, 2009). Work is fundamental and centrally related to a person's quality of life (Roessler \& Rubin, 1998; Salkever, 2000) providing a sense of structure, status, and purpose (Salkever, 2000). Satisfaction with one's work has been associated with overall life satisfaction extending the experience of work beyond the physical boundaries of the workplace (Judge \& Wantanabe, 1996). Thus, work is more than simply a place to earn a living; it is where employees find personal "meaning, stability, and a sense of community and identity" (Cartwright \& Homes, 2006, p. 202).

Employees desire positive feelings about their work experiences that go beyond global attitudes of job satisfaction or commitment (Buckingham \& Coffman, 1999; Harter, Schmidt, \& Hayes, 2002; Harter, Schmidt, \& Keyes, 2003; Wagner \& Harter, 2006). Job satisfaction is defined as an individual's attitude toward his or her work (Brayfield \& Rothe, 1951), while employee commitment is defined as an employee's "willingness to persist in a course of action and reluctance to change plans" (Vance, 2006, p. 4). While these variables and others like them are important indicators regarding employee sentiment, measures such as these are based in generalities of work, subject to 
temporary swings in affect depending on the day-to-day challenges of work. Rather, more enduring steady indications of employees' understanding of work are grounded in their experience. Such indications provide a more stable measurement for understanding desired positive work experiences. One such variable grounded in an employee's experience of work is employee engagement. Employee engagement is defined as "a distinct and unique construct consisting of cognitive, emotional, and behavioral components ... associated with individual role performance" (Saks, 2006, p. 602). Employee engagement is inclusive of long-term emotional involvement and is an antecedent to more temporary generalities of employee sentiment, such as job satisfaction and commitment (Wagner \& Harter, 2006). Engaged employees come to work every day feeling a connection to their organization, have a high level of enthusiasm for their work (Buckingham \& Coffman, 1999), and consistently produce at high levels (Meere, 2005).

While it is conservatively estimated that only $30 \%$ of those who work are partially engaged (Buckingham \& Coffman, 1999; Crabtree, 2004; Czarnowsky, 2008; Gebauer \& Lowman, 2009; Wagner \& Harter, 2006), several attractive and important benefits have been associated with those who are (Crabtree, 2004). For example, engaged employees average $27 \%$ less physical absenteeism (Wagner \& Harter, 2006) than their peers, saving organizations an average of 86.5 million days per year in lost productivity (The Gallup Organization, 2001). Engaged employees have also been found to stay with their company longer, thus reducing turnover and saving companies appreciably in recruitment and retraining costs. Moreover, engaged employees are $87 \%$ less likely to leave a company (Buchanan, 2004; Corporate Leadership Council [CLC], 2004); five times less likely to leave than employees who are not engaged (Vance, 2004). Once engaged, an 
employee's willingness to go above and beyond the call of duty increases by $57 \%$, resulting in a $20 \%$ increase in individual performance improvement (Buchanan, 2004). Additionally, engaged employees have been found to have fewer accidents on the job (Wagner \& Harter, 2006), significantly reducing worker compensation claims and associated legal fees.

Engaged employees also positively affect the experience of customers and coworkers. For instance, engaged employees have been shown to score between $12 \%$ (Wagner \& Harter, 2006) and 34\% (Vance, 2004) higher on customer satisfaction-rating scales and average $\$ 80,000$ to $\$ 120,000$ in higher sales each month (Wagner \& Harter, 2006). Further, employees who are engaged tend to trust management and are more focused on mission attainment, strategic direction, and organizational outcomes (Payne, Cangemi, Fuqua, \& Muhleakamp, 1998), whereas those who are not engaged focus on their unhappiness and distrust toward management, often sharing their poor experience with coworkers.

As a final benefit, recent evidence is beginning to point toward a direct employee engagement-profit linkage (Czarnowsky, 2008; Fleming \& Asplund, 2007; Ketter, 2008; Wagner \& Harter, 2006). Having a higher proportion of engaged employees in an organization has been shown to have a positive relationship with a company's profit margin (Fleming \& Asplund, 2007; Ketter, 2008; Wagner \& Harter, 2006). For example, one large manufacturing firm in the United Sates reported a \$2 million increase in sales as a result of employee engagement initiatives and another large retail supply company in the United States reported a \$2.1 million performance-related cost difference between low engagement teams and high engagement teams (Vance, 2006). 
Moreover, it is estimated that employees who are not engaged conservatively cost the U.S. economy between $\$ 250$ and $\$ 300$ billion a year in lost productivity (Rath \& Clifton, 2004). "When you add workplace injury, illness, turnover, absences, and fraud, the cost [of unengaged employees] could surpass $\$ 1$ trillion per year, or nearly $10 \%$ of the U.S. Gross Domestic Product" (Rath \& Clifton, 2004, p. 1). Globally, similar studies report that unengaged employees cost the German economy \$263 billion each year (Merre, 2005), the Australian economy $\$ 4.9$ billion dollars each year (Gopal, 2003), and the Asian market more than $\$ 2.5$ billion each year (Ratanjee, 2004). Thus, there is evidence that lack of employee engagement is financially harmful for organizations throughout the world. Conversely, organizations that focus on developing engaged employees can achieve significant organizational benefits such as higher retention rates, improved productivity, and increased profit.

In response to the many benefits of having an engaged workforce, organizations are increasingly turning toward human resource researchers and practitioners to develop and support strategies that facilitate engagement-encouraging cultures (Vance, 2006). For example, human resource practitioners are being asked to enhance structured courses used to educate managers on increasing their communication and management skills (Gebauer \& Lowman, 2009). Further, human resource professionals are being asked for support in developing employee climate surveys, establishing flexible training programs, and creating long range strategic plans, all in hopes of developing an engaged workforce (Ayers, 2008; Gebauer \& Lowman, 2009). As human resource professionals look for creative means to facilitate these new strategies in organizations, traditional human resource levers such as "job design, recruitment, selection, training, compensation, and 
performance management" for understanding and developing employee engagement have been inadequate (Vance, 2006, p. 28).

Notwithstanding, there are promising new variables that could meaningfully influence or predict employee engagement and its related organizational outcomes (Khan, 1990; Resick, Baltes, \& Shantz, 2007; Rhoades, Eisenberger, \& Armeli, 2001). For the purposes of this study, the researcher identified those variables that had been found to predict or influence employee engagement as antecedent variables; the organizational outcomes associated with the degree of employee engagement were considered outcome variables. An antecedent variable is defined as a specific condition or factor that influences or predicts a particular behavior to emerge in practice; whereas, an outcome variable refers to the resulting effect of a specific activity or condition (Saks, 2006). According to the research literature (Brown \& Leigh, 1996; Harter et al., 2002; Harter et al., 2003; Resick et al., 2007; Rhoades et al., 2001), three promising antecedent variables had the potential for revealing a better understanding of employee engagement development beyond those variables previously identified by researchers (Macey \& Schneider, 2008; Saks, 2006). These antecedent variables were job fit (Resick, et al., 2007), affective commitment (Rhoades et al., 2001), and psychological climate (Brown \& Leigh, 1996).

Job fit is defined as the degree to which a person feels their personality and values fit with their current job (Resick et al., 2007). Good job fit has been shown to promote a sense of belonging resulting in professional alignment with interests and values (Kahn, 1990; Saks, 2006) and is shown to significantly affect the development of job related attitudes such as employee engagement (Resick et al., 2007). Affective commitment is 
defined as a sense of belonging and emotional connection with one's job, organization, or both (Rhoades et al., 2001). Such an emotional connection is thought to be a prior condition for the development of employee engagement (Harter et al., 2003; Kahn, 1990; 1992; Saks, 2006). Last, psychological climate is defined as the perception and interpretation of an organizational environment in relation to an employee's perception of well-being (Brown \& Leigh, 1996). Psychological climate has been shown to significantly affect the development of work-related attitudes (Kahn, 1990; Harter at el., 2002) and research suggests that workplace climate is an important dynamic in the development of employee engagement (Brown \& Leigh, 1996; Harter et al., 2003; Kahn, 1990).

These three specific variables (i.e., job fit, affective commitment, and psychological climate) showed research promise because they each examined unique aspects of how an employee experiences and interprets his or her work. An employee's interpretation of their work is thought to be related to the development of employee engagement (Harter et al., 2003; Macey \& Schneider, 2008; Saks, 2006). Moreover, research (Brown \& Leigh, 1996; Kahn, 1990; Pfeffer, 1994) has suggested that these variables have implications for organizational competitiveness and productivity. Additionally, the presence of employee engagement might also influence various outcome variables (Harter et al., 2002). Two outcome variables were identified as having a potential relation with employee engagement (Harter at al, 2002; Lloyd, 2008; Saks, 2006). These variables were discretionary effort and intention to turnover. Discretionary effort is defined as voluntary effort directed toward organizational goals above the minimum work required (Lloyd, 2008) and intention to turnover is defined as an 
employee's voluntary intention to leave an organization (Saks, 2006). The presence of employee engagement was thought to result in increased discretionary effort and decreased turnover (Lockwood, 2007; Meere, 2005; Saks, 2006; Towers Perrin, 2007). Although preliminary evidence suggested these antecedent and outcome variables may have a relation to employee engagement, no research had examined this unique combination of variables.

\section{Problem Statement}

Organizations are focusing on employee engagement as a promising strategy to increase retention and improve productivity (Lockwood, 2007); however, there remains a surprising shortage of research on employee engagement in the academic literature (Macey \& Schneider, 2008; Saks, 2006). Macey and Schneider (2008) suggested that attention to employee engagement is only now moving from the practitioner to the academic literature. While human resource researchers and practitioners are being asked to play an increased role in the development of engagement-enhancing strategies, and employee engagement is being included in organizational strategic planning, little research about how to effectively develop employee engagement exists. The research supporting the possible importance of employee engagement is clear; yet, research about how to create employee engagement and what might be the outcomes of doing so is remarkably undeveloped. This knowledge gap has created a void of information to guide further research and practice aimed at facilitating employee engagement in organizations. 


\section{Purpose of the Study}

The purpose of this study was to examine a hypothesized employee engagement model by exploring the relation among job fit, affective commitment, psychological climate, discretionary effort, intention to turnover, and employee engagement.

\section{Research Questions and Hypotheses}

Two overarching research questions guided this study: (a) What is the relation between the antecedent variables of job fit, affective commitment, and psychological climate with employee engagement? and (b) What is the relation between employee engagement and the outcome variables discretionary effort and intention to turnover? To explore these two research questions, three hypotheses were tested:

$H_{1}$ : There is a relation between job fit, affective commitment, and psychological climate, and employee engagement.

$\mathrm{H}_{2}$ : There is a relation between employee engagement, discretionary effort, and intention to turnover.

$H_{3}$ : After controlling for job fit, affective commitment, and psychological climate, employee engagement will predict unique variance in discretionary effort and intention to turnover.

\section{Theoretical Framework}

Kahn (1990) posited that engagement, manifested outwardly toward work-related activities, was the concurrent expression of one's preferred self and the promotion of connection to others. Presently, many of the contemporary conceptualizations of engagement (e.g., Harter et al., 2002; Macey \& Schneider. 2008; Saks, 2006) build from Kahn's (1990) seminal work, which provides a foundational and empirically tested (May, 
Gilson, \& Harter, 2002) framework for understanding the state of employee engagement. According to Kahn's $(1990 ; 1992)$ conceptualization, three constructs are important to understanding how engagement develops: meaningfulness, safety, and availability.

Meaningfulness was conceptualized as feeling that one's work was worthwhile and is accompanied by a sense of value in one's accomplishments at work (Kahn, 1990). Meaningfulness completes a circular model where employees add value and significance to what they are doing as well as receive feedback about their value and significance to an organization (Kahn, 1990; Maslow, 1970). Literature around meaningful work has suggested that employees who receive feedback and feel they contribute in important ways to their place of employment are more engaged and satisfied and are also less likely to turnover (Brown \& Leigh, 1996; Czarnowsky, 2008; Harter et al., 2002; Fredrickson, 1998; Towers Perrin, 2003; Wagner \& Harter, 2006). Conversely, without feeling that they meaningfully contribute or receiving feedback on their performance, employees can develop feelings of loneliness, ostracism, rejection, friendlessness (Maslow, 1970) and eventually burnout (Maslach, Schaufeli, \& Leiter, 2001).

Safety was conceptualized as the ability to be one's preferred self without fearing "negative consequences to self image, status, or career" (Kahn, 1990, p. 705). Kahn (1990) posited that employees needed to trust their working environment in ways that allowed employees to be their authentic selves at work as well as reasonably understand what was expected of them when they were working. Knowing what is expected at work was more than having a working knowledge of one's job description (Wagner \& Harter, 2006); an employee must also know how his or her job fits into the larger organization as well as how their job might change when their work environment and circumstances 
change (Fleming \& Asplund, 2007; Harter et al., 2002). Often focused on as a physical variable, an employee's perception of safety is just as much about employees fearing emotional and psychological harm (Fredrickson \& Joiner, 2002; Kahn, 1990) from their place of work.

Availability was conceptualized as having the physical, emotional, and psychological resources necessary for the completion of work (Kahn, 1990). Employees must feel that they have the tools to complete their work or that at a minimum, these tools can and will be obtained. Tangibly, the availability of resources can be understood as items such as supplies, sufficient budget, and manpower to complete a task (Harter et al., 2002; Wager \& Harter, 2006). Intangibly, availability of resources can be understood as opportunities for learning and skill development (Czarnowsky, 2008), a reasonable degree of job fit (Resick et al., 2007), and commitment to the organization (Meyer \& Allen, 1997). The availability of the resources necessary for the completion of work frees an employee to complete his or her work with focus on the task rather than worrying about a lack of resources.

Building upon the aforementioned framework, the following section explores the antecedent and outcome variables used in this study. These variables included job fit, affective commitment, psychological climate, discretionary effort, and intention to turnover.

\section{Antecedent Variables}

The following section presents the antecedent variables used in this study. First, job fit will be discussed, followed by affective commitment, and finally psychological climate. 
Job Fit

Job fit has been shown to be related to employee attitudes and behaviors and is strongly related to job satisfaction and organizational commitment (Resick et al., 2007). Employees who have good job fit feel strongly that they belong and as a result experience professional congruence with their organization. For example, an employee with high levels of job fit would agree that the demands of his or her job (e.g. stress levels, autonomy in decision making, professional ethics) allows them to work within a level of emotional and physical comfort and that his or her personal values match those of the job role. This fit influences employees to derive a sense of psychological meaningfulness from their work (Kahn, 1992). Resick et al. (2007) have suggested that psychological characteristics of the job, such as job fit, are salient cues used when an employee is developing job-related attitudes that ultimately affect performance. One such job-related attitude is employee engagement.

\section{Affective Commitment}

An employee's emotional bond with his or her organization has been considered an important determinant of commitment and loyalty (Rhoades et al., 2001). Employees who are affectively committed "increase their involvement in the organization's activities" (Rhoades et al., 2001, p. 825). Affectively committed employees derive a sense of importance (i.e., meaningfulness; Kahn, 1990) from their work and feel emotionally and psychologically safe to engage in work (Kahn, 1990; Rhoades et al., 2001). Consequently, employee's who are affectively committed have been shown to be more productive, less physically absent, and less likely to turnover (Mathieu \& Zajac, 
1990; Meyer \& Allen, 1997); all suggested outcomes of employee engagement

(Czarnowsky, 2008; Fleming \& Asplund, 2007; Ketter, 2008; Wagner \& Harter, 2006). Psychological Climate

Overall psychological climate of an organization has been shown to significantly impact job involvement, turnover, and productivity (Brown \& Leigh, 1996; Lawler, 1990; Pfeffer, 1994). Psychological climate has been operationalized as including flexible and supportive management, role clarity, freedom of self-expression, a sense of contribution toward organizational goals, adequate recognition, and challenging work (Brown \& Leigh, 1996). Harter et al. (2002) found that these variables significantly relate to the perception of an employee's experience of work and affect the development of employee engagement. Psychological climate promotes an awareness of safety and availability with work (Brown \& Leigh, 1996; Kahn 1992; Wagner \& Harter, 2006) and encourages meaningfulness in individual work roles (Kahn, 1990). The variables that affect an employee's experience of work, such as role clarity, job challenge, and having a supportive supervisor have been consistently linked with employee engagement (Buckingham \& Coffman, 1999; Czarnowsky, 2008; Fleming \& Asplund, 2007; Harter et al., 2002; Harter et al., 2003; Towers Perrin, 2003, 2007; Wagner \& Harter, 2006).

\section{Outcome Variables}

As outcomes variables, Saks (2006) suggested that engagement is positively related to extra in-role behaviors such as discretionary effort and has a negative relationship to intention to turnover. Discretionary effort and intention to turnover parallel the behavioral components of Saks' (2006) definition of employee engagement. The following section discusses discretionary effort and intention to turnover. 


\section{Discretionary Effort}

Discretionary effort has long been associated with performance and effort and is defined as consisting of an employee's willingness to go above minimal job responsibilities (Lloyd, 2008). An employee's willingness to engage in discretionary effort indicates an intention to act that results in behavior (Lloyd, 2008). Effort has been linked to increased productivity and profit generation and is thought to be a behavioral outcome variable of an engaged employee (Harter et al., 2002; Macey \& Schneider, 2008; Wagner \& Harter, 2006) As a work motivator, engaged employees put in more work effort and are less likely to turnover (Lloyd, 2008; Maslach et al., 2001).

\section{Intention to Turnover}

Intention to turnover has been recognized as a strategic leverage point for human resource practitioners (Lockwood, 2007). Turnover conservatively costs an organization 50-60\% of an employee's annual salary (Allen, 2008). Carmeli and Wiesberg (2006) found that an employee's intention to engage in a certain type of behavior, such as an employee's intention to turnover, is a significant predictor of that employee's future behavior. Steel and Ovalle (1984) suggest that turnover intent is more predictive of actual turnover than job satisfaction or commitment. Several pieces of literature suggest a link between employee engagement and turnover intent. For example, Gubman (2004) reported that employees who were not engaged in their work were more likely to leave their current place of employment. Further, Towers Perrin (2003) reported that $66 \%$ of employees who report high levels of employee engagement have no intention of leaving their current organization. Finally, Caterpillar, a large multi-national construction equipment manufacturer, estimates the company saved $\$ 8.8$ million in turnover costs 
alone by increasing the proportion of engaged employees at one of their European based plants (Vance, 2006).

Thus, if employees work in jobs where the demands of a job are congruent with their interests and values (job fit; Resick et al., 2007), feel as if they bond and identify with their place of work (affective commitment; Rhoades et al., 2001), and work in a positive psychological climate (Brown \& Leigh, 1996; Johns, 2001) it was hypothesized they will be engaged (see Figure 1). Furthermore, this hypothesized model suggested that employee engagement would have a relation to important organizational outcomes such as discretionary effort and intention to turnover.

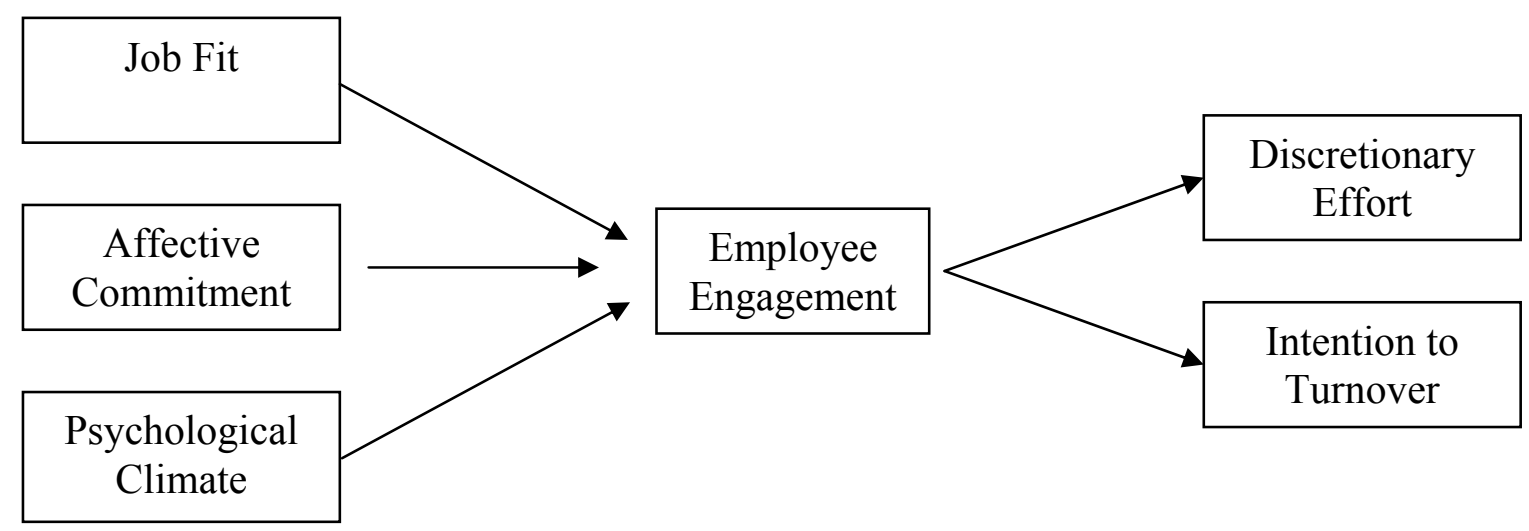

Figure 1. Hypothesized Model of Employee Engagement.

Significance of the Study

The term employee engagement has gained considerable popularity in the last 20 years (Macey \& Schneider, 2008), but the concept remains in need of more empirical research (Saks, 2006). This study created knowledge in the area by testing a new employee engagement model. This new information could serve as a structure for implementing focused and effective employee engagement interventions within 
organizations. Consequently, objective and empirically sound employee engagement research could benefit over time.

Additionally, the new knowledge generated by this research informed theory building related to employee engagement. For example, this research extended and built on the theoretical frameworks of current engagement theory (Harter et al., 2002; Kahn, 1990; Saks, 2006) and proposed new ways of understanding employee engagement. Additionally, results of this study make contributions to theory building around each of the antecedent and outcomes variables examined. For instance, this research tested a unique combination of variables untested simultaneously and findings illuminate new understandings of how each variable impacted employee engagement and consequently how each variable impacted one another.

Further, findings from this study provide support for utilizing the research variables examined in this study in the development of specific and objective workoriented interventions. For example, as a result of this research, HRD professionals could focus on creating developmental interventions that promote good job fit, encourage a positive psychological climate, and create opportunities for employees to become affectively committed with their work as a way of impacting the development of employee engagement. These interventions could take the form of utilizing new recruitment and selection techniques that more strategically match a potential recruits' skill with essential job functions (Resick et al., 2007), encouraging the display of trust building behaviors such as the development of consistent communication channels to create a more positive psychological climate (Druskat \& Wolff, 2001), and developing an openness to new ideas as a way to encourage affective commitment through supportive 
management behaviors (Brown \& Leigh, 1996). As a result, findings from this study will help position human resource professionals as important stakeholders in the future of their organization's success as these variables were shown to have a significant relation with important organizational performance variables (e.g., discretionary effort and intention to turnover). As an added benefit, knowledge from this study could be used to inform other fields of study (e.g., education, public affairs, nonprofit administration) that are challenged with similar organizational variables and conditions.

\section{Definitions of Terms}

Antecedent. This term referred to a specific condition or factor that influenced or predicted a particular behavior that will emerge in practice (Saks, 2006). Antecedents examined in this study included job fit as measured by the Person-Organization Fit Scale (POFS; Resick et al., 2007), affective commitment (Rhoades et al., 2001) as measured by the Affective Commitment Scale (ACS; Allen \& Meyer, 1990; Meyer \& Allen, 1997; Meyer, Allen, \& Smith, 1993; Mowday, Steers, \& Porter, 1979; Rhoades et al., 2001), and psychological climate as measured by the Psychological Climate Measure (PCM; Brown \& Leigh, 1996).

Basic human need. This term is defined as "the condition of a person that is essential and necessary for life, growth, and well-being" (Reeve, 2001, p. 50).

Commitment. This word described an employee's "willingness to persist in a course of action and reluctance to change plans" (Vance, 2006, p. 4).

Employee disengagement. This phrase described the separation of self emotionally, psychologically, and at times, physically from work. When employees 
become disengaged, they withdraw and defend themselves, promoting a lack of connectedness, emotional absence, and passive behavior (Kahn 1990).

Employee engagement. This phrase was operationally defined as the degree of meaningfulness, safety, and availability an employee reported as measured by the Psychological Engagement Scale (PES; May, Gibson, \& Harter, 2004).

Job satisfaction. This term described an individual's attitude towards his or her work (Brayfield \& Rothe, 1951).

Manager. This term referred to the person who is charged with the direct supervision of an employee (Buckingham \& Coffman, 1999).

Outcome. This term referred to the resulting effect of a specific activity or condition (Saks, 2006). Outcomes examined in this study included discretionary effort as measured by the Discretionary Effort Scale (DES; Lloyd, 2008) and intention to turnover as measured by the Intention to Turnover Scale (ITS; Colarelli, 1984).

Work. This term referred to a goal-directed activity for social, economic, or other desired outcomes. Work is a means by which individuals define themselves as a part of society and access self-fulfillment and creative expression (Khan, 1990).

Assumptions and Delimitations of the Study

There were several assumptions and delimitations in this study. Assumptions

The study's assumptions included: (a) every employee has the potential to be engaged at work; (b) human beings naturally seek positive experiences at work and employees who have these experiences become more engaged with their work; (c) employee engagement can be developed; and (d) work is a personal experience. 


\section{Delimitations}

The first delimitation of this study included the effect of local, regional, and national economic conditions, which were not examined as variables in this study. Economic conditions could have affected engagement levels as an extraneous variable. The second delimitation included factors external to this study (e.g., a recent promotion, salary increase, or new position) that may have contributed to the development of employee engagement. Such external factors may enhance or detract from the development of employee engagement, but these factors were not examined in this study. The third delimitation concerned personality-related variables that may have contributed to the presence or non-presence of employee engagement. Researchers have demonstrated that personality-related variables such as self-efficacy (Macey \& Schneider, 2008; Saks, 2006), curiosity (Reio, \& Callahan, 2004; Reio, Petrosko, Wiswell, \& Thongsukmag, 2006) and self-esteem promote proactive work-oriented behaviors. The presence of these personality-related variables could have promoted or detracted from the presence of employee engagement; however, an examination of the relation between these personality-related variables and employee engagement was beyond the scope of the current study. Finally, the parameters of the sample population may have also been a delimitation. The sample population for this study consisted of a heterogeneous sampling of employees in the South Florida area who were members of a specific Chamber of Commerce association. While a potential participant's membership was not expected to be a delimitation, the parameter of membership constitutes a limitation on who the survey was available to. 


\section{Organization of the Study}

This chapter included the background to the problem, problem statement, purpose statement, and theoretical framework. The significance of the study, definitions of terms assumptions and delimitations were also discussed. Chapter 2 provides a review of the literature that supported the study. Chapter 3 describes the research method used to conduct the study. Chapter 4 presents the findings of the study and chapter 5 concludes with a discussion of the results and implications for theory, research, and practice. 


\section{CHAPTER II}

\section{LITERATURE REVIEW}

This chapter begins with an introduction to employee engagement by situating the concept as an emerging perspective. Second, an overview of the academic approach to employee engagement is followed by an examination of the literature around potential personality and demographic variables that might effect employee engagement. Fourth, relevant literature around each of the antecedent and outcomes variables examined in this study is explored. The chapter concludes with a hypothesized model, brief summary, and an overview of the next chapters.

\section{Employee Engagement: Situating the Concept}

Interest in the study of employee engagement has experienced dramatic expansion (The Ken Blanchard Companies [TKBC], 2008; Czarnowsky, 2008; Ketter, 2008; Lockwood, 2007; Macey \& Schneider, 2008). Many organizations believe that employee engagement is a dominant source of competitive advantage and thus, have been drawn to its reported ability to solve intractable organizational challenges such as decreasing turnover rates and increasing productivity. Research has propagated this belief by suggesting that organizations with high levels of employee engagement report positive organizational outcomes (Kular, Gatenby, Rees, Soane, \& Truss, 2008). For example, North Shore LIJ Health System recently invested \$10 million into training and development and encouraged employees to further their education in hopes of raising engagement scores (States, 2008). As a result, the company reported a 1 year retention rate of $96 \%$, and increased patient-satisfaction scores, and enjoyed record setting profits. At Johnson and Johnson, engagement has become a part of the work culture as teams are 
provided real time feedback about how their work enables their individual business units to meet their quarterly goals (States, 2008). Such real-time communication programs have helped create a positive, accountability-driven workplace resulting in increased productivity levels, profit margins, and engagement scores (Towers Perrin, 2007).

Further, evidence points toward the growing popularity of the concept in the corner offices of organizations today. In a survey of 1,800 corporate managers and leaders, 58\% listed "creating an engaged workforce" (TKBC, 2008, p. 3) as the top management challenge of their organizations. In another study, $82 \%$ of the surveyed workforce said that employee engagement was one of the most important issues facing their company right now (Czarnowsky, 2008). This research suggests that organizations recognize the need for employees who are proactive, work well with others, and work toward the success of their organizations (Bakker \& Schaufeli, 2008). Organizations need engaged employees (Bakker \& Schaufeli, 2008) and they are looking for ways to develop such a workforce.

As the concept of employee engagement has grown in popularity, it has undergone significant developments in definition, measurement, and conceptualization, all while research in the academic community has lagged behind (Macey \& Schneider, 2008). Such bottom-up growth has resulted in a significant gap in scholarly literature (Macey \& Schneider, 2008). As practitioners turned to the academic literature for strategies on developing an engaged workforce, they were met with a deficiency of research on the concept (Saks, 2006). Thus, the popularity of employee engagement in the practitioner community as well as the need for answers and the burgeoning emergence of the concept in the academic community led inevitably to differing 
perspectives on the concept: the practitioner approach and the academic approach (Zigarami et al., 2009)

The practitioner approach and the academic approach are very different in purpose and outcome (Macey \& Schneider, 2008; Wefald \& Downey, 2009). For example, the practitioner approach is concerned with the usability of the construct and its actionable outcomes such as improved retention, commitment, and productivity levels and focuses more on aggregating data at the macro or group level to increase the functionality of work-groups (Wefald \& Downey, 2009). While this approach presents an important perspective of the concept, it often blends employee engagement with other related organizational concepts such as satisfaction or commitment and little validity or reliability estimate data is currently available among practitioner metrics (e.g., Corporate Leadership Council [CLC], 2004; Czarnowsky, 2008; Towers Perrin, 2003, 2007; Vance, 2006). On the other hand, the academic approach is focused on defining and validating the psychological concept itself and focused more toward the micro or individual level (Wefald \& Downey, 2009) to better understand antecedent variables that influence the development of engagement. The academic approach is a recent phenomenon in the scholarly literature (Saks, 2006; Wefald \& Downey, 2009).

The focus of this research is scholarly, and thus this review of the literature is focused on scholarly works including seminal publications that inform the research questions examined in this study. The following major sections include, a review of the academic perspective on employee engagement, a review of literature around potential demographic and personality variables that may effect the development of employee 
engagement, and both antecedent and outcome variables. Finally, a hypothesized model and concluding thoughts bring this chapter to a close.

Review of the Academic Perspective of Employee Engagement

Within the academic perspective, four major approaches define the existing state of the concept of employee engagement: (a) Kahn's (1990) need-satisfying approach, (b) Maslach et al.'s (2001) burnout-antithesis approach (c) Harter et al.'s (2002) satisfactionengagement approach, and (d) Saks's (2006) multidimensional approach. A discussion of each approach follows.

Kahn (1990) is widely credited with the first application and use of engagement theory to the workplace in his article "Psychological Conditions of Personal Engagement and Disengagement at Work" which appeared in the Academy of Management Journal (Kahn, 1990). In his ethnographic study, Kahn (1990) interviewed 32 employees, 16 summer camp counselors and 16 financial professionals, and defined engagement as "the simultaneous employment and expression of a person's 'preferred self' in task behaviors that promote connections to work and to others, personal presence, and active full role performances" (p. 700). Developing from the works of Freud and Maslow (psychologists; 1922; 1970), Goffman (sociologist; 1961), Slater (1966) and Smith and Berg (group theorists; 1987), Kahn (1990) posited that the conditions of meaningfulness, safety, and availability were important to fully understanding why a person would become engaged in his or her work.

Kahn (1990) defined meaningfulness as the positive "sense of return on investments of self in role performance" (Kahn, 1990, p. 705). Safety was defined as the ability to show one's self "without fear or negative consequences to self image, status, or 
career" (Kahn, 1990, p. 705). Lastly, availability was defined as the "sense of possessing the physical, emotional, and psychological resources necessary" (Kahn, 1990, p. 705) to complete one's work. According to Kahn, by positively fulfilling the criteria for these domains (i.e., my work is meaningful, I feel safe, and I have the resources to complete my work) engagement was psychologically, socially, and physically present when occupying and performing work roles (Kular et al., 2008).

In a later article, Khan (1992) reexamined the meaning of psychological presence in work as an extension of the meaningfulness, safety, and availability conditions. Kahn suggested that being fully present in work was what it meant to live life to the fullest (Kahn, 1992). "When fully present, people feel joined with someone outside themselves; they experience themselves as accessible to people or tasks, as reserves to be drawn on" (p. 326). Further, Kahn (1992) went on to suggest that it was unreasonable to expect employees to be fully present at work when they felt their basic needs (i.e., meaningfulness, safety, and availability) were not being met as of a result of their work experience.

The only study located that empirically examined Kahn's (1990) conceptualization of engagement suggested that all three of Kahn's $(1990,1992)$ conditions were important constructs in the development of engagement (May, Gilson, \& Harter, 2002). Using a sample of 203 employees from a large insurance firm, results indicated that engagement had a positive relation to meaningfulness $(r=.63)$, availability $(r=.29)$, and safety $(r=.45)$. Kahn's research is widely cited as the foundational scaffolding for employee engagement. In spite of Kahn's (1990) application of engagement theory, new research did not emerge about the concept until interest in the 
employee burnout literature led to a reemergence of attention. Table 1 presents a summary of the major literature reviewed in this section concerning the needs-satisfying approach (Kahn, 1990).

Table 1

Summary of Needs-Satisfying (Kahn, 1990) Literature

\begin{tabular}{|c|c|c|}
\hline Article Citation & Major Contribution & Research Type \\
\hline Kahn, W. (1990). & Published early-grounded & Empirical: Ethnographic \\
\hline Psychological conditions & theoretical framework of & research with 16 summer \\
\hline of personal engagement & personal engagement and & camp counselors and 16 \\
\hline and disengagement at & disengagement. First to define & financial firm members \\
\hline work. Academy of & engagement as a separate & \\
\hline Management Journal, 33, & concept using research. One of & \\
\hline \multirow[t]{3}{*}{$692-724$} & two early theories about the & \\
\hline & development of employee & \\
\hline & engagement. & \\
\hline Kahn, W. (1992). To be & Explored psychological & Conceptual \\
\hline fully there: Psychological & presence and its meaning to & \\
\hline presence at work. Human & employees and managers in a & \\
\hline \multirow[t]{3}{*}{ Relations, 45, 321-349 } & workplace context. Introduces & \\
\hline & concept of meeting basic needs & \\
\hline & as a function of engagement. & \\
\hline May, D. R., Gilson, R. L., & First to publish empirical & Empirical: Survey of 199 \\
\hline \& Harter, L. M. (2004). & research testing Kahn's (1990) & employees in a large \\
\hline
\end{tabular}


The psychological

conditions of conceptualization of employee engagement. mid-western insurance

firm

meaningfulness, safety,

and availability and the

engagement of the human

spirit at work. Journal of

Occupational Psychology,

$77,11-37$

In a second approach, Maslach et al. (2001) conceptualized employee engagement as the positive antithesis to burnout, defining engagement as "a persistent positive affective state...characterized by high levels of activation and pleasure" (p.417). Burnout was theorized to be the erosion of engagement (Maslach, et al., 2001); what was once important, meaningful, and challenging work became unpleasant, unfulfilling, and meaningless (Maslach, et al., 2001, p. 416). Engagement was operationalized as the reverse of scores on the Maslach Burnout Inventory (MBI-GS; Maslach \& Leiter, 1997) as it was thought that anyone who was not experiencing burnout must be engaged.

Schaufeli, Salanova, González-Roma, and Bakker (2002) tested the Maslach et al. (2001) framework using the MBI-GS, although used a slightly different definition of engagement. Schaufeli at al. (2002) defined engagement as a "positive, fulfilling, workrelated state of mind that is characterized by vigor, dedication, and absorption" (p. 74) and renamed the state of engagement (Kahn, 1990) as "work engagement" (Schaufeli at al., 2002). Using a sample of 314 Spanish university students and 619 Spanish employees 
from private and public companies $(N=933)$, results of their research suggested a negative relation between burnout and work engagement $(r=-.46$ and $r=-.61)$.

As a critique of the Maslach et al. (2001) and Schaufeli et al. (2002) models, research (Johnson, 2003) has suggested that this approach to understanding engagement is devoid of the cognitive engagement processes conceptualized by Kahn (1990) and focuses only on emotional and physical absences of burnout. Further, Shorim (2003) examined the Maslach et al. (2001) and Schaufeli et al. (2002) models of engagement and suggested that previous research (i.e., Kahn, 1990; Maslach et al., 2001; Schaufeli et al., 2002) had conceptualized engagement on a continuum as the opposite of a negative, not a separate state. Shorim (2007) suggested that as a result of the Maslach et al. (2001) and Schaufeli et al. (2002) models, employee engagement could be differentiated from other psychological constructs such as flow (Csikszentmihalyi, 2003), commitment (Allen \& Meyer, 1990), and peak experiences (Schaufeli, Martinez, Pinto, Salanova, \& Bakker, 2002). Studies using a similar framework provide additional empirical support for the Maslach et al. (2001) approach (for example, see Shraga, 2007; Shorim, 2003, 2007; Wefald, 2008). Table 2 presents a summary of the major pieces of literature reviewed concerning the burnout-antithesis approach (Maslach et al., 2001). 
Table 2

Summary of Burnout-Antithesis (Maslach et al., 2001) Literature

\begin{tabular}{|c|c|c|}
\hline Article Citation & Major Contribution & Research Type \\
\hline Maslach, C., Schaufeli, W. & Was the first major work on & Conceptual \\
\hline B., \& Leiter, M. P. (2001). & employee engagement after & \\
\hline Job burnout. Annual & Kahn (1990) and is the other of & \\
\hline Review of Psychology, 52, & the two early developmental & \\
\hline \multirow[t]{9}{*}{$397-422}$. & theories on employee & \\
\hline & engagement. Maslach, & \\
\hline & Schaufeli, \& Leiter (2001) & \\
\hline & pioneered reaching across & \\
\hline & academic boundaries for & \\
\hline & definitions of employee & \\
\hline & engagement, conceptualizing the & \\
\hline & construct as the positive & \\
\hline & antithesis to burnout. & \\
\hline Schaufeli, W. B., & Tested Maslach et al. (2001) & Empirical: 314 Spanish \\
\hline Salanova, M., González- & burnout model with measure of & university students and \\
\hline Roma, V., \& Bakker, A. & employee engagement. Results & 619 Spanish employees \\
\hline B. (2002). The & indicated a negative relationship & from private and public \\
\hline measurement of & between levels of burnout and & companies \\
\hline engagement and burnout: & employee engagement. & \\
\hline A two-sample & & \\
\hline
\end{tabular}


confirmatory factor

analytic approach. Journal

of Happiness Studies, 3,

$71-92$

Shirom, A. (2003).

Examined the Maslach (2001)

Conceptual

Feeling vigorous at work?

and Schaufeli (2002) models of

The construct of vigor and

engagement and proposed that

the study of positive affect

engagement was a separate

in organizations. In D. psychological state. Proposed

Ganster \& P. L. Perrewe several research questions

(Eds.). Research in

around the psychological state

organizational stress and

of vigor.

well-being. (Vol. 3, pp.

135-165). Greenwich, CN:

JAI Press.

Welfad, A. (2008). An

Critically examined the concept Empirical: 382

examination of $o b$

of employee engagement and

employees and managers

engagement,

provided empirical evidence

at a mid-sized financial

transformational

regarding its validity as a work- institution

leadership, and related related construct.

psychological constructs.

Unpublished doctoral 
dissertation, Kansas State

University.

Distinct yet encompassing of Kahn (1990) and Maslach et al.’s (2001) engagement frameworks, Harter et al. (2002) published one of the most widely cited pieces of literature on employee engagement and introduced the third academic approach to employee engagement. Using a research foundation pioneered by the late Donald O. Clifton, Harter et al. (2002) used data from a meta-analysis of 7,939 business units across multiple fields of industry. The researchers defined employee engagement as an "individual's involvement and satisfaction with as well as enthusiasm for work" (Harter et al., 2002, p. 417). Using the Gallup Work Audit (GWA), a proprietary twelve-item questionnaire (Buckingham \& Coffman, 1999), results suggested employee engagement had a positive relation to important business outcomes such as customer satisfaction $(r=$ $.33)$, turnover $(r=-.36)$, safety $(r=-.32)$, productivity $(r=.20)$ and profitability $(r=.17)$. Harter et al. (2002) further suggested that companies who scored .43 standard deviations above the median on the composite GWA enjoyed higher levels of overall performance (i.e., an average of a $103 \%$ higher success rate at the business unit level) than those on the lower end of the median. Results of their research suggested that while the study indicated only moderate effect sizes, such modest evidence often translated into significant practical results for an organization's profitability (Harter et al., 2003).

Luthans and Peterson (2002) extended Harter et al.'s (2002) model by examining the relation between managerial self-efficacy, the perception of effective management practices, and employee engagement. Using a sample of 2,900 participants, results of 
their study suggested a positive relation between employee engagement and manager self-efficacy scores when managers rated employee effectiveness $(r=.33)$, and when supervisees rated their manager's level of effectiveness $(r=.89)$. Luthans and Peterson concluded, "the most profitable work units of companies have people doing what they do best, with people they like, and with a strong sense of psychological ownership" (2002, p. 376). Findings from their research extended current theory about a manager's role in creating a supportive psychological climate (Brown \& Leigh, 1996) and paralleled early theories of engagement (Khan, 1990; Maslach et al., 2001; Schaufeli et al., 2002) by suggesting that employees must have the environmental, job resources, and support necessary to complete their work. Studies using a similar framework provided additional empirical support for the Harter et al. (2002) approach (for example, see Arakawa \& Greenberg, 2007 and Heger, 2007). Table 3 presents a summary of the major pieces of literature reviewed in the satisfaction-engagement approach (Harter et al., 2002). 
Table 3

Summary of Satisfaction-Engagement (Harter et al., 2002) Literature

\begin{tabular}{|c|c|c|}
\hline Article Citation & Major Contribution & Research Type/ Sample \\
\hline Harter, J. K., Schmidt, F. & Published first study looking at & Meta-analysis of 7,939 \\
\hline L., \& Hayes, T. L. (2002). & the business unit level between & business units across \\
\hline Business-unit level & the employee engagement- & multiple fields \\
\hline relationship between & satisfaction and business unit & \\
\hline employee satisfaction, & outcomes (profit). One of the & \\
\hline employee engagement, and & first to mention a profit linkage & \\
\hline business outcomes: A & to employee engagement. & \\
\hline \multicolumn{3}{|l|}{ meta-analysis. Journal of } \\
\hline \multicolumn{3}{|l|}{ Applied Psychology, 87, } \\
\hline \multicolumn{3}{|l|}{$268-279}$. \\
\hline Buckingham, M., \& & First widely publication to & Conceptual \\
\hline Coffman, C. (1999). First, & widely distribute GWA. & \\
\hline \multicolumn{3}{|l|}{ break all the rules; What } \\
\hline \multicolumn{3}{|l|}{ the world's greatest } \\
\hline \multicolumn{3}{|l|}{ managers do differently. } \\
\hline \multicolumn{3}{|l|}{ New York: Simon and } \\
\hline \multicolumn{3}{|l|}{ Schuster. } \\
\hline Luthans, F., Peterson, \& S. & Examined the relation between & 170 managers attending \\
\hline J. (2002). Employee & employee engagement and & the Gallup Leadership \\
\hline engagement and manager & manager self-efficacy. Results & Institute and 16 of their \\
\hline
\end{tabular}




\begin{tabular}{|c|c|}
\hline self-efficacy: Implications & indicated that manager self- \\
\hline for managerial & efficacy had a positive \\
\hline effectiveness and & relationship with employee \\
\hline development. Journal of & engagement. \\
\hline
\end{tabular}

Management Development,

21, 376-387.

Arakawa, D., \& Greenberg, Explored the role of managers 117 employees in a

M. (2007). Optimistic in the development of technology department at

managers and the influence employee engagement. an insurance company in

on productivity and Provides evidence that Massachusetts.

employee engagement in a management style could affect

technology organization: the level of engagement,

Implications or coaching optimism, and performance of

psychologists. International a team.

Coaching Psychology

Review, 2, 78-89.

The fourth and final approach to employee engagement emerged from a multidimensional perspective of employee engagement. Saks (2006) hypothesized that employee engagement developed through a social exchange model and was the first academic researcher to separate job engagement and organizational engagement. In his conceptualization, Saks (2006) defined the emerging multidimensional concept of employee engagement as "a distinct and unique construct consisting of cognitive, 
emotional, and behavioral components ... associated with individual role performance" (p. 602). This definition was inclusive of previous literature by suggesting that employee engagement was developed from cognitive (Kahn, 1990; Maslach et al., 2001; Maslow, 1970), emotional (Harter et al., 2002; Kahn, 1990), and behavioral elements (Harter et al., 2002; Maslach et al., 2001) and extended current thinking on the topic by developing a three-component model.

To test the three-component model (cognitive-emotional-behavioral), Saks (2006) enrolled 102 working students in his study who were attending a graduate course at a large, Canadian university. Results indicated a positive relation between the antecedent variables of job characteristics, perceived organization support, and procedural justice ( $r$ $=.37 ; r=.36 ; r=.18)$. Further it was reported that job satisfaction, organizational commitment, and intention to quit had an outcome relation with employee engagement ( $r$ $=.26 ; r=.17 ; r=-.22)$. Perceived supervisor support and rewards and recognition were also tested antecedent variables, but no significance was indicated.

Results from this study suggested that antecedent variables such as supportive climate, job characteristics, and fairness influenced the development of engagement and that employee engagement mediated the relationship between antecedent and outcomes variables. This research extended Schaufeli et al's (2002) model of engagement by suggesting engagement could be experienced emotionally and cognitively and manifested behaviorally. Similarly to Schaufeli et al. (2002), Saks viewed the development of engagement as an absorption of a person's resources into the work they performed. This view not only paralleled Schaufeli et al. (2002), but also Kahn (1990) and Harter et al. (2002). Each framework suggested that for absorption to occur, an employee must readily 
have the physical, emotional, and psychological resources to complete their work. Without them, the psychological state of burnout develops (Maslach et al., 2001; Schaufeli et al., 2002) and employees eventually disengage.

Providing support for the Saks (2006) model, Britt, Castro, and Adler (2005) suggested that soldiers who were more psychologically and emotionally engaged in their work experienced less stress and fatigue. Notwithstanding, the same soldiers also reported feeling overworked and disengaged when faced with stressors that obstructed their ability, or the perception of their ability to complete their jobs well (Britt et al., 2005). Further, conceptual work by Macey \& Schneider (2008) extended Saks (2006) model suggesting each proceeding state of engagement (cognitive-emotional-behavioral) built on the next, eventually leading to complete employee engagement. Saks's (2006) model remains widely cited in the academic literature (Macey \& Schneider, 2008). Table 4 presents a summary of the major pieces of literature reviewed in the multidimensional approach (Saks, 2006). 
Table 4

Summary of Multidimensional (Saks, 2006) Engagement Literature

\begin{tabular}{|c|c|c|}
\hline Article Citation & Major Contribution & Research Type/ Sample \\
\hline Saks, A. M. (2006). & First research to examine & Empirical: 102 employee \\
\hline Antecedents and & antecedents and consequences & working in a wide range \\
\hline consequences of employee & to employee engagement in the & of occupations in the \\
\hline engagement. Journal of & academic literature. Prior to & Toronto, Canada area \\
\hline Managerial Psychology, & Saks (2006), practitioner & \\
\hline \multirow[t]{4}{*}{$12,600-619$} & research was the only body of & \\
\hline & work connecting employee & \\
\hline & engagement drivers to employee & \\
\hline & engagement consequences. & \\
\hline Britt, T. W., Castro, C. A., & Examined the role of & Empirical: 176 United \\
\hline \& Adler, A. B. (2005). & psychological, emotional, and & States combat soldiers \\
\hline Self-engagement, & cognitive resources on combat & currently serving at their \\
\hline stressors, and health: A & soldiers. Engaged employee & home station \\
\hline longitudinal study. & whether soldiers or team & \\
\hline Personality and Social & members experience less stress & \\
\hline Psychology Bulletin, 31, & and fatigued when engaged in & \\
\hline $1475-1486$. & their work. & \\
\hline Macey, W. H., \& & The first to conceptualize trait, & Conceptual \\
\hline Schneider, B. (2008). The & state, and behavioral & \\
\hline meaning of employee & engagement as separate but & \\
\hline
\end{tabular}




$\begin{array}{ll}\begin{array}{l}\text { engagement. Industrial } \\ \text { and Organizational }\end{array} & \text { related constructs. Presented } \\ \text { Psychology, 1, 3-30. } & \text { that might feed the development } \\ & \text { of employee engagement within } \\ & \text { organizations }\end{array}$

\section{Summary of Employee Engagement Literature}

In summary, four approaches form the scaffolding for the academic approach to employee engagement: (a) Kahn's (1990) need-satisfying approach, (b) Maslach et al.’s (2001) burnout-antithesis approach (c) Harter et al.'s (2002) satisfaction-engagement approach, and (d) Sak's (2006) multidimensional approach. According to the research (Christian \& Slaughter, 2007), no single approach dominates the field in methodology or definition, however Maslach et al. (2001) is by far the most widely cited $(N=1420)$. Furthermore, while each approach proposes a different perspective, the varying approaches remain clear and unanimous in conclusion: the development of employee engagement inside organizations has the potential to significantly impact important organizational outcomes (Arakawa \& Greenberg, 2007; Harter et al., 2002; Luthans \& Peterson, 2002; Maslach et al., 2001; Macey \& Schneider, 2008; Saks, 2006; Schaufeli et al., 2002). In such uncertain and challenging business environments (Gebauer \& Lowman, 2009), engaging employees has become a strategic organizational imperative. Potential Demographic and Personality Variables that Effect Employee Engagement Several personality and demographic variables have been previously studied in relation to employee engagement; yet there are major inconsistencies (Maslach \& Leiter, 
2008). Maslach \& Leiter (2008) suggested that variables such as age, work experience, sex, and occupation type make interpreting demographic variables in relation to engagement a challenging task due to a lack of research evidence. The following section explores the role of race, age, gender, workplace location and personality variables in the development of employee engagement.

\section{Race and Employee Engagement}

Jones and Harter (2005) explored the relation between race, employee engagement, and intention to turnover. Using a sample of 2014 employees, Gallup researchers asked two questions (i.e., "What is your race?" and "What is the race of your current manager or supervisor?") along with the standard twelve items on the GWA. The intent of the research was to examine engagement and intention to turnover differences among employee-manager dyads of different races. Results indicated that employees who reported higher levels of engagement and were in cross-race dyads had a higher shortterm intention to remain $(r=.21)$ than do respondents from same-race dyads. While race and engagement levels were not reported in the results, implications suggested that one's race could be an influential factor in engagement levels when working with supervisors of a different race. No other studies examining this link were found.

\section{Age and Employee Engagement}

In one study on age and employee engagement, age was explored as social identity variable (Avery, McKay, \& Wilson, 2007). Avery et al. (2007) examined the relation between age, organizational tenure, perceived co-worker age, and satisfaction with older $(>55)$ and younger $(<40)$ co-workers in the United Kingdom. Using a sample of 901 employees, findings indicated that engagement was negatively correlated to 
organizational tenure $(r=-.11)$, positional tenure $(r=-.17)$, and age $(r=-.12)$. In contrast, employee engagement had a positive relation with job satisfaction of younger co-workers $(r=.29)$ and gender dissimilarity $(r=.08)$.

The results suggested that workers who reported greater satisfaction with their coworkers tended to be more engaged. Moreover, employees who have been with an organization longer and/or in the same position reported lower levels of engagement (i.e., $r=-.17)$ and were thought to be more likely to turnover. These findings are supported by James, Swanberg, \& McKechnie (2007) who also reported that older workers (> 55) were more engaged when they worked with a supportive supervisor in a supportive psychological climate. Other researchers offer further support this claim (for example, see Morison, Erickson, \& Dychtwald, 2006; Dychtwald, Erickson, \& Morison, 2006).

\section{Gender and Employee Engagement}

In an examination of gender and employee engagement, Avery et al. (2007) reported that women were more engaged $(r=.19)$ than their male co-workers. However, research by Yildirim (2008) who studied Turkish counselors, reported that levels of engagement did not differ significantly between males and females. While results vary, some researchers (Schaufeli, Bakker, \& Salanova, 2006; Sprang, Clark, \& WhittWoosley, 2007) have suggested that females are at higher risk of developing stress due to competing work and home responsibilities and therefore, report higher levels of burnout and consequently may report lower levels of engagement. The literature on gender and employee engagement remains inconclusive.

\section{Workplace Location and Employee Engagement}


Researchers have explored the relation between employee engagement levels and workplace location. Some researchers have suggested that engagement levels tend to be lower for employees working in rural areas (Sprang, Clark, \& Whitt-Woosley, 2007; Watt \& Kelly, 1996). While the research is scarcely supported, problems such as professional loneliness (Waltman, 1990; Watt \& Kelly, 1996), lack of formal resources (Davenport \& Davenport, 1982), and challenges with transportation (Ginsberg, 1998) have all been noted. No other studies examining this link were found.

\section{Personality Variables and Employee Engagement}

In their conceptual model, Macey and Schneider (2008) suggested that a proactive personality, autotelic personality, conscientiousness, and trait positive affect led to the development of employee engagement. It has been hypothesized that a person's personality traits could be a determinant of their ability to be engaged. This framework was based in Maslach et al's (2001) belief that an employee's perception of their work environment would lead to organizational outcomes (Maslach, 1998; Maslach et al., 2001). Some researchers (Macey \& Schneider, 2008; Maslach, 1998; Maslach et al., 2001) believe that employees are predisposed to certain outlooks on life and that such outlooks are a part of a person's frame of reference (Maslach et al., 2001). In 2007, Shraga (2007) and Shirom (2003, 2007) suggested a significant relationship between vigor (i.e. engagement; Maslach et al., 2001) and the openness and extroversion factors of the Big Five personality variables (Neuroticism, Extroversion, Openness, Agreeableness, and Conscientiousness). Additionally, Shraga and Shirom (2007) reported that openness predicted engagement and that extroversion predicted levels of engagement at different points in time. 
Additionally, other models have suggested that personality variables such as curiosity (Reio, \& Callahan, 2004; Reio, Petrosko, Wiswell, \& Thongsukmag, 2006), optimism, self-efficacy (Macey \& Schneider, 2008; Saks, 2006), self-esteem, and coping style (Storm \& Rothmann, 2003; Rothmann, 2003; Xanthopoulou, Bakker, Demerouti, Schaufeli, 2007), all play a part in the development of work-oriented variables. Although no specific research has explored these connections and engagement (Maslach \& Leiter, 2008), research has demonstrated a link between personality characteristics like those mentioned above and job satisfaction, commitment, and job involvement (Judge, Van Vianen, \& De Pater, 2004).

\section{Antecedents of Employee Engagement}

Despite employee engagement's demonstrated benefits, few studies have investigated its antecedents (for example, see May et al., 2002; Saks, 2006). Schaufeli and Salanova (2007) suggested that antecedents for engagement included variables that influence salient characteristics of the job, the type of climate an employee works in, and the emotional climate of a workplace. The following section examines relevant literature around each of the antecedent variables examined in this study and explores their linkages with employee engagement. First, job fit will be examined, followed by affective commitment, and psychological climate.

\section{Job Fit}

Researchers who study job fit (Hoffman \& Woehr, 2006; Resick et al., 2007; Verquer et al, 2003) suggest that good job fit provides opportunities for employees to be involved in individually meaningful work (Cartwright \& Holmes, 2006; Kahn, 1990) and further, that meaningful work effects the development of work-related attitudes (Hoffman 
\& Woehr, 2006; Resick et al., 2007; Verquer et al, 2003). Based on their work experiences, employees develop job-related attitudes based on their job fit, which in turn effects commitment, performance, and intention to turnover (Cable \& Judge, 1996; Caplan, 1987; Judge \& Cable, 1997; Verquer et al, 2003). Research has further shown that fit with task demands of the job are salient cues used in the development of jobrelated attitudes (Resick et al., 2007). Good job fit provides the cognitive stimulus for employees to engage in behavior directed toward organizational outcomes (Hoffman \& Woehr, 2006). Employees who experience good job fit derive a degree of psychological meaningfulness from their work (Kahn, 1990; Resick et al., 2007), resulting in employees who have the emotional and physical resources to complete their work (Harter et al., 2003). Thus, employees who experience job fit within their work roles are more likely to perform their jobs with enthusiasm and energy and be engaged in their work.

Verquer et al. (2003) conducted the first meta-analysis of the person-organization fit literature using a total of 21 studies with a total sample size of 18,776 participants. Results of their study indicated that subjective measures of person-organization fit, such as an employee expressing positive job-organizational fit, had a strong relation to satisfaction $(r=.61)$, organizational commitment $(r=.59)$, and intention to turnover $(r=$ .58). Measures of objective fit such as personality inventories and prescreening measures were much less conclusive and showed little support for relations with outcome variables like intention to turnover, job satisfaction, and productivity (Verquer et al., 2003). This study provided evidence that an employee's experience and perception of his or her work has a relation to outcome variables such as satisfaction, commitment, and turnover. Further, findings suggested that expectations about an employee's individual perception 
of his or her fit are more likely to effect individual reactions and work-related attitudes such as his or her engagement levels (Cable \& Judge, 1996; Caplan, 1987; Judge \& Cable, 1997; Verquer et al, 2003).

Hoffman and Woehr (2006) extended the meta-analysis of Verquer et al (2003) by exploring the relation between person-organization fit and performance, organizational commitment behavior (OCB), and turnover. Using 24 studies with a total sample size of 14,652 participants and 58 independent data points, results of their meta-analysis showed evidence that person-organization fit was moderately correlated with turnover $(r=-.26)$, task performance $(r=.26)$, and OCB $(r=.21)$. Results of their study further confirmed evidence presented by Verquer et al. (2003) showcasing the important role job fit plays in the development of job-related attitudes such as employee engagement.

Moreover, Kristoff-Brown, Zimmerman, \& Johnson (2005) investigated the relationship between person-job, person-organization, person-group, and personsupervisor fit with pre-entry (e.g., applicant attraction, job acceptance, intent to hire, job offer) and post-entry individual-level criteria (e.g., attitudes, performance, withdrawal behaviors, strain, tenure). Using a meta-analytic data stream of 172 publications and 836 data points, Kristoff et al. (2005) reported that nearly all the confidence intervals did not include 0 , indicating that the results of the study were applicable across a variety of settings. Kristoff et al. (2005) provided evidence that job fit was related to job satisfaction $(r=.44)$, organizational commitment $(r=.39)$, intention to quit $(r=-.37)$, supervisor satisfaction $(r=.28)$, and overall performance $(r=.29)$. Results indicated that job fit was an important facet to many important organizational outcomes (Kristoff et al., 2005) and provided a context for understanding how the work environment influences various 
aspects of employee attitudes and behaviors. According to the results of their study, job fit was an important antecedent in the development of overall workplace-related attitudes and behaviors (Kristoff et al., 2005) and lack of proper job fit could result in employees disengaging from work based on diminishing levels of meaningfulness, safety, and/or availability as originally conceptualized by Kahn (1990).

Adding the work of Kristoff et al. (2005), Resick et al. (2007) examined a model of person-organizational fit and work related attitudes to understand how job fit related to satisfaction and intention to accept a job offer. Resick et al. (2007) used a sample of 299 summer internship students at a large manufacturing facility in the Midwest. Results of the study showed evidence that person-organization fit was related to employee satisfaction when they had or could obtain the resources to complete their work $(r=.74)$ and job choice intention $(r=.39)$. This study highlighted the importance of job fit on an employee's perception of their work environment, how hard they are willing to work, and if they chose to stay. Similar to other studies of job fit (Hoffman \& Woehr, 2006; KristofBrown et al., 2005; Verquer et al., 2003), results indicated that an employee's perception of fit is an important determinant in the development of work-related attitudes (Resick et al., 2007), ultimately effecting productivity and turnover.

Poor job fit results in decreased productivity (Hoffman \& Woehr, 2006; Kristoff et al., 2005; Verquer et al., 2003), decreased satisfaction (Kristoff et al., 2005) and increased levels of turnover (Kristoff et al., 2005; Resick et al., 2007; Verquer et al., 2003). Good job fit provides opportunities for meaningful work to develop as well as the creation of environments where employees feel psychologically and emotionally safe and available (Kahn, 1990; May et al., 2004) and, is connected to the development of 
employee engagement (Kahn, 1990, 1992). Thus, it was hypothesized that degree of job fit would be positively related to employee engagement.

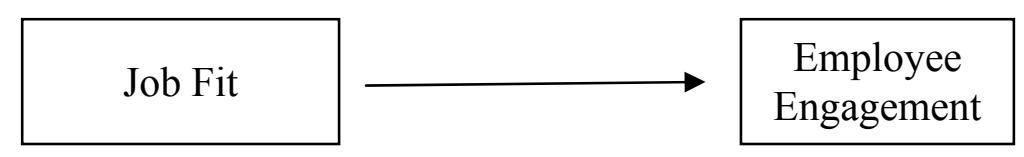

Figure 2. Job Fit Approach to Employee Engagement.

\section{Affective Commitment}

Affective commitment has been conceptualized as having a strong relation to employee engagement (Robinson, Perryman, \& Hayday, 2004). An employee's affective bond with their organization has been considered an important determinate of dedication, loyalty, and satisfaction (Rhoades, Eisenberger, \& Armeli, 2001). More than any other type of commitment, affective commitment emphasizes the emotional connection employees have with their work and closely parallels the emotive qualities of engagement (Saks, 2006, CLC, 2006, Towers Perrin, 2003; 2007; Macey \& Schneider 2008), including such conditions as meaningfulness and safety (Kahn, 1990).

Research has suggested a relationship between affective commitment and workoriented antecedent variables such as rewards and recognition, procedural justice, and supervisor support (Rhoades et al., 2001; Saks, 2006), as well as outcome variables such as absenteeism, performance, and turnover (Mathieu, \& Zajac, 1990; Meyer \& Allen, 1997; Mowday, Porter, \& Steers, 1987; Rhoades et al., 2001). Such emotive qualities can motivate employees to willingly engage in extra-in role behavior directed toward desired organizational outcomes that emphasize the emotional fulfillment employees experience as a result of being engaged (Fredrickson, 1998; Harter et al., 2003; Kahn, 1990). 
Emotional fulfillment is an important component of being engaged in work and is indicative of an engaged employee (Harter et al., 2003). Employees who are affectively committed feel a greater sense of belonging, increasing willingness to pursue organizational goals and be involved in discretionary effort (Allen \& Meyer, 1990; Mowday et al., 1982; Rhoades et al., 2001). Several studies have supported the use of affective commitment as an antecedent to employee engagement.

In one of the first studies of affective commitment, Allen and Meyer (1990) replicated an affective commitment model published by Jones (1986) to better understand antecedent and outcome variables of the affective commitment framework. Allen and Meyer (1990) chose 132 participants from a sample pool of recently hired (e.g., less than 12 months on the job) employees participating in undergraduate and graduate business courses. To obtain a longitudinal perspective of their experience, each participant was surveyed twice; once at six months into their jobs and again at 12 months. Allen and Meyer (1990) hypothesized that by being relatively new in their position, the socialization process for newcomers would have an effect on the development of commitment. Results of the study provided evidence that job fit was significantly related to the development of commitment at six months $(r=.50)$ and 12 months $(r=.46)$. Further, results of the study suggested that the perception an employee held about their job, such as their job fit, had a relation to affective commitment, and job-related attitudes. At the time of this research, this finding was an important distinction because it was previously thought that affective commitment had no influence in the workplace. Additionally, findings from this study suggested that levels of affective commitment had implications for productivity, satisfaction, and turnover (Allen \& Meyer, 1990) and 
promoted emotional connections to work such as meaningfulness and safety (Kahn, 1990). It was later hypothesized that a psychologically, emotionally, and socially safe work environment affected the perception of meaningful work and levels of engagement (Fredrickson, 1998; Harter et al., 2003; Kahn, 1992). At the time of this research, Allen and Meyer's (1990) research on affective commitment and Kahn's (1990) theory of engagement were being published around the same time.

In 2001, Rhoades et al. extended Allen and Meyer's (1990) original work by examining a model of interrelationships among work experiences, perceived organization support, affective commitment, and employee turnover. Rhoades et al. (2001) used a sample size of 367 alumni from a university in the eastern United States. Results of the study indicated that perceived organizational support mediated the relationship between organizational rewards $(r=.24)$, procedural justice $(r=.37)$, supervisor support $(r=.33)$ and affective commitment $(r=.72)$. Further, affective commitment had a negative relationship with turnover $(r=-.23)$. This study provided evidence that the perception of support, such as the type of support an employee might find in a positive psychological climate or in a supervisor they enjoy working with, affects an employee's overall experience of work (Brown \& Leigh, 1996) and that an employees interpretation of their work experience mediated by levels of affective commitment has important consequences for outcomes in the workplace such as an employee's intention to turnover (Rhoades et al., 2001). Further, results suggested that affective commitment was an important facet of an employee's experience and interpretation of their work directly related to meaningfulness, safety, and availability (Kahn 1990; May et al., 2004) as well as to the development of work-related attitudes and behaviors (Rhoades et al., 2001) such as an 
employee's level of engagement. Thus it was hypothesized that affective commitment would be positively related to employee engagement.

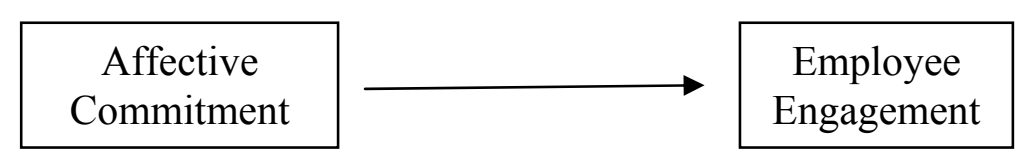

Figure 3. Affective Commitment Approach to Employee Engagement.

\section{Psychological Climate}

Psychological climate was developed using the framework of Kahn's (1990) original theory of engagement (Brown \& Leigh, 1996). Psychological climate has important linkages to employee involvement and overall work performance (Brown \& Leigh, 1996) and it is suggested that psychological climate " provide[s] constraints on or opportunities for behaviors and attitudes in organizational settings" (Johns, 2001, p. 32). Psychological climate is the lens employees use to understand their environment and "captures the meaningful psychological representations made by individuals relative to [the] structures, processes, and events that occur [inside] organization[s]" (O’Neil \& Arendt, 2008, p. 355). Psychological climate provides a framework to a particular organization's culture and research (Brown \& Leigh, 1996; O’Neill \& Arendt, 2008) Work environments that are perceived as psychologically safe impact performance (Brown \& Leigh, 1996) because they free employees to focus on available resources and desired work outcomes (Brown \& Leigh, 1996; O’Neil \& Arendt, 2008).

Psychological climate has been operationalized as including the following: autonomy in work (O’Neill and Arendt, 2008; Brown \& Leigh, 1996; James \& Jones, 1974), supportive management (Brown \& Leigh, 1996), rewards and recognition (O’Neill 
\& Arendt, 2008; James \& Jones, 1974; Brown \& Leigh, 1996) and self-expression (Brown \& Leigh, 1996). The facets of psychological climate as operationalized by Brown and Leigh (1996) directly parallel the conditions of engagement as defined by Kahn (1990, 1992). Thus, employees who experience positive psychological climate (Brown \& Leigh, 1996) are more likely to involve themselves in extra in-role discretionary effort, mediated by engagement in work. Several studies have supported the use of psychological climate as an antecedent to employee engagement.

Brown and Leigh (1996) examined a model of psychological climate, job involvement, effort, and performance using a sample from three companies: one paper goods manufacturer $(n=77)$ and two office supply companies $(n=85$ and $n=16)$, for a total sample size of 178. The researchers developed an operational definition of psychological climate using the employee's interpretation of their organizational setting in relation to their own well-being (Brown \& Leigh, 1996). This operational definition was grounded in Kahn's (1990) original conceptualization of engagement by using the conditions of meaningfulness, safety, and availability (Kahn, 1990) as a framework for interpreting the conditions of positive psychological climate. Results of the study showed evidence that a modest, yet statistically significant relation between psychological climate and job involvement $(r=.36)$ was present. Further, job involvement was related to effort $(r=.43)$ and effort was related to performance $(r=.35)$.

Findings from Brown and Leigh (1996) suggested that positive psychological climate had a relation with how employees involve themselves in their work, ultimately affecting productivity. Results suggested empirical support for the relation between psychological climate and employee engagement. Further, in 2007, D'Amato and Zijlstra 
extended Brown and Leigh's (1996) work suggesting that psychological climate affected an employee's ability and willingness to work, providing further evidence for a psychological climate-employee engagement linkage.

Building on the frameworks of D'Amato and Zijlstra (2007) and Brown and Leigh (1996), O’Neil and Arendt (2008) examined a five-component psychological climate model. The model examined the relation that autonomy, pressure structure, selfexpression, and trust had with job satisfaction, affective commitment, and intention to leave. Using a sample of 208 participants from a global manufacturing firm located in the Midwestern United States, results indicated that all five variables were positively correlated with job satisfaction and affective commitment and negatively correlated with an employee's intent to leave. See Table 5 for specific correlations.

Table 5

O'Neil and Arendt (2008) Correlations for Psychological Climate and Outcome

Variables

Climate and Autonomy Pressure Structure SelfTrust

Outcome expression

Variables

Job Satisfaction

$.38^{* *}$

$.36^{* *}$

$.43 * *$

$.43 * *$

$.39 * *$

Affective $.38^{* *}$ $.28 * *$ $.44 * *$ $.37 * *$ $.45^{* *}$

Commitment

Intention to Leave $-.25 * *$ $-.39 * *$ $-.40 * *$ $-.35 * *$ $-.37 * *$ 
O'Neil and Arendt's (2008) study provided evidence highlighting the importance of psychological climate in the development of specific work outcomes. Based on their interpretation of climate, it was posited that employees made decisions about how hard they will work, how satisfied they were, and how committed they would be to the organization (O'Neil and Arendt, 2008) as a result of their personal experience of work. Because workplace climate is influenced by an employee's manager (Arawarka \& Greenberg; Brown \& Leigh, 1996), this study highlighted the importance of the managerial role (i.e., a managers influence over levels of autonomy, pressure, structure, self-expression, and trust) in producing positive workplace climates as well as highlighting the importance of psychological climate. The context of an employee's work unit, mediated by the influence of a manager, was the most immediate situational influence on the perception of psychological climate (O’Neil \& Arendt, 2008); this finding parallels previous research (Czarnowsky, 2008; Fleming \& Asplund, 2007; Harter, et al., 2003; May et al, 2002; Wagner \& Harter, 2006). Evidence showed that psychological climate was a critically important antecedent variable in the development of workplace attitudes and behaviors and is derived from Kahn's (1990) original conceptualization of employee engagement (i.e., meaningfulness, safety, and availability). Thus it was hypothesized that psychological climate would be positively related to employee engagement.

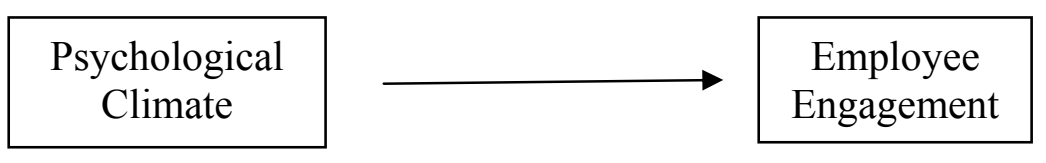

Figure 4. Psychological Climate Approach to Employee Engagement. 


\section{Outcomes of Employee Engagement}

Several researchers (Harter et al., 2002; Harter et al., 2003; Saks, 2006; Schaufeli \& Bakker, 2004; Sonnentag, 2003) have suggested that engaged employees produce positive work outcomes as a function of their engagement level. Schaufeli and Bakker (2004) described the experience of being engaged as a rewarding and positive workrelated experience that produced positive work outcomes (Kahn, 1990, 1992). Positive work experiences are related to overall employee wellbeing (Harter et al., 2003; Saks, 2006) and positive work affect (Sonnentag, 2003), both of which have been shown to result in positive work outcomes such as increased productivity, satisfaction, and reduced turnover (Kahn, 1990, 1992; Saks, 2006). As suggested by Schaufeli \& Bakker (2004) and Saks (2006), engaged employees are more likely to work harder through increased levels of discretionary effort and be less likely to leave their organization than those who are disengaged. As Wefald (2008) suggested, "so far, research points to a reciprocal relationship between resources, engagement, and positive outcomes" (p. 13). The following section examines research around discretionary effort and intention to turnover as outcomes of employee engagement.

\section{Discretionary Effort}

Discretionary effort is an important organizational variable (Lloyd, 2008) and is thought to be a positive work related outcome of employee engagement (CLC, 2004; Kular et al., 2008; Towers Perrin, 2003, 2007). Discretionary effort is defined as voluntary effort directed toward organizational goals above the minimum work required (Lloyd, 2008). This includes activities such as persistence on challenging projects and putting in extra hours to achieve faster results (Lloyd, 2003). While it is thought that 
discretionary effort cannot be observed, Lloyd (2008) suggested, "some behavior, such as cognitive acts of solving a problem or effort [such as discretionary effort], can only be observed as a result of these behaviors" (p. 23). Discretionary effort is the behavioral manifestation of the cognitive and emotional decision to engage (Macey \& Schneider, 2008; Saks, 2006). This statement directly parallels Saks's (2006) definition of employee engagement, providing a conceptual linkage between discretionary effort and employee engagement. Several studies have supported the use of discretionary effort as an outcome variable of employee engagement.

Using a large group of insurance agents, Dubinsky and Yammarino (1985) examined the distinction between motivation and discretionary effort and discovered that while the two the constructs where moderately correlated $(r=.21)$, they were distinct and separately measurable. Dubinsky and Yammarino (1985) distinguished discretionary effort from motivation and suggested that individuals with differing levels of motivation vary in the amount of effort they actually expend toward organizational goals. For example, it was hypothesized that an employee can be highly motivated but takes no actual action (Dubinsky \& Yammarino, 1985). However an employee displaying high levels of discretionary effort, mediated by engagement levels, would be both motivated and take action.

Implications of the study suggested that employees who were motivated did not necessarily take any behavioral action (Dubinsky \& Yammarino, 1985). Research by Campbell, McCloy, Oppler, and Sager (1993) further supported this research suggesting that without motivation, there is no effort, but motivation does not necessarily translate into action. This implication parallel's early building blocks of employee engagement 
(Kahn, 1990) highlighting that satisfaction is not enough to produce discretionary effort, but that employee engagement, a positive forward moving motivational variable directed toward organizational outcomes, would be more likely to be present in harder working employees.

Further, using a sample of 476 participants recruited by university students enrolled in a business administration class, Lloyd (2008) examined whether discretionary effort was distinct from extra in-role behaviors such as customer service and successfully managing ones time and OCB. Using a three-factor hierarchical model, Lloyd (2008) provided evidence that indicated discretionary effort was a separate construct from both in role behaviors and OCB. Further, results indicated that the variables skill $(r=.56)$ and autonomy $(r=.51)$ were important factors for predicting discretionary effort. Results indicated that while in-role behaviors and OCB's may be present in engaged employees, discretionary effort was a common outcome among employees who experienced job fit and positive psychological climate (Lloyd, 2008).

These findings provide support for a linkage between employee engagement and discretionary effort (Harter et al., 2002; Kahn, 1990; Saks, 2006). Thus, it was hypothesized that discretionary effort would be positively related to employee engagement.

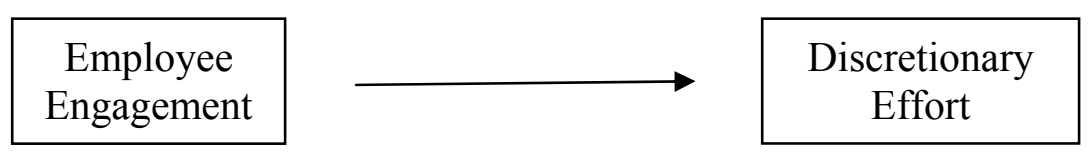

Figure 5. Employee Engagement Approach to Discretionary Effort. 


\section{Intention to Turnover}

Intention to turnover has been thought to be related to employee engagement (Berry \& Morris, 2007; Harter et al., 2002; Wagner \& Harter, 2006). Turnover intent is defined as an employee's voluntary intention to leave (Saks, 2006) and is more predictive of actual turnover than any other variable (Berry \& Morris, 2008). While some employees leave an organization for reasons beyond the control of the organization, human resource professionals become concerned when high performing employees choose to leave an organization due to circumstances within the organization's control (Allen, 2008; Lockwood, 2007). Circumstances within the organization's control include problematic working environments, job fit, difficult supervisors, and poor workplace climate (Berry \& Morris, 2008). Turnover is such an important human resource outcome that most interventions are measured by it (Bernthal \& Wellins, 2000; Lockwood, 2007; Lum et al., 1998). Previous studies have indicated a negative relation with intention to turnover and employee engagement.

For example, Verquer et al. (2003) and Hoffman and Woehr (2006) indicated that job fit was negatively related to intention to turnover $(r=-.58$ and $r=-.26)$. Intention to turnover has also been negatively related to affective commitment (Rhoades et al., 2001; $r=-.23$ ), psychological climate (Brown \& Leigh, 1996; $r=.43$ ), and effort (Schaufeli \& Bakker, 2004). Further, the International Survey Research (n.d.) examined a model of intention to turnover, recognition and rewards, individual development, career development, management practices, leadership practices, climate, commitment, and job fit. Results of the study indicated that a lack of these drivers showed a relationship to intention to turnover. Harter et al. (2002) found that engaged employees were less likely 
to turnover $(r=-.36)$ as did Towers Perrin $(2003 ; 2007)$ who reported that $66 \%$ of highly engaged employees had no intention to leave their current organization, compared with only $12 \%$ of disengaged employees (Towers Perrin, 2003). Lastly, in the only empirical model tested to date, Saks (2006) provided evidence that suggested employee engagement was negatively related intention to turnover $(r=-.44$ and $r=-.41)$. Thus, it was hypothesized that intention to turnover would be negatively related to employee engagement.

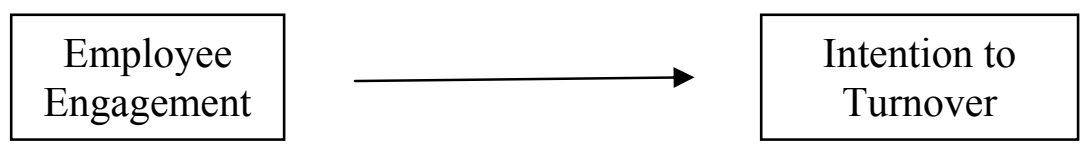

Figure 6. Employee Engagement Approach to Intention to Turnover. Proposed Employee Engagement Model

While conceptual and some empirical connections were highlighted, the review of literature was not sufficient in answering the research questions proposed in chapter 1 , as the interrelation between antecedent and outcome variables with employee engagement were not specifically addressed. Based on the various theories and concepts reviewed in the literature, a new conceptual model of employee engagement evolved (see Figure 1).

Summary

Chapter 2 examined the literature surrounding employee engagement including an introduction and examination of scholarly perspectives the concept. Literature focusing on job fit, affective commitment, psychological climate, discretionary effort, and intention to turnover were also examined and discussed. Finally, a proposed employee engagement model was presented. Chapter 3 will discuss the method used in this study. 
Chapter 4 presents the findings and chapter 5 concludes with a discussion of the results and implications for theory, research, and practice. 


\section{CHAPTER III}

\section{METHOD}

This chapter begins by repeating the purpose of the study and research questions from chapter 1. Second, research design, population and sampling, variables and instrumentation, data management, and data analysis follow. This chapter concludes with a summary of relevant points.

\section{Purpose of the Study}

The purpose of this study was to examine a hypothesized employee engagement model by exploring the relation among job fit, affective commitment, psychological climate, discretionary effort, intention to turnover, and employee engagement.

\section{Research Questions and Hypotheses}

Two overarching research questions guided this study: (a) what is the relation between the antecedent variables of job fit, affective commitment, and psychological climate with employee engagement and (b) what is the relation between employee engagement and the outcome variables discretionary effort and intention to turnover? To explore these two research questions, three research hypotheses were tested:

$H_{1}$ : There is a relation between job fit, affective commitment, and psychological climate, and employee engagement.

$H_{2}$ : There is a relation between employee engagement, discretionary effort, and intention to turnover.

$H_{3}$ : After controlling for job fit, affective commitment, and psychological climate, employee engagement will predict unique variance in discretionary effort and intention to turnover. 


\section{Research Design}

The framework for this study was derived from theories and concepts related to the workplace. The design of this research was non-experimental. In non-experimental research design, the manipulation of variables and randomization of samples are not present (Pedhazur \& Scmelkin, 1991). In this type of research design, the researcher approaches the phenomenon as it exists, affecting the direction in which inferences can be made about the study's findings. In non-experimental designs, inferences are generally made by attempting to uncover independent variables by first starting with a dependent variable (Pedhazur \& Scmelkin, 1991). At times, non-experimental design has been compared to correlational research design, however this is not appropriate because correlational design refers to analytical rather than design characteristics (Cook \& Campbell, 1979). Thus, the operation used to analyze data does not determine the design of the study (Pedhazur \& Scmelkin, 1991).

Distinctions between analytical and design levels are important in differentiating explanatory and predictive non-experimental research. Explanatory design seeks to explain phenomena, while predictive non-experimental design seeks to predict values of one or more dependent variables using one or more independent or control variables. The differences between these two design methods have implications for data collection, analysis, and interpretation. Predictive studies are driven by practical purposes, while explanatory studies are driven by theory and used to uncover the relationship between independent and dependent variables. The focus of this research was to uncover potential antecedents and outcomes of employee engagement, thus a non-experimental explanatory research design was used. 


\section{Population and Sample Size}

The population for this study consisted of individuals from a heterogeneous sampling of organizations from the fields of service, technology, healthcare, retail, banking, nonprofit, and hospitality that were all members of a local Chamber of Commerce association. The Chamber of Commerce association used as a data collection site for this study represented one of the largest and oldest Chamber of Commerce associations in the State of Florida. Several of the organizations represented in the association recently appeared in Fortune's list of the "100 Best Companies to Work For." This partnership promoted representation of many types of organizations to increase external validity estimates and generalizability of research findings (Hinkle, Wiersma, \& Jurs, 2006). To be able to make inferences regarding the characteristics of the population from measures of this sample, size of the sample was considered (Hinkle et al., 2006).

For methods such as correlational analysis, a sample size of at least 5 and up to 50 participants per variable is recommended (Green, 1991). Given that this study had 6 variables, a minimum total sample size of 30 was recommended (Green, 1991). Further, a power analysis of .80 with an effect size of .15 and an alpha of .05 recommended a sample size of 120 (Hinkle et al., 2006). However, for the purposes of this study, a sample size of approximately 300 participants was sought to strengthen statistical power and reduce the likelihood of a Type II error.

\section{Variables and Instrumentation}

The following section details each of the survey battery instruments used in measuring each research variable. First, employee engagement will be discussed, followed by each of the antecedent and outcome variables. Each scale was scored by 
aggregating the total scores for each question on a given measure and reporting the total score as the composite score for the measure. All instruments were scored using 5-point Likert continuum from 1 (strongly agree) to 5 (strongly disagree). Both composite and individual scores from each question on a given measure were examined for significance. Instruments were scored and reported separately. Full versions of each scale can be found in the Appendix.

\section{Employee Engagement}

Employee engagement was measured by combining three modified scales originally developed by May et al. (2004) to evaluate an individual's degree of engagement at work. The scales combined and used in this study were the: meaningfulness scale, safety scale, and availability scale (May et al., 2004). The combined 17-item scale asks participants to respond along a 5-point Likert continuum from 1 (strongly disagree) to 5 (strongly agree). Using Kahn's original conceptualization of engagement, May et al. (2004) conducted an exploratory principal components factor on each scale developed for use in examining the role of meaningfulness, safety, and availability in the development of engagement at work (May et al., 2004). Reliability estimates in the May et al. (2004) study were as follows: meaningfulness $=.63$; safety $=$ $.29 ;$ availability $=.45$.

Final versions of the May et al. (2004) scale were administered and validity estimates were obtained using 199 participants from a large insurance firm located in the midwestern United States (May et al., 2004). Convergent validity was estimated by May et al. for this scale using a principle components factor analysis with oblique rotation and .40 as a cutoff point for cross-loading. Using a revised path analytical framework of 
engagement, May et al. (2004) reported coefficient alphas for each scale respectively: meaningfulness $=.90 ;$ safety $=.71 ;$ availability $=.85$. Results provided evidence to suggest that each scale represented one dimension of Kahn's (1990) original conditions of engagement (i.e., meaningfulness, safety, and availability; May et al., 2004). Moreover, these scales paralleled the conceptual framework of employee engagement proposed for use in this study (Kahn, 1990). In the present study, the safety scale was revised by excluding question 9, "I am afraid to express myself at work" due to poor question construction. Accordingly, coefficient alpha scores for each of the scales in the present study were as follows: meaningfulness, $\alpha=.93$; safety, $\alpha=.74$; availability, $\alpha=$ .75. The reliability estimate for the combined scale was $\alpha=.89$.

Sample items from the modified scales included, "The work I do is very important to me" (e.g., meaningfulness), "I can be myself at work" (e.g., safety), and "At work, I have the resources to complete my job" (e.g., availability).

\section{Antecedent Variables}

The following section details the respective instruments used to measure job fit, affective commitment, and psychological climate.

Job Fit

Job fit was measured using the Person-Organization Fit Scale (POFS; Resick, Baltes, \& Shantz, 2007). The original POFS was a 5-item scale where participants responded along a 5-point Likert continuum from 1 (strongly agree) to 5 (strongly disagree). The POFS measures the degree to which a person feels his or her personality and values fit with his or her current organization. Original versions of the POFS (2007) were developed by Cable and Judge (1996) and Saks and Ashforth (1997), all of whom 
addressed person-organizational fit through separate scales. Scale items from both the Cable and Judge (1996) and Saks and Ashforth (1997) scales were combined, administrated, and validity estimates obtained by Resick et al. (2007) in a combined form with 299 interns from a variety of disciplines (i.e., human resources, sales, marketing, information technology) at a large manufacturing plant in the midwestern United States. This combined scale resulted in the 13-item updated Resick et al. (2007) version of the POFS scale. Convergent and discriminatory validity were estimated by Resick et al. (2007) with a confirmatory factor analysis, which indicated the 13 items were associated with separate perceived fit factors (comparative fit index $=.98$, goodness of fit index $=$ .93 , nonnormed fit index $=.97$, and root-mean-square error of approximation $=.07$ ). Resick et al. (2007) reported a coefficient alpha of .94 for the POFS. Coefficient alpha for the POFS in the present study was $\alpha=.92$. A sample item of the POFS (Resick et al., 2007) is, "I feel my personality matches the 'personality' or image of the organization."

\section{Affective Commitment}

Affective commitment was measured using the Affective Commitment Scale (ACS; Allen \& Meyer, 1990; Meyer \& Allen, 1997; Meyer, Allen, \& Smith, 1993; Mowday, Steers, \& Porter, 1979; Rhoades, Eisenberger, \& Armeli, 2001). The original ACS is a 6-item scale where participants responded along a 7-point Likert continuum from 1 (strongly agree) to 7 (strongly disagree). The ACS (Allen \& Meyer, 1990) was developed to test a 3-component (affective-continuance-normative) model of organizational commitment with 593 non-unionized employees. The original model (Allen \& Meyer, 1990) reported reliability estimates between .74 and .88 . 
Rhoades et al. (2001) developed and obtained validity estimates for a similar version of the ACS as a subscale in their study of affective commitment and organizational support with 367 working alumni from a university in the eastern part of the United States. Because of its brevity and similarity to the original scale (Allen \& Meyer, 1990), the Rhoades et al., (2001) version of the ACS was used for this study. Convergent and discriminate validity was established by Rhoades et al. (2001) using a confirmatory factor analysis, which indicated that the ACS (Rhoades et al., 2001) correlated with the broadly used 15-item Organizational Commitment Scale (Mowday, Steers, \& Porter, 1979) $(r=.83, p<.01)$ and associated with separate perceived fit factors (Allen \& Meyer, 1990). Rhoades et al. (2001) reported a coefficient alpha of .88 for the ACS. Coefficient alpha for the ASC (Rhoades et al., 2001) in the present study was $\alpha=.91$. A sample item of the ACS (Rhoades et al., 2001) is, "I am proud to tell others I work at my organization."

\section{Psychological Climate}

Psychological climate was measured using the Psychological Climate Measure (PCM; Brown \& Leigh, 1996). The original PCM is a 21 -item scale consisting of six subscales where participants responded along a 7-point Likert continuum from 1 (strongly agree) to 7 (strongly disagree). The subscales are as follows: supportive management, role clarity, contribution, recognition, self-expression, and challenge. Concepts for the PCM were developed using Kahn's (1990) definition of engagement and the supporting organizational variables Kahn believed to be related to the development of engagement in the workplace. Working from the theoretical framework of the General Psychological Climate measure (GPC; James, James, \& Ashe, 1990), validity estimates for the PCM 
was originally gathered by Brown and Leigh (1996) using two independent samples of participants: 77 sales representatives from a paper manufacturer and 101 representatives with an office supply manufacturer. Confirmatory factor analysis indicated that the 21 items on the PCM were associated with separate perceived fit factors (goodness-of-fit index $=.781$, root mean square residual $=.141$, and RMS error of approximation $=.083$ ). Such a fit was satisfactory for a large number of indicators estimated on two independent samples (Brown \& Leigh, 1996).

Only four of the dimensions, supportive management, contribution, recognition, and challenge were measured in the present study. Brown and Leigh (1996) reported coefficient alpha scores for each subscale per sample as follows: supportive management $(\alpha=.83$ and .85), contribution $(\alpha=.78$ and .71), and recognition $(\alpha=.76$ and .70). No coefficient alpha score was reported for the challenge subscale by Brown and Leigh (1996). Coefficient alpha scores for each of the scales in the present study were as follows: supportive management, $\alpha=.87$; contribution, $\alpha=.88$; recognition, $\alpha=.77$; and challenge, $\alpha=72$. Reliability estimates for the combined scale was $\alpha=.83$. A sample item of the PCM is, "I rarely feel my work is taken for granted."

\section{Outcome Variables}

The following section details the instruments used for measuring discretionary effort and intention to turnover.

\section{Discretionary Effort}

Discretionary effort was measured using the Discretionary Effort Scale (DES; Lloyd, 2008). The original DES is a 7-item scale where participants responded along a 5point Likert continuum from 1 (never) to 5 (always or nearly always). The DES measures 
an employee's voluntary willingness to engage in behaviors above the minimum required for his or her job. Lloyd (2008) obtained validity estimates for the DES using a sample of 476 respondents from a variety of industries to examine the relationship between discretionary effort and various performance domains including organizational citizenship behaviors (OCB), autonomy, in-role behaviors (IRB), and skills. The items in the survey represented levels of energy and determination in emotional efforts that are observed in behavior. Convergent and discriminate validity was established (Lloyd, 2008) using a three-factor hierarchical model with the variables IRB and OCB; confirmatory factor analysis provided evidence to suggest that discretionary effort was related to variables the IRB $(\alpha=.60, p<.000)$ and $\mathrm{OCB}(\alpha=.60, p<.000)$ but was a separate and distinct construct (goodness-of-fit index $=.951$, root mean square residual $=$ .031 , and RMS error of approximation $=.050)$. Lloyd (2008) reported a coefficient alpha of .87 for the DES. Coefficient alpha for the DES (Lloyd, 2008) in the present study was $\alpha=.93$. A sample item of the DES scale is, "I do more than is expected of me."

\section{Intention to Turnover}

Intention to turnover was measured using the Intention to Turnover Scale (ITS;

Colarelli, 1984). The original ITS is a 3-item scale where participants responded along a 5-point Likert continuum from 1 (strongly disagree) to 5 (strongly agree). The ITS measures an employee's future intentions to leave an organization. Validity estimates for the ITS were gathered in a study investigating the effectiveness of realistic job previews in the banking industry (Colarelli, 1984) using a sample of 164 bank tellers inside a large metropolitan bank in the United States. The items in the survey represent the future intentions of an employee to stay with his or her current organization or seek employment 
elsewhere. Colarelli's (1984) and Saks \& Ashforth (1997) each reported coefficient alpha's of .75 and .86 respectively. In a recent study by Cheng and Stockdale (2003), the ITS demonstrated a coefficient alpha of .79. Coefficient alpha for the ITS (Colarelli, 1984 ) in the present study was $\alpha=.81$. A sample item of the ITS is, "I frequently think of quitting my job.”

\section{Procedures}

An Internet-based self-report survey was used to collect data for this study. Internet-based self-report surveys are utilized in research more often than any other mode of data collection (Dillman, Smyth, \& Christian, 2009) and offer researchers tremendous cost savings and time efficiency as opposed to traditional mail surveys (Dillman, 2000). The following sections further describe Internet survey research, Internet-based selfreport surveys, and the sampling procedures used for this study.

\section{Internet Survey Research}

Internet surveys are one technique for gathering data in business. Because the Internet and use of the World Wide Web has become widely used (Dillman, Tortora, \& Bowker, 1999), its use as a data collection tool has grown in interest for both academic and organizational researchers (Dillman et al., 2009; Kiesler \& Sproull, 1986; Schmidt, 1997; Stanton, 1998). This data collection technique is a means of gathering information that describes the characteristics of a particular set of data ranging from descriptive information to attitudes and opinions (Isaac \& Michael, 1995). Internet surveys are commonly used in gathering both quantitative and qualitative data from a group of individuals (Creswell, 1994; Fowler, 1984). Dillman (1991, 2002) suggested that by using an Internet survey research method, participants might provide more truthful 
answers to a survey than if they were being interviewed either face-to-face or by telephone. For example, participants being interviewed about sensitive types of beliefs or behaviors such as views on race, religion, or perceptions of work might respond more openly to an Internet survey (Dillman, 1991, 2002). Additionally, the use of surveys often allows for the inclusion of a larger sample of the population thereby increasing the generalizability of the research findings.

\section{Internet-Based Self-Report Surveys}

An Internet-based self-report survey involves a computerized, self-administered questionnaire sent by the researcher, which the respondent receives, and completes (Crim, 2006; Simsek \& Veiga, 2001). Internet-based self-report surveys can include the following methods of collecting data: (a) sending an email message with the survey as a part of the message text; (b) sending the survey as an attachment to an email message that the respondent must open and respond to; and (c) sending an email message with a URLembedded-message in the text which the respondent clicks and is then taken to a host site where they view and respond to a survey instrument (Simsek \& Veiga, 2001). Internetbased self- report surveys have both advantages and limitations that were considered in the present study (Kiesler \& Sproull, 1986; Lockhart \& Russo, 1996; Manfreda, Batagelj, \& Vehovar, 2002).

\section{Advantages of Internet-Based Self Report Surveys}

The advantages of Internet-based self-report surveys include the following: design flexibility, interactivity, ability to reach large samples of the population, anonymity, cost, time efficiency, minimized interviewer error, and minimized interviewer bias (Schaefer \& Dillman, 1998; Sheehan \& Hoy 1999; Simsek \& Veiga, 2001). These advantages can 
make using Internet-based self-report surveys attractive for researchers. Although appealing, careful consideration was given to limitations associated with this method.

\section{Limitations of Internet-Based Self Report Surveys}

The limitations of Internet-based self-report surveys include low response rates (Dillman et al., 2009) and technical challenges (Yun \& Trumbo, 2000). Response rates for Internet-based surveys are at times lower than traditional mail surveys (Cawford et al., 2001; Dillman \& Bowker, 2001), although not always the case (Dillman et al., 2009). For example, in his analysis on response rates, Groves (2006) suggested that traditional mail survey response rates can range from $25 \%$ to $91 \%$. For Internet-based self-report surveys, Schonlau, Fricker, and Elliott (2001) suggested that response rates can range from $6 \%$ to $68 \%$. Further, similar studies of this type indicated response rates upwards of $30 \%$ (Crawford et al., 2001). Taking into account average response rates from similar studies (Crawford et al., 2001), the researcher estimated a 30\% response rate for this study. Approximately 1000 surveys were sent in order to accumulate enough representative and usable responses.

Moreover, technical issues can greatly affect a study's response rate. Dillman et al. (1999) suggested that technical challenges such as the design of the survey, technical competence of the end user, and advanced computer programming languages can all affect response rates by creating unforeseen challenges for the participant. For example, if the Internet-based self-report survey is written in a computer programming language that is not compatible with participants' computers, response rates can be affected. A low response rate increases the probability of four types of error. The four types of error are: 
sampling error, coverage error, measurement error, and nonresponse error (Crawford et al., 2001; Dillman et al., 2009; Sheehan \& Hoy, 1996). Coverage, Sampling, Measurement, and Nonresponse Error

Coverage error is defined as "all units of a population not having a known probability greater than zero of inclusion in the sample that is drawn to represent the entire population" (Dillman et al., 1999, p.2). Sampling error is defined as "error resulting from surveying a portion of the population rather than all of its members" (Dillman et al., 1999. p.2). Measurement error is defined as "the result of inaccurate answers to questions that stem from poor question wording, poor interviewing, survey mode effects, and/or answering behavior of the respondent" (Dillman et al., 1999. p.2). Nonresponse error is defined as "not getting some people in the sample to respond to the survey who, had they done so, would have provided a different distribution of answers than those who did respond" (Dillman et al., 1999. p. 2).

According to Dillman and Bowker (2001), coverage and sampling errors can be reduced by giving each member of a defined population an equal chance of being surveyed and therefore increasing the response rate. Measurement error can be reduced by conducting a pilot study in an attempt to better understand the appropriateness and easing of wording of questions (Dillman, 2007). Lastly, pre-notification and interval follow-up of initial survey mail outs have been shown to increase response rates, thereby increasing the sample size and reducing the probability of nonresponse error (Dillman, 1978; Murphy, Daley, \& Dalenberg, 1991; Rogelberg \& Luong, 1998; Sheehan \& McMillan, 1999; Simsek \& Veiga, 2001; Taylor \& Lynn, 1998). To reduce the probability of the four types of aforementioned measurement error and to increase 
response rate, Dillman et al's (2009) Tailored Design Method was used as the data collection framework for the present study.

\section{Sampling Procedures}

Methods used for conducting the present research study are discussed in the following section. Specific procedures for carrying out the research study in association with Dillman et al.'s (2009) Tailored Design Method are integrated throughout the procedures.

First, permission to conduct the study was sought from Florida International University's Gradate School and Human Subjects Review Board. After permission was granted, the researcher prepared the survey instrument for distribution. To adequately prepare for distribution, the researcher followed the four-stage recommendation suggested by Dillman et al. (2009) to provide each member of the defined population an equal chance of being surveyed and to check the wording and appropriateness and wording of questions. The four guidelines followed were: (a) survey content was reviewed by knowledgeable colleagues, (b) interviews were conducted to evaluate cognitive and motivational qualities of content, (c) a pilot study was conducted, and (d) a final check was completed. Table 6 acknowledges each step followed in Dillman et al.'s (2009) Tailored Design Method and provides the purpose of each step. 
Table 6

Steps in Dillman et al. 's (2009) Tailored Design Method

\begin{tabular}{|c|c|}
\hline Steps & Purpose of Step \\
\hline $\begin{array}{l}\text { 1. Survey content should be reviewed by } \\
\text { knowledgeable colleagues }\end{array}$ & $\begin{array}{l}\text { This step is designed to elicit suggestions } \\
\text { on research content by those who have } \\
\text { experience with previous surveys and study } \\
\text { objectives. }\end{array}$ \\
\hline $\begin{array}{l}\text { 2. Conduct interviews to evaluate cognitive } \\
\text { and motivational qualities of content }\end{array}$ & $\begin{array}{l}\text { The step is designed to test the } \\
\text { appropriateness of questions, the order of } \\
\text { questions, and the delivery methods works } \\
\text { as intended. }\end{array}$ \\
\hline 3. Conduct a pilot study & $\begin{array}{l}\text { The step is designed to emulate the } \\
\text { procedures that will be used for the } \\
\text { research study }\end{array}$ \\
\hline 4. Do a final check & $\begin{array}{l}\text { The step is designed to finalize any last } \\
\text { changes to the study and seeks the opinion } \\
\text { of someone not involved in study to review } \\
\text { the instrument for missing information. }\end{array}$ \\
\hline
\end{tabular}

To adhere to Dillman et al.'s (2009) four-stage recommendations, after explaining the purpose of the study, knowledgeable colleagues were sought to review the survey content. Three content experts in different but related areas (one director of training for a for-profit organization in the hospitality industry, one organizational behavior scholar, 
and one human resource development scholar) of human resources examined the survey battery under the condition of anonymity. Minor changes were made (e.g., layout of the survey format and rewording of participant directions) as a result of feedback received. Next, a survey research expert was sought to evaluate overall qualities of the survey content. No changes were made in step 2 as a result of the evaluation. Next, in stage 3 , the modified survey was pilot-tested with a group of participants reflective of the final sample population (i.e., all adults employed full time in various industries across South Florida; $N=17$ ). Time to completion was reported from each participant (average completion time $=7$ minutes and 21 seconds.) and changes were made to clarify instructions and add demographic variables (e.g., industry and position in organization) as a result of the feedback. The psychometric properties of the survey battery were not examined at this time because of the low sample size (Tabachnick \& Fidell, 2001).

Finally, a final check for clarity was completed (stage 4) with two individuals outside the study. Each individual was asked to take the questionnaire and report any feedback. No problems were reported.

Permission was then requested to conduct the study from the research sponsor. A research sponsor is someone who is particularly helpful in identifying potential participants when conducting research (Bogdan \& Biklen, 2007). The research sponsor for the present study was President of the local Chamber of Commerce association. Email addresses for all potential participants were accessed through the sponsor who was asked to forward all research-related communication for this study, including the survey link, to potential participants on behalf of the researcher. 
Once an agreement was reached and permission granted, the survey was prepared for administration. For scheduling purposes, Dillman et al.'s (2009) interval-scheduling framework was used to make initial contact, administer the survey, and send follow-up reminders to participants. Table 7 contains the scheduling framework used for this study in accordance with Dillman et al.’s (2009) Tailored Design Method.

Table 7

Scheduling Framework: Based on Dillman et al. 's (2009) Tailored Design Method

\begin{tabular}{ll}
\hline \multicolumn{1}{c}{ Time Frame } & \multicolumn{1}{c}{ Action } \\
\hline Week one & Invitation pre-notification \\
3 days after invitation pre-notification & Survey e-mail sent \\
1 week after initial survey e-mail & Reminder e-mail sent \\
2 weeks after initial survey e-mail & Reminder e-mail sent \\
Conclusion of survey & Thank you e-mail sent \\
\hline
\end{tabular}

Adhering to Dillman et al.’s (2009) Tailored Design Method, participants received a pre-notification e-mail from the researcher and the research sponsor inviting them to participate in the study. Three days after the pre-notification invitation, participants received an e-mail with a welcome message, a second invitation to participate in the study, a confidentiality notice, and instructions to assist in completing the survey battery. The survey was placed in a computer survey tool for administration $\left(\right.$ SurveyMonkey $\left.{ }^{\circledR}\right)$. Participation was strictly voluntary and participants were able to opt out of the study at any point. Each survey was assigned a unique URL address linked to the survey instrument by the website administrator. The purpose of the unique URL 
address was to track response rates as well as prevent participants from responding to the survey more than once. After participants submitted the completed survey, data was recorded in an electronic file accessible only to the researcher. Because the file did not contain any identifying information, participant confidentiality was reasonably assured.

Specific individual responses were not shared with any member of a participating organization or the research sponsor (Gall, Borg, \& Gall, 2006). Participants who had not responded to the survey 1 week after the initial survey e-mail received a reminder e-mail to encourage participation in the study. In total, three waves of invitations to participate in the study were sent out: the initial invitation, a follow-up reminder one week later, and one follow-up reminder 15 days later.

Data were downloaded, saved on a portable hard drive, and secured in a locked filing cabinet in the researchers home office. Data will be kept for 3 years from the completion of the study after which time the data will be destroyed.

\section{Data Analysis}

All quantitative data was entered into the SPSS database (version 15.0 for Windows) and examined for statistically significant relationships using correlational and hierarchical regression analyses (Aiken \& West, 1991; Hinkle et al., 2006). Characteristics were analyzed using descriptive statistics including frequency, mean, standard deviation, and chi-square tests of homogeneity. An alpha level of .05 (onetailed) was used in all three hypothesis tests. Variables were all continuous.

$H_{1}$ : There is a relation between job fit, affective commitment, psychological climate, and employee engagement. 
To test $H_{l}$, a correlational analysis was conducted to test the relation among job fit, affective commitment, psychological climate, and employee engagement. The resulting correlation coefficient indicated the strength and direction of relationship between the variables of interest simultaneously (Hinkle et al., 2006).

$\mathrm{H}_{2}$ : There is a relation between employee engagement, discretionary effort, and intention to turnover.

To test $\mathrm{H}_{2}$, a correlational analysis was conducted to test the relation between discretionary effort, intention to turnover, and employee engagement. As in $\mathrm{H}_{1}$, the resulting correlation coefficient indicated the strength and direction of the relationship between the variables of interest simultaneously (Hinkle et al., 2006).

$H_{3}$ : After controlling for job fit, affective commitment, and psychological climate, employee engagement will predict unique variance in discretionary effort and intention to turnover.

To test $\mathrm{H}_{3}$, a hierarchical regression analysis was performed where the combination of job fit, affective commitment, psychological climate and employee engagement variables were examined for their unique contributions to the dependent variables (i.e., discretionary effort and intention to turnover). Hierarchical regression analysis is an advanced form of linear regression, used as an alternative to comparing betas when assessing the unique variance contributed by independent variables (Aiken \& West, 1991). Such analysis allows a researcher to examine the extent to which regression coefficients vary across different variables, while borrowing strength from the full sample. Because of its ability to detect unique variance in the outcome variables (Hinkle et al., 2006), from the pooled variance of independents (e.g., job fit, affective 
commitment, psychological climate and employee engagement) the researcher had sufficient reason to believe this technique was appropriate for answering the research question.

\section{Summary}

Chapter 3 detailed the research processes including the research design, sampling and population, instruments, and procedures used for data collection and analysis in the present study. Chapter 4 presents detailed findings and is followed by chapter 5 . Chapter 5 includes a discussion of the results and implications for theory, research, and practice. 


\section{CHAPTER IV}

\section{RESULTS}

This chapter presents the results of the study and is organized into three main sections: background of the sample, examination of the hypotheses, and brief summary of the chapter. To examine the hypotheses, correlational and hierarchical regression analyses were used to test the hypothesized model of employee engagement and identify important relations between the variables of interest. Prediction methods, such as hierarchical regression, are helpful in determining which set of variables, or predictors, are most closely linked to a specific outcome (Green, 1991).

\section{Background of the Sample}

Two hundred and eighty three respondents participated in this study representing $27.3 \%$ of the total population. The participant's background, i.e., gender, age, ethnicity, level of completed education, position in company, and industry are examined in the following sections.

\section{Gender}

Approximately $53.3 \%(n=151)$ of the sample was female and $32.8 \%(n=93)$ of the sample was male. $13.8 \%(n=39)$ of the sample did not report their gender.

$$
\text { Age }
$$

A frequency analysis of age indicated that $1 \%(n=1)$ of the respondents reported belonging to the $16-19$ group, $8.1 \%(n=23)$ to the $20-29$ group, $24.7 \%(n=70)$ to the 30-39 group, $23.3 \%(n=66)$ to the $40-49$ group, $23.6 \%(n=67)$ to the $50-59$ group, $3.5 \%$ $(n=10)$ to the $60-69$ group, and finally $2.4 \%(n=7)$ to the $70-79$ age group. Approximately fourteen percent $(n=39)$ of respondents did not report their age. 


\section{Race/Ethnicity}

A frequency analysis of ethnicity indicated that $47.3 \%(n=134)$ of the respondents were Caucasian, 5.3\% $(n=15)$ African American, 32.1\% $(n=91)$ Hispanic, and 1\% $(n=3)$ selected "other." No respondent indicated affiliation with an Asian ethnicity. Approximately fourteen percent $(n=39)$ of respondents did not report their race/ethnicity.

\section{Highest Level of Education Completed}

A frequency analysis of highest education completed indicated 15.5\% $(n=44)$ of the participant's highest educational attainment was a high school diploma, $14.8 \%(n=$ 42) reported earning an Associate's Degree, 28.3\% $(n=80)$ reported earning a Bachelor's Degree, 20.1\% $(n=57)$ reported earning a Master's Degree and 4.6\% $(n=13)$ reported earning a Doctorate. Approximately seventeen percent $(n=47)$ of respondents did not report their level of education.

\section{Position within Organization}

Question nine asked respondents to choose a term that best described their position within the organization they currently work. A frequency analysis indicated that $39.2 \%(n=111)$ indicated they were a frontline team member, $27.2 \%(n=77)$ a supervisor or manager, and $18.4 \%(n=52)$ were at an executive level. Approximately fifteen percent $(n=43)$ of respondents did not report their position within their current organization.

\section{Industry}

Question 10 asked respondents to choose a term that best described the industry where they currently work. A frequency analysis indicated that $34.2 \%(n=97)$ were 
employed in a service industry, $3.1 \%(n=9)$ were employed in a manufacturing industry, $37.4 \%(n=106)$ were employed in a professional industry, and $11.3 \%(n=32)$ were employed in a nonprofit industry. Approximately fourteen percent $(n=39)$ of respondents did not report their industry.

Table 8 provides a frequency table of all demographic variables examined in this study. 
Table 8

Frequency Table of Demographic Variables

\begin{tabular}{|c|c|c|c|}
\hline Category & Variable & $f$ & Percent \\
\hline \multirow[t]{4}{*}{ Gender } & Male & 93 & 32.9 \\
\hline & Female & 151 & 53.4 \\
\hline & Total & 244 & 86.2 \\
\hline & Missing & 39 & 13.8 \\
\hline \multirow[t]{9}{*}{ Age } & $16-19$ & 1 & .4 \\
\hline & $20-29$ & 23 & 8.1 \\
\hline & $30-39$ & 70 & 24.7 \\
\hline & $40-49$ & 66 & 23.3 \\
\hline & $50-59$ & 67 & 23.7 \\
\hline & $60-69$ & 10 & 3.5 \\
\hline & $70-79$ & 7 & 2.5 \\
\hline & Total & 244 & 86.2 \\
\hline & Missing & 39 & 13.8 \\
\hline \multirow[t]{6}{*}{ Race/Ethnicity } & Caucasian & 134 & 47.3 \\
\hline & African American & 15 & 5.3 \\
\hline & Hispanic & 91 & 32.3 \\
\hline & Other & 3 & 1.5 \\
\hline & Total & 244 & 86.2 \\
\hline & Missing & 39 & 13.8 \\
\hline \multirow[t]{7}{*}{ Education } & High School Diploma & 44 & 15.5 \\
\hline & Associates Degree & 42 & 14.8 \\
\hline & Bachelors Degree & 80 & 28.3 \\
\hline & Masters Degree & 57 & 20.1 \\
\hline & Doctorate & 13 & 4.6 \\
\hline & Total & 236 & 83.4 \\
\hline & Missing & 47 & 16.6 \\
\hline \multirow{6}{*}{$\begin{array}{l}\text { Position within } \\
\text { Organization }\end{array}$} & Frontline Team & 111 & $39 ?$ \\
\hline & Member & & \\
\hline & $\begin{array}{l}\text { Supervisor or } \\
\text { Manager }\end{array}$ & 77 & 27.2 \\
\hline & Executive & 52 & 18.4 \\
\hline & Total & 240 & 84.8 \\
\hline & Missing & 43 & 15.2 \\
\hline \multirow[t]{6}{*}{ Industry } & Service & 97 & 34.3 \\
\hline & Manufacturing & 9 & 3.2 \\
\hline & Professional & 106 & 37.5 \\
\hline & Nonprofit & 32 & 11.3 \\
\hline & Total & 244 & 86.2 \\
\hline & Missing & 39 & 13.8 \\
\hline
\end{tabular}




\section{Cross Tabulation of Background Demographic Variables}

Cross tabulation analyses of the demographic variables were examined for meaningful relations using inferential statistics. Inferential statistical procedures such as chi-square analysis help researchers draw conclusions about a population from a sample and provide evidence regarding the generalizability of findings to a broader population (Creswell, 2005). In this section, chi-square analysis was used to test the null hypothesis $\left(H_{0}\right)$, meaning there is no significant difference between the expected and observed result of a given variable distribution (Babbie, 2004). A chi-square test is often used to compare the distribution of a sample variable with a given theoretical distribution, often the normal distribution (Green, 1991). The degree of freedom $(d f)$ provides information on how many data points were used to calculate a particular statistic and the $d f$ is usually one less than the number of variables. The $p$ value is the probability that the deviation of the observed from that expected is due to chance alone (Creswell, 2005). Using $p<0.01$, for example, you would expect any deviation to be due to chance alone $1 \%$ of the time or less. Table 9 lists the variables of the calculated chi-square $\left(\chi^{2}\right)$. 
Table 9

Demographic Variable Cross Tabulation

\begin{tabular}{lccc}
\hline Variable Combination & $\chi^{2}$ Value & $d f$ & $p$ \\
\hline Gender and Ethnicity & 4.82 & 4 & .31 \\
Gender and Education & 1.65 & 4 & .80 \\
Gender and Position & 12.94 & 2 & .00 \\
Age and Ethnicity & 66.36 & 24 & .00 \\
Age and Education & 27.85 & 24 & .27 \\
Age and Position & 55.95 & 12 & .00 \\
Industry and Ethnicity & 19.71 & 12 & .07 \\
Industry and Education & 17.07 & 12 & .15 \\
Industry and Position & 1.36 & 6 & .96 \\
\hline
\end{tabular}

The results of the chi-square tests indicated statistical significance for three demographic combinations: gender and position, age and ethnicity, and age and position. For the variable combination gender and position, a greater proportion of women $(52 \%)$ reported being in frontline team member positions than men (48\%). For the variables age and ethnicity, there was greater representation of Hispanic males in the 30-39 age group. For age and position, older employees indicated being employed in higher-level positions as expected. For the remaining variable combinations there were no statistical differences between distributions of each sample variable.

Additionally, because a number of participants neglected to complete the demographics-related questions, the researcher conducted a series of one-way 
MANOVAs to test for possible systematic bias. The nonrespondents were treated as a separate group when running the analyses (coded as a “9.").

For gender, the Box's Test (Equality of Covariance Matrices) reveals that equal variances can be assumed, $F(3,1652365)=.806, p=.331$; therefore, the Wilks's lambda was used as a test statistic. The Wilks's lambda criterion indicated no significant group differences by gender category with respect to the combination of dependent variables, Wilks's $\Lambda=.995, F(4,462)=.307, p=.873$, multivariate $\eta^{2}=.003$.

For race/ethnicity, the Box's Test reveals that equal variances can be assumed, $F(9,299.042)=.866, p=.749 ;$ therefore, the Wilks's lambda was used as a test statistic. The Wilks's lambda criterion indicated no significant group differences by ethnic category with respect to the combination of dependent variables, Wilks's $\Lambda=.932, F(10$, 456) $=1.627, p=.096$, multivariate $\eta^{2}=.034$.

For the education variable, the Box's Test reveals that equal variances can be assumed, $F(15,10492.583)=.609, p=.411$; therefore, the Wilks's lambda was used as a test statistic. The Wilks's lambda criterion indicated no significant group differences by education category with respect to the combination of dependent variables, Wilks's $\Lambda=$ $.951, F(10,456)=1.164, p=.313$, multivariate $\eta^{2}=.025$.

For the industry variable, the Box's Test reveals that equal variances can be assumed, $F(9,5536.051)=1.426, p=.171$; therefore, the Wilks's lambda was used as a test statistic. The Wilks's lambda criterion indicated no significant group differences by industry category with respect to the combination of dependent variables, Wilks's $\Lambda=$ $.965, F(8,458)=1.022, p=.418$, multivariate $\eta^{2}=.018$. 
For the position variable, the Box's Test reveals that equal variances can be assumed, $F(9,1196.879)=1.190, p=.111$; therefore, the Wilks's lambda was used as a test statistic. The Wilks's lambda criterion indicated no significant group differences by position category with respect to the combination of dependent variables, Wilks's $\Lambda=$ $.919, F(6,460)=1.326, p=.274$, multivariate $\eta^{2}=.014$

Finally, for the age variable, the Box's Test reveals that equal variances can be assumed, $F(18,910.677)=1.314, p=.088$; therefore, the Wilks's lambda was used as a test statistic. The Wilks's lambda criterion indicated significant group differences by age category with respect to the combination of dependent variables, Wilks's $\Lambda=.905, F(12$, $454)=1.947, p=.027$, multivariate $\eta^{2}=.049$. Univariate ANOVA results were interpreted using a more conservative alpha level $(\alpha=.025)$. The results reveal that age category significantly differs for only intent to turnover $F(6,228)=2.596, p=.019$, partial $\eta^{2}=.064$ and not discretionary effort $F(6,228)=1.630, p=.140$, partial $\eta^{2}=.041$. Examination of the Bonferroni post hoc results demonstrated that intent to turnover was significantly different from the 20-29 and the 30-39 and 40-49 age categories. In other words, those in the 20-29 age category demonstrated statistically significant lower group means for intent to turnover versus those in the 30-39 and 40-49 age categories.

For each of the aforementioned variables, the nonrespondents did not differ statistically from those in the other category groups per variable. Thus, the researcher retained the nonrespondent group and pooled these results with the other data for each research variable (Tabachnick \& Fidell, 2001). For only the age category variable did intent to turnover differ significantly by group, with the 20-29 age group demonstrating lower intent to turnover group means as compared to the 30-39 and 40-49 age groups. 
Thus, those in the 20-29 age group were less likely to turnover than those in the 30-39 and 40-49 age groups.

\section{Examination of Hypotheses}

Two hypothesized models of employee engagement were tested using correlational and hierarchical regression analyses. The model hypothesized that job fit, affective commitment, psychological climate, discretionary effort, and intent to turnover would be related to employee engagement. Prior to testing the model, underlying assumptions about correlational and hierarchal regression analyses techniques where examined. The four conditions examined were multicollinearity, linearity, and homoscedasticity (Hinkle et al., 2005). Serious violations of these assumptions may make inferences drawn from results of this study untrustworthy.

\section{Multicollinearity}

Multicollinearity occurs when variables are so highly correlated it is difficult to obtain reliable estimates of their individual regression coefficients (Cohen \& Cohen, 1983). When two variables are highly correlated, they are basically measuring the same phenomenon or construct. To avoid multicollinearity, correlation between predictor variables greater than .90 should be removed or combined (Green, 1991). High intercorrelations of predictors increase the standard error of the beta coefficients and make assessment of the unique role of each predictor variable difficult or impossible (Green \& Salkind, 2005; Tabachnick \& Fidell, 2001). Intercorrelations were checked and no correlation between predictor variables was found to be greater than .90 . 


\section{Linearity}

The assumption of linearity assumes the relationship between the independent and dependent variables is linear (Cohen \& Cohen, 1983). While hard to confirm, this assumption was tested with a bivariate scatterplot (Green, 1991). An examination of the bivariate scattterplots showed they formed relatively linear lines, thus there were no violations of linearity.

\section{Homoscedasticity}

Homoscedasticity is the assumption that the variability in scores for one variable is roughly the same at all values of the other variable, which is related to normality. When normality is not met, variables are not homoscedastic (Cohen \& Cohen, 1983; Green 1991). The homoscedasticity assumption was tested with bivariate scatterplots and examined for an oval shape versus a cone or funnel shape (Green, 1991). An oval shape provides evidence that the variance of residual error was constant for all values of the predictor variables. The scatterplot showed a generally oval shape for all predictor variables.

\section{Correlational Analysis for Testing $H_{1}$}

$\mathrm{H}_{1}$ stated that there would be a relation among job fit, affective commitment, psychological climate, and employee engagement. Zero-order correlational coefficients between the variables of interest were examined for meaningfulness according to effect size standards (Cohen, 1998). Following Cohen's (1988) effect size evaluation criterion,

correlational coefficients $< \pm .28$ are small effects; medium effects range from $\pm .28-.49$; and, large effects are greater than \pm .49. 
First, each scale was examined with subscales aggregated together to give a total composite score. Employee engagement was positively and significantly correlated with job fit $(r=.66, p<.001)$, affective commitment $(r=.71, p<.001)$, and psychological climate $(r=.78, p<.001)$. Results suggested a strong (Cohen, 1988) and positive relation among all variables, providing empirical support for $\mathrm{H}_{1}$. Employees who scored highly on employee engagement also reported high levels of job fit, affective commitment, and experienced positive psychological climate.

Second, each subscale within each major scale was examined for meaningful relations. Each of the three subscales used to measure employee engagement was examined for significant relationships with the variables of interest according to effect size standards (Cohen, 1998). The meaningfulness subscale was positively and significantly correlated with job fit $(r=.49, p<.001)$, affective commitment $(r=.58, p<$ $.001)$, and psychological climate $(r=.62, p<.001)$. The availability subscale was positively and significantly correlated with job fit $(r=.54, p<.001)$, affective commitment $(r=.55, p<.001)$, and psychological climate $(r=.67, p<.001)$. Finally, the safety subscale was positively and significantly correlated with job fit $(r=.49, p<.001)$, affective commitment $(r=.59, p<.001)$, and psychological climate $(r=.66, p<.001)$. Results suggest a medium to strong (Cohen, 1988) positive relation between all the variables of interest as well as each dimension of employee engagement, providing further support for $\mathrm{H}_{1}$. Employees who scored highly on each subscale of employee engagement (i.e., meaningfulness, safety, and availability) also were more likely to report higher levels of job fit, affective commitment, and positive psychological climate. 
Psychological climate was measured using four subscales (i.e., supportive management, contribution, challenge, and recognition). Each of the four psychological climate subscales was examined for statistical significance with all three employee engagement subscales. The meaningfulness subscale was positively and significantly correlated with supportive management $(r=.41, p<.001)$, contribution $(r=.69, p<$ $.001)$, challenge $(r=.36, p<.001)$, and recognition $(r=.50, p<.001)$. The safety subscale was positively and significantly correlated with supportive management $(r=.56$, $p<.001)$, contribution $(r=.62, p<.001)$, challenge $(r=.20, p<.001)$, and recognition $(r$ $=.60, p<.001)$. The availability subscale was positively and significantly correlated with supportive management $(r=.56, p<.001)$, contribution $(r=.57, p<.001)$, challenge $(r=$ $.59, p<.001)$, and recognition $(r=.26, p<.001)$. Finally, each of the four psychological climate subscales was positively and significantly correlated with total engagement (supportive management, $r=.62, p<.001$; contribution, $r=.76, p<.001$; challenge, $r=$ $.67, p<.001$; and recognition, $r=.33, p<.001)$. Employees who scored highly on each subscale of psychological climate (i.e., supportive management, contribution, challenge, and recognition) also were more likely to report higher levels of total engagement and engagement (i.e., meaningfulness, safety, and availability).

Additionally, job fit was significantly and positively correlated with affective commitment $(r=.74, p<.001)$ as well as psychological climate $(r=.64, p<.001)$. Job fit was also significantly and positively correlated with each psychological climate subscale (supportive management, $r=.51 p<.001$; contribution, $r=.55, p<.001$; challenge, $r=.58, p<.001$; and recognition, $r=.36, p<.001)$. This suggests that employee's who experienced a high degree of job fit also were more likely to report 
higher levels of affective commitment and report experiencing a more positive psychological climate.

Finally, affective commitment was significantly and positively correlated with psychological climate $(r=.72, p<.001)$ including all four subscales (supportive management, $r=.53, p<.001$; contribution, $r=.67, p<.001$; challenge, $r=.59, p<$ .001 ; and recognition, $r=.44, p<.001)$. This suggests that employees who report a high degree of affective commitment also were more likely to report experiencing a more positive psychological climate. The effect sizes of these associations were in the medium to large range (Cohen, 1988).

In summary, results indicated that employee engagement, job fit, affective commitment, and psychological climate were all significantly and positively related. Thus, the research evidence supports $\mathrm{H}_{1}$. Table 10 provides detailed correlational statistics regarding the relations among employee engagement, job fit, affective commitment, and psychological climate. 
Table 10

Zero-Order Correlation Coefficients for Employee Engagement, Job Fit, Affective Commitment, and Psychological Climate Scales

\begin{tabular}{|c|c|c|c|c|c|c|c|c|c|c|c|}
\hline Variables & $\mathrm{ME}$ & $\mathrm{SE}$ & $\mathrm{AE}$ & $\mathrm{TE}$ & JF & $\mathrm{AC}$ & SMPC & $\mathrm{CPC}$ & RPC & CHPC & PCT \\
\hline $\mathrm{ME}$ & -- & & & & & & & & & & \\
\hline SE & $.54 * *$ & -- & & & & & & & & & \\
\hline $\mathrm{AE}$ & $.45 * *$ & $.68 * *$ & -- & & & & & & & & \\
\hline $\mathrm{TE}$ & $.79 * *$ & $.88 * *$ & $.83 * *$ & -- & & & & & & & \\
\hline JF & $.49 * *$ & $.54 * *$ & $.59 * *$ & $.66 * *$ & -- & & & & & & \\
\hline $\mathrm{AC}$ & $.58 * *$ & $.55 * *$ & $.59 * *$ & $.71 * *$ & $.74 * *$ & -- & & & & & \\
\hline SMPC & $.41 * *$ & $.56 * *$ & $.56 * *$ & $.62 * *$ & $.51 * *$ & $.53 * *$ & -- & & & & \\
\hline $\mathrm{CPC}$ & $.69 * *$ & $.62 * *$ & $.57 * *$ & $.76 * *$ & $.55 * *$ & $.67 * *$ & $.57 * *$ & -- & & & \\
\hline RPC & $.50 * *$ & $.60 * *$ & $.59 * *$ & $.67 * *$ & $.58 * *$ & $.59 * *$ & $.64 * *$ & $.64 * *$ & -- & & \\
\hline $\mathrm{CHCP}$ & $.36 * *$ & $.20 * *$ & $.26 * *$ & $.33 * *$ & $.36 * *$ & $.44 * *$ & $.16^{*}$ & $.42 * *$ & $.28 * *$ & -- & \\
\hline PCT & $.62 * *$ & $.67 * *$ & $.66 * *$ & $.78 * *$ & $.64 * *$ & $.72 * *$ & $.86 * *$ & $.85 * *$ & $.84 * *$ & $.48 * *$ & -- \\
\hline
\end{tabular}

Note. ${ }^{* *} p<.01 .{ }^{*} p<.05$. ME is Meaningfulness Engagement scale. SE is Safety Engagement scale. AE is Availability Engagement scale. TE is Total Engagement scale. JF is Person Organizational Fit scale. AC is Affective commitment scale. SMPC is Supportive Management Psychological Climate subscale. CPC is Contribution Psychological Climate subscale. RPC is Recognition Psychological Climate subscale. CHCP is Challenge Psychological Climate subscale. PCT is the Psychological Climate scale. $N=283$. 


\section{Correlational Analysis for Testing $\mathrm{H}_{2}$}

$\mathrm{H}_{2}$ stated there would be a relation among employee engagement, discretionary effort, and intent to turnover. Zero-order correlational coefficients between the variables of interest were examined for significance according to effect size standards (Cohen, 1998). The engagement scale used for this study (May et al., 2004) was positively and significantly correlated with discretionary effort $(r=.43, p<.001)$ and negatively and significantly correlated with intention to turnover $(r=-.56, p<.001)$. Results suggest a strong (Cohen, 1988) relation between the variables of interest. According to the results, employees who reported higher levels of employee engagement were also more likely to report higher levels of discretionary effort and were less likely to report an intention to turnover.

Similar to $\mathrm{H}_{1}$, each of the three subscales used to measure employee engagement was examined for statistical significance with the variables of interest for $\mathrm{H}_{2}$ according to effect size standards (Cohen, 1998). The meaningfulness subscale was positively and significantly correlated with discretionary effort $(r=.42, p<.001)$ and negatively and significantly correlated with intention to turnover $(r=-.48, p<.001)$. The availability subscale was positively and significantly correlated with discretionary effort $(r=.31, p<$ $.001)$ and negatively and significantly correlated with intention to turnover $(r=-.39, p<$ .001). Finally, the safety subscale was positively and significantly correlated with discretionary effort $(r=.33, p<.001)$ and negatively and significantly correlated with intention to turnover $(r=-.49, p<.001)$. All correlations fell within the medium range (Cohen, 1988). Results from each subscale and the variables of interest suggest a 
moderate relation between the variables of interest and each dimension of employee engagement, providing further support for $\mathrm{H}_{2}$.

Additionally, discretionary effort was significantly and negatively correlated with intention to turnover $(r=-.24, p<.001)$. This suggests that employees who reported a high degree of discretionary effort were less likely to leave their current employer. The effect sizes of the associations for $\mathrm{H}_{2}$ were in the small to large range (Cohen, 1988). In summary, results indicated that employee engagement, discretionary effort, and intention to turnover were all significantly related, supporting $\mathrm{H}_{2}$. Table 11 provides detailed correlational statistics regarding the relations among employee engagement, discretionary effort, and intention to turnover.

Table 11

Zero-Order Correlation Coefficients for Employee Engagement, Discretionary Effort, and Intention to Turnover

\begin{tabular}{|c|c|c|c|c|c|c|}
\hline Variables & $\mathrm{ME}$ & $\mathrm{SE}$ & $\mathrm{AE}$ & $\mathrm{TE}$ & $\mathrm{DE}$ & ITT \\
\hline $\mathrm{ME}$ & -- & & & & & \\
\hline SE & $.54 * *$ & -- & & & & \\
\hline $\mathrm{AE}$ & $.45 * *$ & $.68 * *$ & -- & & & \\
\hline $\mathrm{TE}$ & $.79 * *$ & $.88 * *$ & $.83 * *$ & -- & & \\
\hline $\mathrm{DE}$ & $.42 * *$ & $.31 * *$ & $.33 * *$ & $.43 * *$ & -- & \\
\hline ITT & $-.48 * *$ & $-.40 * *$ & $-.49 * *$ & $-.56 * *$ & $-.24 * *$ & -- \\
\hline
\end{tabular}

Note. ${ }^{* *} p<.01 . \mathrm{ME}$ is Meaningfulness Engagement subscale. SE is Safety Engagement subscale. AE is Availability Engagement subscale. TE is Total Engagement scale. DE is Discretionary Effort scale. ITT is Intention to Turnover Scale. $N=283$. 


\section{Hierarchical Regression Analyses for $\mathrm{H}_{3}$}

Hierarchical regression analyses were performed to test $\mathrm{H}_{3}$ that stated after controlling for job fit, affective commitment, and psychological climate, employee engagement would predict unique variance in both discretionary effort and intention to turnover. The first outcome variable examined was discretionary effort. Job fit, affective commitment, and psychological climate were entered as the first variables in the model. All three engagement subscales were loaded into the second model. Results of hierarchical regression analysis on discretionary effort can be found in Table 12 . 
Table 12

Summary Hierarchical Regression Analysis with Psychological Climate, Affective Commitment, Job Fit, and Employee Engagement Predicting Discretionary Effort

\section{Discretionary Effort Model}

Variable

$\beta \quad R \quad R^{2}$

Sig. F Change

Step 1

Psychological Climate

Supportive Management $\quad .20 * *$

Contribution $\quad .50 * *$

Recognition $\quad-.13$

Challenge $.22 * *$

Affective Commitment $\quad-.03$

Job Fit $\quad-.03$

$\begin{array}{llll}\text { Block } & .63 & .38 & .000\end{array}$

Step 2

Employee Engagement

Meaningfulness $\quad .05$

Safety $\quad-.13$

Availability $\quad .01$

$\begin{array}{lll}\text { Block } & .06 \quad 00\end{array}$

Total adjusted $R^{2}$

.38

Note. ${ }^{* *} p<.01$ 
Testing the first regression model, in the first block, three of the psychological climate subscales, supportive management $(\beta=.22, p<.01)$, contribution $(\beta=.52, p<$ $.01)$, and challenge $(\beta=.20, p<.01)$ contributed unique variance to the prediction of discretionary effort $\left(R^{2}=.38, p<.01\right)$ in the regression equation. In the second block, after controlling for psychological climate, affective commitment, and job fit, employee engagement did not contribute additional variance to the regression equation $\left(R^{2}=.00, p\right.$ $>.05)$; thus, $H_{3}$ was not supported in this model. Accordingly, employees who reported higher supportive management, contribution, and challenge scores, but not affective commitment, job fit, and engagement scores, were more likely to participate in discretionary efforts in the workplace. These findings suggest that discretionary effort can be predicted by the psychological climate of the workplace; i.e., how supportive an employee feels their manager is, an employee's perception of their ability to contribute to their place of work, and the level of challenge an employee has with their work. Overall, the regression model explained $38.0 \%$ of the variance in discretionary effort (large effect size; Cohen, 1988).

To examine the collinearity between the variables of interest in this model, the variance inflation factor (VIF) was examined. VIF statistically quantifies the degree of multicollinearity between variables by providing an index that estimates how much variance is inflated due to collinearity (Green, 1991). Values of VIF that exceed 10.0 are regarded as indicating multicollinearity (Green, 1991). None of the variables examined in this model met or exceeded 10.0 (all less than 3.32).

In the second hierarchical regression, intent to turnover was examined as a dependent variable. Job fit, affective commitment, and psychological climate were 
entered into the first block of variables. All three engagement subscales were loaded into the second block. Results of the hierarchical regression analysis on intent to turnover can be found in Table 13 . 
Table 13

Summary Hierarchical Regression Analysis with Psychological Climate, Affective

Commitment, Job Fit, and Employee Engagement Predicting Intention to Turnover

Intent to Turnover Model

Variable

$\begin{array}{llll}\beta & R & R^{2} & \text { Sig. } F \text { Change }\end{array}$

Step 1

Psychological Climate

Supportive Management $\quad-.15$

Contribution $\quad-.08$

Recognition $\quad-.03$

Challenge $\quad .10$

Affective Commitment $\quad-.51 * *$

Job Fit $\quad .05$

$\begin{array}{llll}\text { Block } & .62 & .37 & .000\end{array}$

Step 2

Employee Engagement

Meaningfulness $\quad-.21^{* *}$

Safety $\quad .04$

Availability $-.19 *$

$\begin{array}{llll}\text { Block } & .65 & .04 & .004\end{array}$

Total adjusted $R^{2}$

Note. ${ }^{* *} p<.01 * p<.05$. 
Testing the second regression model, in the first block, affective commitment ( $\beta=$ $.51, p<.01)$ contributed unique variance to the prediction of intent to turnover in the regression equation $\left(R^{2}=.37, p<.01\right)$. In the second block of the equation, after controlling for psychological climate, affective commitment, and job fit, the evidence suggested that two subscales of the employee engagement measure, meaningfulness ( $\beta=$ $-.21, p<.001)$ and availability $(\beta=-.19, p<.05)$, added unique variance to the regression equation predicting intent to turnover $\left(R^{2}=.04, p<.01\right)$; thus, the third hypothesis was partially supported. As a result, employees who reported higher meaningfulness and availability scores were less likely to have an intention to turnover. The psychological climate, job fit, and safety variables did not reach statistical significance. These findings suggest that an employee's intent to turnover can be predicted by the degree of affective commitment an employee has with their place of work, the degree of meaningfulness they feel with their work, and the degree of availability they experience with their work. Overall, the regression model explained $41.0 \%$ of the variance in intention to turnover (large effect size; Cohen, 1988).

Similar to the first regression model (See Table 13), collinearity between the variables of interest in this model were examined using the VIF. None of the variables examined in this model met or exceeded 10.0 (Green, 1991).

In summary, $H_{1}$ and $H_{2}$ were both supported as the antecedent and outcome variables showed evidence of statistically significant correlations with employee engagement. $H_{3}$ was partially supported with no measure of engagement predicting unique variance in discretionary effort; however, two subscales of engagement predicted unique variance in intent to turnover. 


\section{Summary}

Results of this study partially support the hypotheses proposed in this study. The variables job fit, affective commitment, psychological climate, discretionary effort, and intent to turnover were all significantly associated with employee engagement. Furthermore, after controlling for job fit, affective commitment, and psychological climate two dimensions of employee engagement, meaningfulness and availability, predicted unique variance in intent to turnover. No measures of engagement predicted unique variance in the outcome variable discretionary effort. Chapter 5 discusses the results and implications of these findings for research, theory, and practice. 


\section{CHAPTER V \\ DISCUSSION}

Chapter 5 provides a brief summary of the study, followed by a discussion of results. Implications for theory, research, and practice are offered followed by limitations of the study.

\section{Summary of the Study}

Interest in employee engagement has gained considerable popularity in the last 20 years (Macey \& Schneider, 2008). Employee engagement is defined as "a distinct and unique construct consisting of cognitive, emotional, and behavioral components ... associated with individual role performance" (Saks, 2006, p. 602). Employees who are engaged in their roles at work are $27 \%$ less physically absent (Wagner \& Harter, 2006) then those who are not engaged saving 86.5 million days per year in lost productivity (The Gallup Organization, 2001). Engaged employees also stay with their organization longer (Buchanan, 2004), have fewer accidents on the job (Wagner \& Harter, 2006), are more productive (Buckingham \& Coffman, 1999) and score higher on customer satisfaction-rating scales (Vance, 2004). Further, recent evidence points towards a direct employee engagement-profit linkage (Czarnowsky, 2008).

In response to the benefits of having an engaged workforce, organizations are increasingly turning toward human resource researchers and practitioners to develop and support strategies that facilitate engagement-encouraging cultures (Vance, 2006); however, there remains a surprising shortage of research on employee engagement in the academic literature (Macey \& Schneider, 2008). The proposed employee engagement model (see Figure 1) suggested that employees who work in jobs where the demands of a 
job are congruent with their interests and values (job fit; Resick et al., 2007), feel as if they bond and identify with their place of work (affective commitment; Rhoades et al., 2001), and work in a positive psychological climate (Brown \& Leigh, 1996; Johns, 2001) will have higher levels of engagement. Furthermore, high levels of employee engagement would predict unique variance in the outcome variables of discretionary effort and intention to turnover providing a link to important organizational outcomes.

The purpose of this study was to examine a hypothesized employee engagement model by exploring the relation among job fit, affective commitment, psychological climate, discretionary effort, intention to turnover, and employee engagement. Two overarching research questions guided this study: (a) what is the relation between the antecedent variables of job fit, affective commitment, psychological climate and employee engagement and (b) what is the relation between employee engagement and the outcome variables discretionary effort and intention to turnover? Three research hypotheses were tested to examine these questions:

$H_{1}$ : There is a relation between job fit, affective commitment, and psychological climate, and employee engagement.

$\mathrm{H}_{2}$ : There is a relation between employee engagement, discretionary effort, and intention to turnover.

$H_{3}$ : After controlling for job fit, affective commitment, and psychological climate, employee engagement will predict unique variance in discretionary effort and intention to turnover

A survey battery of instruments was used to investigate the relation among the variables of interest. Existing literature was used to provide a foundation for the study 
and guide the research. Correlational and hierarchical regression analyses were used to test the hypothesized model and examine the hypotheses.

Results suggested that job fit, affective commitment, and psychological climate were all significantly related to employee engagement and that employee engagement was significantly related to both discretionary effort and intention to turnover. Moreover, three of the psychological climate subscales (i.e., supportive management and contribution, and challenge) were found to be unique predictors of discretionary effort. Affective commitment and two of the employee engagement subscales (i.e., meaningfulness and availability) were found to be unique predictors of intention to turnover. Interestingly, contrary to the hypothesized model, there was no significant predictive relationship between employee engagement and discretionary effort.

\section{Discussion of the Results}

Guided by theory and research, the following section discusses the results of each hypothesis tested. Results of this study suggested that there were statistically significant and meaningful relations to explore among the variables of interest. First, $H_{l}$ is explored followed by $\mathrm{H}_{2}$ and $\mathrm{H}_{3}$. A brief summary closes the section.

\section{Hypothesis 1}

The first hypothesis stated that there would be a relation between job fit, affective commitment, psychological climate, and employee engagement. Results from the correlational analysis indicated there was a significant positive relation between job fit, affective commitment, psychological climate, and employee engagement. Findings show support for $H_{l}$ and thus, the null hypothesis was rejected. The following sections discuss 
the results of each antecedent variable and its relation to employee engagement starting with job fit, followed by affective commitment, and psychological climate.

Job Fit

Employees who experienced a high degree of job fit were more likely to be engaged. This finding is consistent with previous research on job fit and its relation to the development of employee attitudes and behaviors (Bakker \& Demerouti, 2008; Resick et al., 2007). When employees experience poor job fit, the physical, emotional, and social discomfort resulting from poor fit can be overwhelming for employees (Bakker \& Demerouti, 2008). When overwhelmed by their experiences of work, employees perceive their job as less meaningful, safe, and lacking the resources for the completion of work (Kahn, 1990, 1992). Consequently, employee engagement is less likely to develop. Saks (2006) suggested that good job fit provides incentive for employees to bring more of themselves into their work, which leads to higher levels of engagement. This finding is consistent with Macey, Schneider, Barbera, and Young (2009) who further suggested that for engagement to develop, employees must have the capacity in their role to engage. Capacity is developed from feeling competent and autonomous, understanding one's job role, and having a high degree of fit between an employee and their specific job responsibilities (Macey et al., 2009). The perceived fit of one's job role, the balance of work-role demands, and the development of employee behavior share a significant relation to the development of employee engagement (Resick et al., 2007).

\section{Affective Commitment}

Employees who had a high degree of affective commitment to the organization at which they work were more likely to be engaged. This finding is consistent with previous 
studies (Mathieu \& Zajac, 1990; Meyer \& Allen, 1997; Rhoades et al., 2007) on affective commitment and the development of employee sentiment and behavior.

For example, recent models of employee engagement (Macey et al., 2008; Macey et al., 2009; Zigarmi et al., 2010) have discussed the affective component of employee engagement in some detail. In Macey and Schneider (2008) and Macey et al.'s (2009) conceptual employee engagement models, an employee's affective bond with their workplace fulfills a belonging and acceptance need that leads to displays of engaging behaviors. Fulfilling these needs parallels the condition of meaningfulness in Kahn's (1990) conceptualization of employee engagement. As an employee develops positive perceptions of meaningfulness in his or her role at work, engagement increases. Moreover, Harter et al. (2002), Schaufeli and Salavona (2007), Maslach et al. (2001), and Zigarmi et al. (2010) used terms such as emotion, affect, positive state, and enthusiasm to define various definitions of engagement in their respective models.

Findings from this study however are inconsistent with research by other scholars (Heger, 2007; Robinson et al., 2004; Saks, 2006) who have studied employee engagement from a social exchange lens. For example, using social exchange theory, Saks (2006) provided evidence that employee engagement was a reciprocal process based on social norms, not motivated by an emotive state (Macey et al., 2009). Although Saks (2006) acknowledged the role emotions play in the development of engaging behaviors through his definition of the concept, he suggested that engagement in work was an act of reciprocity rather than a state of being. Evidence from this research however suggested that affective commitment has an important and statistically significant relation with employee engagement. Notwithstanding, this study is the first known research to 
statistically link the affective component of an employee's decision-making processes and the development of employee engagement.

\section{Psychological Climate}

Employees who reported working in positive psychological climates were more likely to be engaged. This finding is consistent with that found in previous research (Bakker \& Derks, 2010; Brown \& Leigh, 1996; Hodges, 2010 Luthans, Norman, Avolio, \& Avey, 2008).

Zigarami et al. (2010) suggested that an employee's cognitive and emotive appraisal of his or her workplace climate results in behavior that is either engaging or disengaging. The interpretation of the environment is determined by an employee's understanding of the situation, level of empowerment, capabilities, and beliefs (Zigarami et al., 2010); this framework parallels the conditions for employee engagement as outlined by Kahn (1990). For example, the ability for a workplace climate to provide meaning, be perceived as safe, and provide the necessary resources for the completion of work is critical for the overall development of employee engagement. Employees who work in positive psychological climates are more likely to be productive and fulfill desired organizational objectives (Brown \& Leigh, 1996; O’Neill \& Arendt, 2008).

In addition, each of the sub-elements of psychological climate (i.e., supportive management, challenge, contribution, and recognition) had a significant positive relation to the development of employee engagement. This finding is consistent with other scholarly research on supportive management practices (Arakawa \& Greenberg, 2007; Kroth \& Keeler, 2009), levels of appropriate challenge in work roles (Britt et al., 2007; Brown \& Leigh, 1996), perceived contribution to work (Harter et al., 2003; O’Neil \& 
Ardent, 2008), and recognition (Brown \& Leigh, 1996; O’Neil \& Ardent, 2008).

\section{Hypothesis 2}

The second hypothesis stated that there would be a relation between employee engagement, discretionary effort, and intention to turnover. Results from the correlational analysis indicated there was a significant positive relation between discretionary effort and employee engagement and a significant negative relation between intention to turnover and employee engagement. Results showed support for $\mathrm{H}_{2}$ and thus, the null hypothesis was rejected. The following sections discuss the results of each outcome variable and its relation to employee engagement starting with discretionary effort followed by intention to turnover.

\section{Discretionary Effort}

Employees who reported higher levels of employee engagement were more likely to put in more discretionary effort. Research (Harter et al., 2002; Lloyd, 2008; Macey \& Schneider, 2008; Maslach et al., 2001) has long suggested that extra in-role behaviors such as discretionary effort have been associated with employee engagement.

Lloyd (2008) suggested that discretionary effort is a common outcome where employees feel valued, have an appropriate degree of autonomy with their work, and reasonable access to resources to complete job related tasks. Using the employee engagement lens (Kahn, 1990), employees who work in positions where they provide a meaningful contribution, are safe emotionally, psychologically, and physically, as well as have access to the resources to complete job role tasks report working harder than those who do not. This result is supported by the strong positive correlations between all three conditions of engagement and discretionary effort. 
In combination with the antecedent variables of this study (i.e., job fit, affective commitment, and psychological climate), employees who work in jobs where they experience a good degree of job fit, are bonded emotionally with their place of employment, report working in positive psychological climates, and have higher levels of engagement were more likely to display higher levels of discretionary effort. Moreover, findings from this study parallel numerous empirical studies (Harter et al., 2002, Lloyd, 2008; Maslach et al., 2001; May et al., 2001; Saks, 2006, Schaufeli et al., 2002; Zigarami et al., 2010) that report linkages between employee sentiment and what can be characterized as discretionary efforts (e.g., really exerting oneself, persisting in task completion, or doing more than is expected). Moreover, by providing evidence for the relation between employee engagement and discretionary effort, this study provides support for Macey and Schneider (2008) and Macey et al.'s (2009) theoretical employee engagement models; both suggest extra-role behavior as an outcome of the emotive and cognitive states of employee engagement.

\section{Intention to Turnover}

Employees who reported higher levels of employee engagement were less likely intending to turnover. Intention to turnover is more predictive of actual turnover than measures of job satisfaction or organizational commitment (Ovalle, 1984). Extensive research (Allen, 2008; Gubman, 2004; Harter et al., 2002; Lockwood, 2007; Macey \& Schneider, 2008; Macey et al., 2009; Maslach et al., 2001; Saks, 2006) links an employee's intention to turnover with organizational performance constructs such as employee engagement. 
Using the employee engagement lens (Kahn, 1990), employees who perceive their work as meaningful, safe, and have access to resources to complete their work report being less likely to leave their current organization. This result is supported by the strong significant negative correlations between all three conditions of engagement and intention to turnover. Parallel to discretionary effort, each of the antecedent variables also demonstrated a significant relation with intention to turnover. Employees who experienced a good degree of job fit, were affectively committed to their place of work, worked in positive psychological climates, and had higher levels of engagement also report being less likely to leave their current place of employment.

Intention to turnover represents one of the most strategic outcome variables for human resource practitioners (Allen, 2008). Human resource professionals often utilize data about employees' intention to turnover as a benchmark for the success of their programs (Lockwood, 2007). Results from this study provide support for and parallel other research (Gubman, 2004; Harter et al., 2002; Saks, 2006) suggesting that to the degree an employer can develop higher levels of engagement, they could potentially lower turnover intention.

\section{Hypothesis 3}

The third hypothesis stated that after controlling for job fit, affective commitment, and psychological climate, employee engagement would predict unique variance in discretionary effort and intention to turnover. Results from the hierarchical regression analysis presented evidence that select variables were antecedents to discretionary effort (Lloyd, 2008) and intention to turnover (Colarelli, 1984). Psychological climate (i.e., supportive management, contribution, and challenge; Brown \& Leigh, 1996) was found 
to predict unique variance in discretionary effort. Affective commitment and employee engagement (i.e., meaningfulness and availability; Kahn, 1990) were found to predict unique variance in intention to turnover. Thus, results show partial support for $H_{3}$. The following sections discuss the results from each hierarchical regression analysis starting with discretionary effort followed by intention to turnover.

\section{Predictors of Discretionary Effort}

The first hierarchical regression analysis provided evidence that three subscales scores of the psychological climate measure predicted unique variance in the outcome variable discretionary effort. The three subscales were supportive management, contribution, and challenge. This study revealed that when employees perceived their managers as supportive, felt as if they contributed to their place of work, and experienced an appropriate level of challenge in their work they were more likely to engage in discretionary efforts. The following sections provide further detail and support for each predictor variable.

Supportive management. A manager is one of the most, if not the most influential person in an employee's work-life (Arakawa \& Greenberg, 2007). The ability of a manager to influence environmental and behavioral elements such as discretionary effort is great. When an employee feels that their manager is supportive of their work, they are more likely to be involved in discretionary efforts. Reciprocally, discretionary effort is likely to decrease when employees feel that their manager is not supportive of their work and as a result employees are less likely to bring up new ideas, ask questions about their specific job role, or trust their manager (Brown \& Leigh, 1996). Managers who focus aggressively on pointing out what employees are doing wrong, raising their voices, and 
creating threatening or hostile environments decrease the likelihood that an employee would be involved in discretionary efforts (Arakawa \& Greenberg, 2007; Harter et al., 2002; Heger, 2007). Findings from this research are consistent with other studies on managers and their effect on work related outcome variables such as discretionary effort (Buckingham \& Coffman, 1999; Harter et al., 2003; Kahn, 1990; Kroth \& Keeler, 2009; Rhoades et al., 2001).

Contribution. Human beings desire the opportunity to contribute meaningfully to their surroundings, and research (Kahn, 1990, 1992) has suggested that when a human being feels as if they are contributing, they work harder at contributing more.

Consequently, employees who perceive that they contribute meaningfully to their place of work are more likely to be involved in discretionary efforts. Results suggested that contribution plays a large role in the development of discretionary effort. When employees perceive their work as contributing in meaningful ways (Brown \& Leigh, 1996), they work harder. Cyclically, as employees are provided information about how their work is contributory, they display higher levels of discretionary effort, and their level of contribution is likely to increase. However when employees are provided information that their work is not contributory, they are less likely to be involved in discretionary efforts. This finding parallel's Kahn's (1990) meaningfulness domain and is consistent with Latham and Ernst's (2006) motivation model that suggested an employee's perceived ability to make a contribution to their work increases motivation to work harder. When employees perceive that they are contributing toward the success of the organization, they are more likely to be involved in discretionary efforts. 
Challenge. Appropriate level of perceived challenge was a predictor of discretionary effort. Results indicated that if a job task was too intermediate employees reported not exerting maximum effort toward task completion. Reciprocally, if the task was too challenging or perceived as not accomplishable, minimal effort was exerted. This finding is consistent with research by Britt et al. (2007) and Brown and Leigh (1996) who suggested that in-role tasks should have an appropriate level of challenge for maximum effort to be exerted toward goal completion. An unchallenging task can cause employees to become bored and uninterested, and over a prolonged period of time disengaged (Harter et al., 2002; Kahn 1990). Too challenging of a task and the self-confidence and self-efficacy of the employee become threatened (Bandura, 1997; Britt et al., 2007) and minimal effort is applied.

In summary, supportive management, contribution, and challenge were all found to predict unique variance in discretionary effort (see Figure 7). No significant predictive relation between employee engagement and discretionary effort was found in this model. This result is inconsistent with the hypothesized employee engagement model as well as current research (Maslach et al., 2001; Macey \& Schneider, 2008). The hypothesized model stated that the psychological climate variable would be an antecedent to employee engagement and that discretionary effort would be an outcome of employee engagement. The inconsistency may be because employee engagement and discretionary effort are outputs of psychological climate rather than employee engagement mediating the relation between psychological climate and discretionary effort; thus, in a positive psychological climate, employees are more likely to have both higher levels of employee engagement 
and discretionary effort. Further research is needed to better understand the predictive relation between psychological climate, employee engagement, and discretionary effort.

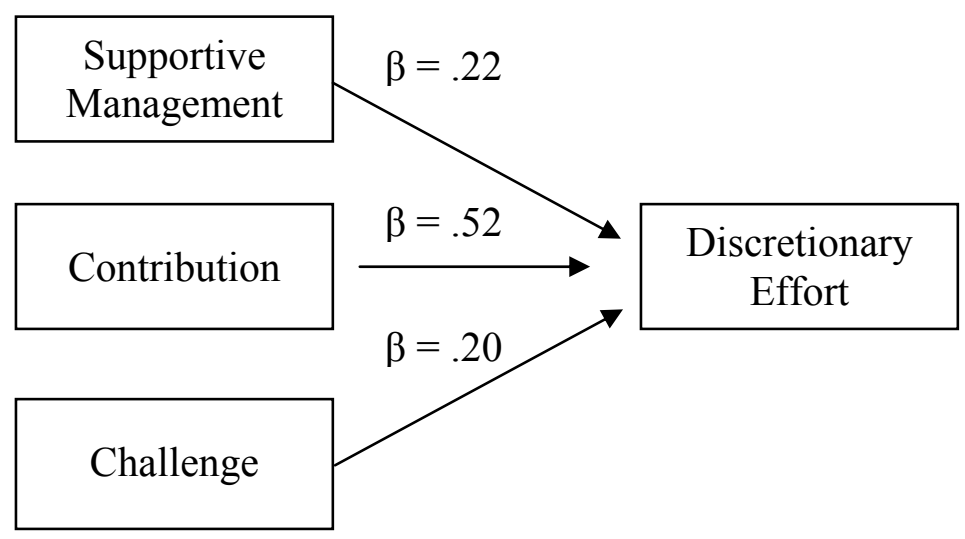

Figure 7. Predictors of Discretionary Effort.

The second hierarchical regression analysis provided evidence that affective commitment and employee engagement (i.e., meaningfulness and availability; Kahn, 1990) predicted unique variance in the outcome variable intention to turnover. This study revealed that when employees are affectively committed to their place of employment, feel their work is meaningful, and perceive that they have appropriate resources to complete their work, they were less likely to have an intention to turnover. The following sections provide further detail and support for each predictor variable.

Affective commitment. An employee's emotional bond with their place of work was shown to be a predictor of intention to turnover. Results from this study are consistent with results of previous research on both affective commitment and employee engagement. For example, Rhoades et al. (2001) suggested that an employee's reported level of affective commitment had a negative relationship to actual turnover. Notwithstanding, May et al. (2004) suggested that an employee's emotional appraisal of 
their work, as a result of their degree of employee engagement, affected specific workplace outcome behaviors such as intention to turnover.

Research around employee engagement has long speculated that employees develop an affective bond with their organization before engaging in behavioral states of employee engagement, and consequently outcomes of employee engagement such a negative intention to turnover (Kahn, 1990; Macey et al., 2009; Macey \& Schneider, 2008; Zigarami et al., 2010). Several definitions of employee engagement specifically mention emotional engagement as an element of the overall employee engagement construct (Macey \& Schneider, 2008; Saks, 2006). Accordingly, affective commitment has been shown to be an important lens an employee uses when making determinations about future behavior at work (Macey \& Schneider, 2008; Mowday et al., 1982). This research is consistent with previous findings (Czarnowsky, 2008; Macey \& Schneider, 2008; Saks, 2006; Wagner \& Harter, 2006).

Meaningfulness. The degree to which an employee perceives his or her work as meaningful was also a predictor of intention to turnover. Results from this study are consistent with research by Kahn (1990), Maslow (1970), Harter et al. (2002) and Fredrickson (1998) who suggested that when employees perceived their work as meaningful they were more likely to be engaged and less likely to leave their place of employment. Meaningful work provides a sense of return on investment for employees (Kahn, 1990) and parallels the contribution subscale of psychological climate (Brown \& Leigh, 1996) as conceptualized by Kahn's (1990) conditions of employee engagement. Meaningful work provides a framework for employees to better understand how they add value and significance to the organization at which they work (Frederickson, 1998). 
Research (Brown \& Leigh, 1996; Harter et al., 2003; Kahn, 1990, 1992; Maslow, 1970; May et al., 2004) has suggested that employees naturally gravitate toward experiences that provide meaning in their lives. On the contrary, employees who do not believe that their work is meaningful develop feelings of isolation and rejection and as a result, eventually leave (Maslach et al., 2001); thus, it is unreasonable to expect an employee to stay in a position where they do not perceive their work as meaningful (Kahn, 1990). Employees who perceive their work as meaningful are more likely to be engaged and thus, less likely to have an intention to turnover.

Availability. Employee's who perceive that they have the physical, emotional, and psychological resources necessary for the completion of work are less likely to have an intention to turnover. Results from this study are consistent with research by Kahn (1990) and May et al. (2004) who both suggested that when employees perceive they have the resources to complete work tasks, they are less likely to leave their place of employment. Moreover this research parallels findings by Britt et al. (2005) who suggested that the availability of physical, emotional, and social resources predicted motivation toward task completion. This research extends those findings (Britt et al., 2007) by providing empirical evidence that resources may not only motivate an employee to be more engaged, but also decrease his or her intention to turnover.

In summary, affective commitment and employee engagement (i.e., meaningfulness and availability; Kahn, 1990) were all found to predict unique variance in the outcome variable intention to turnover. See Figure 8. 


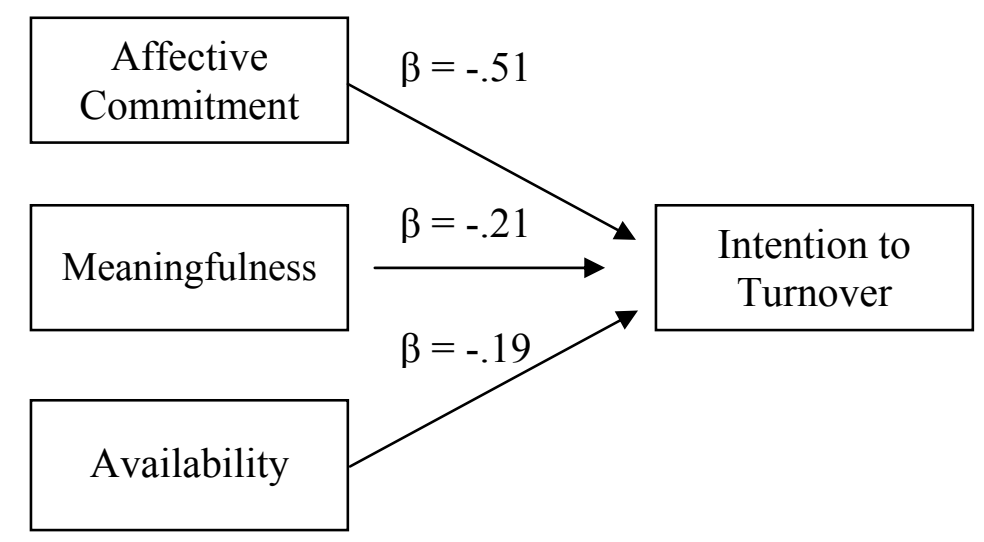

Figure 8. Predictors of Intention to Turnover

Implications for Theory, Research, and Practice

There was evidence that employee engagement is an important organizational variable with links to discretionary effort and intention to turnover. Having gained significant popularity over the past 20 years, employee engagement has been embraced by human resource scholars, researchers, and practitioners as an emerging leverage point for HRD (Lockwood, 2007; Macey \& Schneider, 2008). The following sections examine implications of this study to human resource theory building, research, and practice.

\section{Implications for Theory}

Substantial evidence supports and extends Kahn's (1990) employee engagement model by providing empirical evidence that the conditions of employee engagement (Kahn, 1990) have an important relation with the antecedent and outcome variables examined in this study. Prior to this study, May et al. (2004) was the only known research to empirically examine Kahn's (1990) conditions, and no known research had replicated the use of May et al.'s (2004) meaningfulness, safety, and availability surveys, respectively. Research from this study has demonstrated the relation between the 
conditions for engagement (Kahn, 1990; May et al., 2004) and antecedents and outcomes, and provided empirical evidence regarding the predictive relation of employee engagement (Khan, 1990) in intention to turnover. According to the hierarchical regression model, the combination of employee engagement and affective commitment accounted for $41 \%$ of the variance in predicting lower levels of intention to turnover. If HRD professionals are concerned about reducing voluntary turnover in organizations, evidence suggests that turnover might be examined in light of the engagement conditions of meaningfulness, safety, and availability. HRD professionals could, for example, carefully design interventions that teach managers and supervisors how to help employees be involved in meaningful work that fits their abilities and interests, feel safe at work cognitively, emotionally and physically, and have the available resources, both tangible and intangible, to complete their work. Moreover, for the first time in known research, this study identified how Kahn's (1990) conditions of engagement operate in relation to the antecedent variables of job fit, affective commitment, and psychological climate.

Findings also emphasized the importance of psychological climate in the context of employee engagement. Brown and Leigh's (1996) model explained how various elements of psychological climate affected certain events that initiated positive or negative emotions, ultimately leading to organizational outcomes. Theoretically grounded in Humphrey's (1993) original organizational behavior research on emotional labor and culture in the workplace, this study extends Brown and Leigh's (1996) model by providing empirical evidence for the role of psychological climate in predicting discretionary effort. According to the hierarchical regression model, higher levels of 
psychological climate accounted for $38 \%$ of the unique variance in predicting discretionary effort. Moreover, findings helped identify meaningful relational qualities between psychological climate and job fit, affective commitment, employee engagement, and intention to turnover; thus, this research extends and draws conceptual connections to both Brown and Leigh (1996) and Humphrey (1993) as well as earlier conceptual models which served as theoretical underpinnings to the emotional labor and psychological climate frameworks such as social identity (Ashforth \& Mael, 1989), job stress (Thoits, 1991), job design (Hackman \& Oldham, 1980), and emotion in the workplace (Hochschild. 1979). Increased awareness of the importance of psychological climate and how it is created through a relation with antecedent variables could help HRD professionals refine interventions around engagement theory as well as inform the larger organizational behavior literature base. For example, an HRD professional looking to increase discretionary effort could design positive socialization programs to help set the guidelines of an organization's culture (Reio \& Ghosh, 2009), use proactive social identity models (Ashforth \& Mael, 1989) to help employees understand their contribution to the workplace, and check to see if employees are working within appropriate levels of challenge (Hackman \& Oldham, 1980; Kahn, 1990; Thoits, 1990). Researchers could then systematically examine interventions to test their relation and predictive qualities under a variety of diverse circumstances. Researchers could also introduce new variables not examined in this study to further refine engagement theory.

Finally, findings provided empirical evidence that components of the employee engagement framework have relational and predictive utility. Of particular interest to theory building is the lack of predictive relation between discretionary effort and 
employee engagement as strongly suggested by several contemporary models (CLC, 2004; Kular et al., 2008; Maslach et al., 2001; Towers Perrin, 2003, 2007). The present study demonstrates evidence of a relation at the zero-order correlational level for discretionary effort, but this relation becomes nonsignificant when entered into the regression model. This is not the case in the intention to turnover model. These contrasting findings warrant future research. The findings suggest that the conceptual framework of employee engagement (Goffman, 1961; Kahn, 1990; Slater, 1966; Smith \& Berg, 1987) may benefit from further refinement. The theoretical model could benefit from being revisited more in the context of present day working conditions. Perhaps, the nature of work has changed since the inception of the original employee engagement (Khan, 1990) theorization and thus, employees may experience work and the outcomes associated with engaging work somewhat differently. Notwithstanding, prior to this research, little was known empirically about what variables were related to and/or influenced the development of employee engagement (Saks, 2006). Few models (e.g., Macey \& Schneider, 2008; Maslach et al., 2001; Saks, 2006) existed to conceptualize antecedents and outcomes and currently, no model could be found for specifically understanding how HRD professionals could influence the development of employee engagement. Consequently, it seems prudent to examine existing (Kahn, 1990; Harter et al., 2002) and emerging (Macey \& Schneider, 2008) employee engagement models as a way to extend and develop new theoretical frameworks for HRD. While more research is needed, findings from this study suggest strong strategic leverage points for HRD professionals between each of the antecedent variables, employee engagement, discretionary effort, and intention to turnover. 


\section{Implications for Research}

HRD researchers need to further test this model of employee engagement and the antecedent and outcome variables examined in this study. In addition to replication, research on employee engagement should be examined using casual comparative (Hinkle, et al., 2006) methods with diverse organizational settings and with diverse populations (e.g., knowledge workers, skill worker) using a number of organizationally pertinent variables (e.g., profit, growth, culture). Using an employee engagement lens to examine these variables will assist in refining the boundaries of the employee engagement concept (Macey \& Schneider, 2008). In future studies, grand mean centering along with structural equation modeling could be used as methods to decrease VIF and examine the overall model's goodness of fit (Raudenbush, 1987). Longitudinal employee engagement research would also be of benefit as a way to better understand how engagement levels change over periods of time. Researchers could focus on a specific group of employees in a variety of organizational settings over a week, month, year, or even 5-year period. It would be interesting, for example, to follow new employees for a specific length of time to examine how employee engagement changes over the course of an employee's work cycle. Research could also focus on a single collection site, for instance using a single case study design (Yin, 2003), to provide in depth understanding around the variables of interest. Qualitative studies might also assist in better understanding the phenomenon of employee engagement. For example, where possible, researchers could conduct structured interviews (Patton, 1990) with employees voluntarily leaving an organization and interpret findings through an employee engagement perspective. Such studies might provide more direct insights into the use of employee engagement as an organizational 
performance variable. The convergence of such research methods is necessary to increase the external validity of this research.

Experimental studies of employee engagement could also be utilized to assess the ability of HRD interventions to enhance employee engagement. Such studies could focus on the antecedent variables examined in this study, or use an expanded literature base to guide the selection of control variables. If researchers were to test the utility of an intervention in the development of employee engagement through a series of workshops, using organizational performance data, or customer feedback, pre- and post intervention data could be examined for significant differences. Moreover, examining effect sizes of the intervention could produce additional information about the utility of the intervention and provide information on steps an organization might consider next.

Moreover, the development of new employee engagement measures that are grounded in literature, conceptually clearer, and psychometrically more rigorous would be of great benefit to researchers. Currently, few statistically rigorous tools are available for research (for example, see Maslach, et al., 2001; May et al., 2004; Welfad, 2008). Many for profit consulting companies boast highly reliable tools, though most are too expensive to obtain or not available for academic research; even fewer report reliability and validity estimate data. New, more psychometrically rigorous measurement tools would allow researchers to respond more emphatically to Macey and Schneider (2008) and Saks's (2006) challenge for more scholarly research on the topic of employee engagement. As a result, more precise, predictive models of employee engagement could be possible. Using this research as a foundation, disaggregate analysis of the survey battery could examine challenges with collinearity and identify single-scale items that 
show evidence of a strong relation with outcomes variables. Identifying individual questions that indicate such a strong relation with antecedent and outcome variables could provide statistical leverage points for researchers developing emerging, and perhaps more accurate measures of employee engagement. Cross-validation of the measures used in this study could also provide insight into the stability of the predictive relations indicated in the results of this study.

Still further, an area that offers interesting opportunities for research is the emerging area of employee disengagement or employee withdrawal. With more than an estimated $70 \%$ of the global workforce going to work every day disengaged on some continuum (Buckingham \& Coffman, 1999; Crabtree, 2004; Czarnowsky, 2008; Gebauer \& Lowman, 2009; Wagner \& Harter, 2006), it could be prudent to better understand the variables that influence this state to emerge in theory and practice through further research. Notwithstanding, variables that influence an employee to become disengaged could be different then those related to the development of engagement as identified in this study. Currently, the study of employee disengagement is grounded in the burnout literature (Maslach et al., 2001) and has received little conceptual or empirical attention since early 2001 and could benefit significantly from future study.

Finally, newer models might examine distal antecedents and outcomes such as perceived co-worker support and personality variables as well as demographic and culture variables that might influence the development of employee engagement. As organizations become increasingly diverse (Reio \& Ghosh, 2009), exploring how demographic and cultural variables influence the development of employee engagement could be of benefit to organizations that have an international presence. 


\section{Implications for Practice}

Organizations looking to increase performance could focus on developing employee engagement as an organizational strategic leverage point. This study provides support for utilizing each of the variables examined in this study in the development of specific and objective work-oriented interventions around employee engagement. Human resource practitioners can take an important role in designing and implementing interventions in ways that increase employee engagement and impact organizational outcome variables. For example, in this study, affective commitment and psychological climate were identified as leverage points for practitioners looking to enhance employee engagement. Considering which leverage point to start with would depend on the unique needs of each organization; suggesting a "one size fits all" approach would be inappropriate and out of context for this study. Evidence however has suggested that creating opportunities for employees to work in roles in which their knowledge, skills, and abilities fit with their job responsibilities, creating and then supporting a positive psychological climate, and providing opportunities for employees to affectively bond with their organization are conditions that support a relation with employee engagement (Kahn, 1990; Macey et al., 2009). Thus, these variables should be considered as starting points for conversation and intervention. HRD practitioners could capitalize on this new knowledge by creating carefully constructed and integrated interventions that focus clearly on incorporating current management practices, organizational structure, jobdesign, and culture building (Joo, 2010).

Further, HRD practitioners should encourage the development of employee engagement by training leaders, managers, and supervisors about the conditions that have 
a relation with employee engagement. As highlighted by this study and supported by other research (Arakawa \& Greenberg, 2007; Harter et al., 2002; Kroth \& Keeler, 2009; Lloyd, 2008), an employee's manager strongly influences levels of employee engagement and discretionary effort. Interventions for leaders, managers, and supervisors could take the form of formal development and coaching programs that focus on proven talent management practices (Lockwood, 2007). Research suggests that interventions designed to influence employee engagement should provide opportunities for self-awareness, selfreflection, and real-time feedback (Hamel 2007; Maccoby, 2007).

Finally, it is imperative that organizations looking to increase performance focus on how work gets accomplished, not just how much. To recruit, maintain, and motivate employees in an increasingly competitive environment (Beck, 2003), human resource practices must be innovative and compelling, benefiting both the organization and the employee (Joo, 2010). It is essential that human resource programs balance the good of the organization with the good of the employee; sustainability of organizational performance alongside any intervention or program must be considered. Using results from this study to better understand employee engagement as both an organizational and individual level performance variable (Macey \& Schneider, 2008), could serve as a structure for implementing compelling, focused, and effective HRD interventions. For example, innovative practices could include taking an entire work group to serve in a community-wide service project for the day, encouraging managers to have weekly meetings with new team members during the first 4 weeks of a new job, or encouraging an entire human resource department to redesign their recruitment and selection processes to maximize and maintain the talents of their team. The conditions of employee 
engagement (i.e., meaningfulness, safety, and availability; Kahn, 1990) must be interwoven and present as a foundation to each employee's experience of work, every day. As evidenced by the findings of this study, employee engagement has powerful implications for organizations; consequently those who lead these organizations must work to create the conditions for employee engagement to develop. As the field of HRD evolves, employee engagement provides HRD professionals a way to help everspecialized employees in ever-specialized jobs (Beck, 2003) successfully operate within the inner workings of a complex, and ever-changing organization. Developing high levels of employee engagement in any organization is a work in progress however, thinking differently about work and how each employee experiences work, is the first step in an innovative direction.

\section{Limitations of the Study}

As is the case for all research, the present study has limitations. The first limitation was the use of a convenience sample consisting of members from a range of organizations who were affiliated with a particular Chamber of Commerce association in South Florida. While the use of heterogeneous convenience samples such as this is common in exploratory HRD research (e.g., Reio \& Ghosh, 2009; Yaghi, Goodman, Holton, \& Bates, 2008), caution should be used when generalizing the results beyond the current study.

A second limitation is the use of self-report measures. Self-report measures offer benefits to the researcher such as their inexpensive use and ease of distribution, however using these measures raises the possibility of common source method variance producing inflated correlations among the variables of interest (Crampton \& Wagner, 1994; 
Podsakoff, MacKenzie, Lee, \& Podsakoff, 2003). Common method variance is a potential problem whenever data is collected from a single source, which is the case with the present study. Several steps were taken to reduce the likelihood of this method biasing findings. First, participant anonymity was assured to participants (Podsakoff et al., 2003). Second, Dillman et al.'s (2009) Tailored Design Method was employed to provide a clear procedural approach. A clear procedural approach such as having the survey reviewed by knowledgeable experts and conducting a pilot study reduces the likelihood of coverage, sampling, measurement, and nonresponse error in the collection of data (Dillman et al., 2009). Third, as a diagnostic test, Harman's single-factor test was employed to examine the amount of variance accounted for in the variables. This procedure involved conducting an exploratory factor analysis of all the research variables (unrotated). If a single factor emerges as a result of the factor analysis, evidence would suggest the presence of common method variance. Results from this study revealed little evidence of common method variance as more than one factor emerged (there were three); thus, suggesting results are not likely attributable to common method variance.

Third, this study did not control for nonresponse bias while collecting data in three waves (Rogelberg \& Luong, 1998). Some of the demographic characteristics of nonrespondents might have unknowingly introduced bias into the study's data analysis. For instance, employees belonging to certain positions (i.e., frontline team members) within the sample population might have found it difficult to find time or the opportunity to participate in the survey, and thus, might have reported lower engagement scores. Lastly, the approach taken in this study involved measurement of individual respondents. This method asked individuals to report their own thoughts and feelings 
about their place of work. Social desirability bias could influence responses as participants were asked to report their own frequency of involvement in engaging behaviors (Pearson \& Porath, 2004). Clearly, reporting potentially sensitive information about one's manager or the support and resources available to complete a task could have led to socially desirable responses. Notwithstanding, there is little reason to believe that individual responses or concerns about social desirability influenced results because of the procedural steps taken in Dillman et al.'s (2009) Tailored Design Method. 


\section{REFERENCES}

Aiken, L. S., \& West, S. G. (1991). Multiple regression: Testing and interpreting interactions. Newbury Park, CA: Sage.

Allen, D. G. (2008). Retaining talent: A guide to analyzing and managing employee turnover. Alexandria, VA: The SHRM Foundation.

Allen, N. J., \& Meyer, J. P. (1990). Organizational socialization tactics: A longitudinal analysis of links to newcomers' commitment and role orientation. Academy of Management Journal, 33, 847-858.

Arakawa, D., \& Greenberg, M. (2007). Optimistic managers and the influence on productivity and employee engagement in a technology organization: Implications for coaching psychologists. International Coaching Psychology Review, 2(1), 7889.

Ashforth, B. E., \& Mael, F. (1989). Social identity theory and the organization. Academy of Management Review, 14, 20-39.

Avery, D. R., McKay, P. F., \& Wilson, D. C. (2007). Engaging the aging workforce: The relationship between perceived age similarity, satisfaction with coworkers, and employee engagement. Journal of Applied Psychology, 92, 1542-1556.

Ayers, K. E. (2008). Engagement is not enough: You need passionate employees to achieve your dream. Charleston, SC: Elevate.

Babbie, E. (2004). The Practice of Social Research (10 ${ }^{\text {th }}$ ed.). Belmont, CA: Wadsworth/Thompson Learning.

Bakker, A. B., \& Demerouti, E. (2008). Towards a model of work engagement. Career Development International, 13, 209-223

Bakker, A. B., \& Derks, D. (2010). Positive occupational health psychology. In S. Leka \& Houdmont J. (Eds.), Occupational Health Psychology (pp. 194-224). Malden, MA: Blackwell Publishing.

Bakker, A. B., \& Schaufeli, W. B. (2008). Positive organizational behavior: Engaged employees in flourishing organizations. Journal of Organizational Behavior, 29, 147-154.

Bandura, A. (1997). Self-efficacy: The exercise of control. New York: Freeman 
Baron, R. M., \& Kenny, D. A. (1986). The moderator-mediator variable distinction in social psychological research: Conceptual, strategic, and statistical considerations. Journal of Personality and Social Psychology, 51, 1173-1182.

Beck, J. (2003). Independent workforce theory: Implications for HRD. Human Resource Development International, 6, 21-41.

Bernthal, P. R., \& Wellins, R. S. (2000). Retaining talent: A benchmark study. Developmental Dimensions International (DDI). Retrieved from http://www.ddiworld.com/pdf/ddi_retainingtalentabenchmarkingstudy_es.pdf

Berry, M. L., \& Morris, M. L. (2008). The impact of employee engagement factors and job satisfaction on turnover intent. In T. J. Chermack (Ed.), Academy of Human Resource Development International Research Conference in The Americas (1-3). Panama City, FL: AHRD.

Bogdan, R. C., \& Biklen, S. K. (2007). Qualitative research for education ( $5^{\text {th }}$ ed.). Syracuse, NY: Pearson.

Brayfield, A. H., \& Rothe, H. F. (1951). An index of job satisfaction. Journal of Applied Psychology, 35, 307-311.

Britt, T. W., Castro, C. A., \& Adler, A. B. (2005). Self-engagement, stressors, and health: A longitudinal study. Personality and Social Psychology Bulletin, 31, 1475-1486.

Brown, S. P., \& Leigh, T. W. (1996). A new look at psychological climate and its relationship to job involvement, effort, and performance. Journal of Applied Psychology, 81, 359-368.

Buchanan, L. (2004). The things they do for love. Harvard Business Review, 82, 19-20.

Buckingham, M., \& Coffman, C. (1999). First, break all the rules; What the world's greatest managers do differently. New York: Simon and Schuster.

Cable, D. M., \& Judge, T. A. (1996). Person-organization fit, job choice decisions, and organizational entry. Organizational Behavior and Human Decision Processes, $67,294-311$.

Campbell, J. P., McCloy, R. A., Oppler, S. H., \& Sager, C. E. (1993). A theory of performance. In N. Schmitt, W. C. Borman, \& Associates (Eds.), Personnel selection in organizations (pp. 35-69). San Francisco: Jossey-Bass.

Caplan, R. D. (1987). Person-environment fit theory: Commensurate dimensions, time perspectives, and mechanisms. Journal of Vocational Behavior, 31, 248 -267. 
Carmeli, A., \& Weisberg, J. (2006). Exploring turnover intentions among three professional groups of employees. Human Resource Development International, 9, 191-206.

Cartwright, S., \& Holmes, N. (2006). The meaning of work: The challenge of regaining employee engagement and reducing cynicism. Human Resource Management Review, 16, 199-208.

Cheng, Y., \& Stockdale, M. S. (2003). The validity of the three-component model of organizational commitment in a Chinese context. Journal of Vocational Behavior, $62,465-489$.

Christian, M. S., \& Slaughter, J. E. (2007, August). Work engagement: A meta-analytic review and directions for research in an emerging area. Paper presented at the sixty-seventh annual meeting of the Academy of Management, Philadelphia, PA.

Colarelli, S. M. (1984). Methods of communication and mediating processes in realistic job previews. Journal of Applied Psychology, 69, 633-642.

Corporate Leadership Council. (2004). Driving performance and retention through employee engagement. Retrieved from http://www.mckpeople.com.au/SiteMedia/w3svc161/Uploads/Documents/760af4 59-93b3-43c7-b52a-2a74e984c1a0.pdf

Crabtree, S. (2004). Getting personal in the workplace: Are negative relationships squelching productivity in your company? Gallup Management Journal. Retrieved from http://gmj.gallup.com/content/1 1956/getting-personalworkplace.aspx

Crampton, S. M., \& Wagner, J. A. (1994). Percept-percept inflation in micro organizational research: An investigation of prevalence and effect. Journal of Applied Psychology, 79, 67-76.

Cohen, J., \& Cohen, P. (1983). Applied multiple regression/correlation analysis for the behavioral sciences. Hillsdale, NJ: Erlbaum.

Cohen, J. (1988). Statistical power analysis for the behavioral sciences. San Diego, CA: Academic Press.

Cook, T. D., \& Campbell, D. T. (1979). Quasi experimentation: Design and analysis issues for field settings. Chicago: Rand McNally.

Crawford, S. D., Couper, M. P., \& Lamias, M. J. (2001). Web surveys: Perceptions of burden. Social Science Computer Review, 19, 146-162. 
Creswell, J. W. (2003). Research design: Qualitative, quantitative, and mixed methods approaches $\left(2^{\text {nd }}\right.$ ed.). Thousand Oaks, CA: Sage.

Creswell, J. W. (2005). Educational research planning, conducting and evaluating quantitative and qualitative research $\left(2^{\text {nd }}\right.$ ed.). Upper Saddle River, NJ: Pearson Prentice Hall.

Crim, S. (2006). An examination of social presence in an online learning environment. Unpublished doctoral dissertation, University of Louisville, Kentucky.

Csikszentmihalyi, M. (2003). Good business: Leadership, flow, and the making of meaning. New York: Viking Penguin.

Czarnowsky, M. (2008). Learning's role in employee engagement: An ASTD research Study. Alexandria, VA: American Society for Training \& Development.

D'Amato, A., \& Zijlstra, F. (2007). Psychological climate and individual factors as antecedents of work outcomes. European Journal of Work and Organization Psychology, 17, 33-54.

Davenport, J. A., \& Davenport, J. (1982). Utilizing the social network in rural communities. Social Casework, 63, 106-113.

Dillman, D. A. (1978). Mail and telephone surveys: The total design method. New York: John Wiley \& Sons.

Dillman, D. A. (1991). The design and administration of mail surveys. Annual Review of Sociology, 17, 225-249.

Dillman, D. A. (2000). Mail and internet surveys: The tailored design method ( $2^{\text {nd }}$ ed.). New York: John Wiley \& Sons.

Dillman, D. A. (2002). Presidential address: Navigating the rapids of change: Some observations on survey methodology in the early twenty-first century. Public Opinion Quarterly, 66, 473-494.

Dillman, D. A., \& Bowker, D. K. (2001). The web questionnaire challenge to survey methodologists. Retrieved from http://www.sesrc.wsu.edu/dillman/zuma_paper_dillman_bowker.pdf

Dillman, D. A., Smyth, J. D., \& Christian, L. M. (2009). Internet, mail, and mixed-mode survey: The tailored design method. Hoboken, NJ: John Wiley \& Sons. 
Dillman, D. A., Tortora, R. D., \& Bowker, D. K. (1999). Principles for constructing web surveys. Retrieved from http://survey.sesrc.wsu.edu/dillman/papers/websurveyppr.pdf

Druskat, V. U., \& Wolff, S. B. (2001). Building emotional intelligence of groups. Harvard Business Review, 79, 81-90.

Dubinsky, A. J., \& Yammarino, F. J. (1985). Job-related responses of insurance agents: A multi-firm investigation. Journal of Risk and Insurance, 52, 499-517.

Dychtwald, K., Erickson, T., \& Morison, R. (2006). Workforce crisis: How to beat the coming shortage of skills and talent. Boston: Harvard Business School Press.

Fleming, J. H., \& Asplund, J. (2007). Human sigma. New York: Gallup Press.

Fowler, F. J. (2002). Survey research methods ( $3^{\text {rd }}$ ed.). Newberry Park, CA: Sage.

Frank, F. D., Finnegan, R. P., \& Taylor, C. R. (2004). The race for talent: Retaining and engaging workers in the $21^{\text {st }}$ century. Human Resource Planning, 27, 12-25.

Fredrickson, B. L. (1998). What good are positive emotions? Review of General Psychology, 2, 300-319.

Fredrickson, B. L., \& Joiner, T. (2002). Positive emotions trigger upward spirals toward emotional well-being. Psychological Science, 13, 172-175.

Freud, S. (1922). Group psychology and the analysis of the ego. London: International Psychoanalytic Press.

Gall, M. D., Borg, W. R., \& Gall, J. P. (2006). Educational research: An introduction (8 $8^{\text {th }}$ ed.). White Plains, NY: Longman.

Gebauer, J., \& Lowman, D. (2008). Closing the engagement gap: How great companies unlock employee potential for superior results. New York: Penguin Group.

Gilley, J., \& Maycunich, A. (2000). Organizational learning, performance and change. Cambridge, MA: Perseus.

Ginsberg, L. (1998). Social work in rural communities (3rd ed.). Alexandria, VA: Council on Social Work Education.

Goffman, E. (1961). The presentation of self in everyday life. New York: AnchorDoubleday. 
Gopal, A. (2003). Disengaged employees cost Singapore $\$ 4.9$ billion. Gallup Management Journal. Retrieved from http://gmj.gallup.com/content/default.aspx?ci=1207

Green, S. B. (1991). How many subjects does it take to do a regression analysis? Multivariate Behavioral Research, 26, 449-510.

Green, S. B., \& Salkind, N. J. (2005). Using SPSS for Windows and Macintosh (4 $4^{\text {th }}$ ed.). Upper Saddle River, NJ: Pearson.

Groves, R. M. (2006). Nonresponse rates and nonresponse bias in household surveys. Public Opinion Quarterly, 70, 646-675.

Gubman, E. (2004). From engagement to passion for work: The search for the missing person. Human Resource Planning, 29, 25-26.

Hackman, J. R., \& Oldham, G. R. (1980). Work redesign. Reading, MA: AddisonWesley.

Hamel, G. (2007), The future of management, Harvard Business School Press, Boston.

Harlow, L. L. (2004). The essence of multivariate thinking: Basic themes and methods. Mahwah, NJ: Erlbaum.

Harter, J. K., Schmidt, F. L., \& Hayes, T. L. (2002). Business-unit-level relationship between employee satisfaction, employee engagement, and business outcomes: A meta-analysis. Journal of Applied Psychology, 87, 268-279.

Harter, J. K., Schmidt, F. L., \& Keyes, C. L. M. (2003). Wellbeing the workplace and its relationship to business outcomes: A review of the Gallup studies. In C. L. Keyes \& J. Haidt (Eds.), Flourishing: The positive person and the good life (pp. 205224). Washington, DC: American Psychological Association.

Heger, B. K. (2007). Linking the employee value proposition (evp) to employee engagement and business outcomes: Preliminary findings for a linkage research pilot study. Organizational Development Journal, 25, 121-133.

Hinkle, D. E., Wiersma, W., \& Jurs, S. G. (2003). Applied statistics for the behavioral sciences $\left(5^{\text {th }}\right.$ ed). New York: Houghton Mifflin.

Hodges, T. (2010). An experimental study on the impact of psychological capital on performance, engagement, and the cognation effect. Unpublished doctoral dissertation, University of Nebraska, Lincoln. 
Hoffman, B. J., \& Woehr, D. J. (2006). A quantitative review of the relationship between person-organization fit and behavioral outcomes. Journal of Vocational Behavior, 68, 389-399.

Hochschild, A. R. (1979). Emotion work, feeling rules, and social structure. American Journal of Sociology, 85, 551-575.

Humphrey, R. H. (1993). Emotional labor in service roles: The influence of identity. The Academy of Management Review, 18, 88-115.

International Survey Research. (n.d.). Retention matters: A proactive strategy to address turnover. Stamford, CT: Towers Perrin. Retrieved from www.isrinsight.com/pdf/inisght/retentionmatters.pdf

Isaac, S., \& Michael, W.B. (1995). Handbook in research and evaluation: A study of principles, methods, and strategies useful in the planning, design, and evaluation of studies in education and the behavioral sciences. San Diego, CA: EdITS.

James, L. R., James, L. A., \& Ashe, D. K. (1990). The meaning of organizations: The role of cognition and values. In B. Schneider (Ed.), Organizational climate and culture (pp. 41-84). San Francisco: Jossey Bass.

James, L. R., \& Jones, A. P. (1974). Organizational climate: A review of theory and research. Psychological Bulletin, 81, 1096-1112.

James, J. B., Swanberg, J. E., \& McKechnie, S. P. (2007). Responsive workplaces for older w sorkers: Job quality, flexibility and employee engagement. An Issue in Brief \#11. Chestnut Hill, MA: The Center for Aging and Work/Workplace Flexibility at Boston College.

Johns, G. (2001). In praise of context. Journal of Organizational Behavior, 22, 31-42.

Johnson, J. W. (2003). Toward a better understanding of the relationship between personality and individual job performance. In M. R. Barrick \& A. M. Ryan (Eds.), Personality and work: Reconsidering the role of personality in organizations (pp. 83-120). San Francisco: Jossey-Bass.

Jones, G. R. (1986). Socialization tactics, self-efficacy, and newcomers' adjustments to organizations. Academy of Management Journal, 29, 262-279.

Jones, J. R., \& Harter, J. K. (2005). Race effects on the employee engagement-turnover intentional relationship. Journal of Leadership \& Organizational Studies, 11, 7888 . 
Joo, B. (2010). Organizational commitment for knowledge workers: The roles of perceived organizational learning culture, leader-member exchange quality, and turnover intention. Human Resource Development Quarterly, 21, 69-86

Joo, B., \& McLean, G. N. (2006). Best employer studies: A conceptual model from a literature review and a case study. Human Resource Development Review, 5, 228257.

Judge, T. A., \& Cable, D. M. (1997). Applicant personality, organizational culture, and organizational attraction. Personnel Psychology, 50, 359-393.

Judge, T. A., Van Vianen, A. E. M., \& De Pater, I. (2004). Emotional stability, core selfevaluations, and job outcomes: A review of the evidence and an agenda for future research. Human Performance, 17, 325-346.

Judge, T. A., \& Watanabe, S. (1993). Another look at the job satisfaction-life satisfaction relationship. Journal of Applied Psychology, 78, 939-948.

Kahn, W. (1990). Psychological conditions of personal engagement and disengagement at work. Academy of Management Journal, 33, 692-724.

Kahn, W. (1992). To be fully there: Psychological presence at work. Human Relations, 45, 321-349.

Ketter, P. (2008). What's the big deal about employee engagement? $T+D, 62(2), 44-49$.

Kiesler, S., \& Sproull, L.S. (1986). Response effects in the electronic survey. Public Opinion Quarterly, 50, 402-413.

Kraut, A. I. (1996). Introduction and overview of organizational surveys. In A. I. Kraut (Ed.), Organizational surveys: Tools for assessment and change (pp. 101-110). San Francisco: Jossey-Bass.

Kristof-Brown, A. L., Zimmerman, R. D., \& Johnson, E. C. (2005). Consequences of individuals' fit at work: A meta-analysis of person-job, person-organization, person-group, and person-supervisor fit. Personnel Psychology, 58, 281-342.

Kroth, M., and Keeler, C. (2009). Caring as a managerial strategy. Human Resource Development Review, 8, 506-531.

Kular, S., Gatenby, M., Rees, C., Soane, E., \& Truss, K. (2008). Employee engagement: A literature review. Kingston University, Kingston Business School. Retrieved from http://eprints.kingston.ac.uk/4192/1/19wempen.pdf 
Latham, G. P., \& Ernst, C. (2006). Keys to motivating tomorrow's workforce. Human Resource Management Review, 16, 181-198.

Lawler, E. E. (1990). Strategic pay: Aligning organizational strategies and pay systems. San Francisco: Jossey Bass.

Lee, C. H. (2003). Creating value for employees: Investing in employee development. International Journal of Human Resource Management, 14, 981-1000.

Lloyd, R. (2008). Discretionary effort and the performance domain. The Australian and New Zealand Journal of Organizational Psychology, 1, 22-34.

Lockhart, D. C., \& Russo, J. R. (1996). Mail and telephone surveys in marketing research: A perspective from the field. In P. Bagozzi (Ed.), Principles of marketing research (pp. 116-161). Cambridge, UK: Blackwell.

Lockwood, N. R. (2007). Leveraging employee engagement for a competitive advantage. Alexandria, VA: Society for Human Resource Management.

Lum, L., Kervin, J., Clark, K., Reid, F., \& Sirola, W. (1998). Explaining nursing turnover intent: Job satisfaction, pay satisfaction, or organizational commitment? Journal of Organizational Behavior, 19, 305-320.

Luthans, F., Norman, S.M., Avolio, B.J., \& Avey, J.B. (2008). The mediating role of psychological capital in the supportive organizational climate-employee performance relationship. Journal of Organizational Behavior, 28, 219-238.

Luthans, F., \& Peterson, S. J. (2002). Employee engagement and manager self-efficacy: Implications for managerial effectiveness and development. Journal of Management Development, 21, 376-387.

Maccoby, M. (2007). The leaders we need. Boston: Harvard Business School Press.

Macey, W. H., \& Schneider, B. (2008). The meaning of employee engagement. Industrial and Organizational Psychology, 1, 3-30.

Macey, W. H., Schneider, B., Barbera, K. M., and Young, S. A. (2009), Employee engagement: Tools for analysis, practice, and competitive advantage, WileyBlackwell, Malden, MA.

Manfreda, K. L., Batagelj, Z., \& Vehovar, V. (2002). Design of web survey questionnaires: Three basic experiments. Journal of Computer-Mediated Communications, 7. [Online]. Available from

http://www.ascusc.org/jcmc/vol7/issie3/vehovar.html 
Mangione, T. W. (1998). Mail surveys. In L. Bickman \& D. J. Rog (Eds.), Handbook of applied social research methods. (pp. 399-427). Thousand Oaks, CA: Sage.

McLagan, P. (1989). Models for HRD practice. $T+D, 43(5), 49-59$.

Maslach, C. (1998). A multidimensional theory of burnout. In C. L. Cooper (Ed.), Theories of organizational stress (pp. 68 - 85). Oxford, England: Oxford University Press.

Maslach, C., \& Leiter, M. P. (1997). The truth about burnout: How organizations cause personal stress and what to do about it. San Francisco: Jossey-Bass.

Maslach, C., \& Leiter, M. P. (2008). Early predictors of job burnout and engagement. Journal of Applied Psychology, 93, 498-512.

Maslach, C., Schaufeli, W. B., \& Leiter, M. P. (2001). Job burnout. Annual Review of Psychology, 52, 397-422.

Maslow, A. (1970). Motivation and personality (2 $2^{\text {nd }}$ ed). New York: Harper and Row.

Mathieu, J. E., \& Zajac, D. M. (1990). A review and meta-analysis of the antecedents, correlates and consequences of organizational commitment. Psychological Bulletin, 108, 171-194.

May, D. R., Gilson, R. L., \& Harter, L. M. (2004). The psychological conditions of meaningfulness, safety, and availability and the engagement of the human spirit at work. Journal of Occupational Psychology, 77, 11-37.

Meere, M. (2005). The high cost of disengaged employees (Employee Engagement Industry Briefing). Hawthorne, Victoria: Swinburne University of Technology.

Meyer, J. P., \& Allen, N. J. (1997). Commitment in the workplace: Theory, research, and application. Thousand Oaks, CA: Sage

Meyer, J. P., Allen, N. J., \& Smith, C. A. (1997). Commitment to organizations and occupations: Extension and test of a three-component conceptualization. Journal of Applied Psychology, 78, 538-551.

Morrison R., Erickson T., \& Dychtwald, K. (2006) Managing middlescence. Harvard Business Review, 3, 1-11.

Mowday, R. T., Porter, L. W., \& Steers, R. M. (1982). Employee-organization linkages: The psychology of commitment, absenteeism, and turnover. New York: Academic Press. 
Murphy, P. R., Daley, J., \& Dalenberg, D. R. (1991). Exploring the effects of postcard pre-notification on industrial firms' response to mail surveys. Journal of the Market Research Society, 33, 335-345.

Northouse, P. G. (2007). Leadership: Theory and practice. Thousand Oaks, CA: Sage.

O’Neill, B. S., \& Arendt, L. A. (2008). Psychological climate and work attitudes: The importance of telling the right story. Journal of Leadership \& Organizational Studies, 14, 353-370.

Patton, M. Q. (1990), Qualitative evaluation and research methods ( 2 nd ed.), Sage, Newbury Park, CA.

Payne, K., Cangemi, J. P., Fuqua, H., \& Muhleakamp, R. (1998). Leadership and employee empowerment: The foundation for organizational success and profit in the twenty-first century. In J. P. Cangemi, C. J. Kowalski, \& K. H. Khan (Eds.), Leadership behavior (pp. 119-130). Lantham, MD: University Press of America.

Peason, C. M., \& Porath C. L. (2005). On incivility, its impact, and directions for future research. In R. M. Griffin \& A. M. O'Leary-Kelly (Eds.), The dark side of organizational behavior (pp. 403-425). San Francisco: Jossey-Bass.

Pedhazur, E. J., \& Scmelkin, L. (1991) Measurement, design, and analysis: An integrated approach. Hillsdale, NY: Lawrence Erlbaum AssociatesPublishers.

Pfeffer, J. (1998). The human equation: Building profits by putting people first. Boston: Harvard Business School Press.

Podsakoff, N., MacKenzie, S. B., Lee, J., \& Podsakoff, P. M. (2003). Common method bias in behavioral research: A critical review of the research and recommended remedies. Journal of Applied Psychology, 88, 879-903.

Ratanjee, V. (2005). Gallup study reveals workplace disengagement in Thailand. The Gallup Management Journal. Retrieved from http:/gmj.gallup.com/content/16306/gallup-study-reveals-workplacedisengagement-in.aspx

Rath, T., \& Clifton, D. O. (2004). The power of praise and recognition. The Gallup Management Journal. Retrieved from http://gmj.gallup.com/content/12157/Power-Praise-Recognition.aspx

Raudenbush, S., \& Bryk, A. S. (2002). Hierarchical linear models: Applications and data analysis methods ( $2^{\text {nd }}$ ed.). Thousand Oaks, CA: Sage. 
Reeve, J. (2001). Understanding motivation and emotion. Fort Worth, TX: Harcourt College Publishers.

Reio, T. G., Jr., \& Callahan, J. (2004). Affect, curiosity, and socialization-related learning: A path analysis of antecedents to job performance. Journal of Business and Psychology, 18, 35-50.

Reio, T. G., Ghosh, R. (2009). Antecedents and outcomes of workplace incivility: Implications for human resource development research and practice. Human Resource Development Quarterly, 20, 237-264.

Reio, T. G., Jr., Petrosko, J. M., Wiswell, A. K., \& Thongsukmag, J. (2006). The measurement and conceptualization of curiosity. Journal of Genetic Psychology, $167,117-135$.

Resick, C. J., Baltes, B. B., \& Shantz, C. W. (2007). Person-organization fit and workrelated attitudes and decisions: Examining interactive effects with job fit and conscientiousness. Journal of Applied Psychology, 92, 1446-1455.

Rhoades, L., Eisenberger, R., \& Armeli, S. (2001). Affective commitment to the organization: The contribution of perceived organizational support. Journal of Applied Psychology, 86, 825-836.

Robinson, D., Perryman, S., \& Hayday, S. (2004). The drivers of employee engagement. Brighton: Institute for Employment Studies.

Roessler, R. T., \& Rubin, S. (1998). Case management and rehabilitation counseling. Austin, TX: Pro-Ed.

Rogelberg, S. G. \& Luong, A. (1998). Nonresponse to mailed surveys: A review and guide. Current Directions in Psychological Science, 7, 60-65.

Rogelberg, S. G., \& Luong, A. (1998). Nonreponse to mailed surveys: A review and guide. Current Directions in Psychological Science, 7, 60-65.

Rothmann, S. (2003). Burnout and engagement: A South African perspective. South African Journal of Industrial Psychology, 29, 16-25.

Rothmann, S., \& Storm, K. (2003, May). Work engagement in the South African police service. Paper presented at the 11th European Congress of Work and Organizational Psychology, Lisbon, Portugal.

Saks, A. M. (2006). Antecedents and consequences of employee engagement. Journal of Managerial Psychology, 21, 600-619. 
Saks, A. M., \& Ashforth, B. E. (1997). A longitudinal investigation of the relationships between job information sources, applicant perceptions of fit, and work outcomes. Personnel Psychology, 50, 395-426.

Salkever, D. (2000). Activity status, life satisfaction, and perceived productivity for young adults with developmental disabilities. Journal of Rehabilitation, 66(3), 413 .

Schaefer, D. R., \& Dillman, D. A. (1998). Development of a standard email methodology: Results of an experiment. Public Opinion Quarterly, 62, 378-397.

Schaufeli, W. B., \& Bakker, A. B. (2004). Job demands, job resources, and their relationship with burnout and engagement: A multi-sample study. Journal of Organizational Behavior, 25, 293-315.

Schaufeli, W. B., Bakker, A. B., \& Salanova, M. (2006). The measurement of work engagement with a short questionnaire: A cross-national study. Educational \& Psychological Measurement, 66, 701-716.

Schaufeli, W. B., Martinez, I., Pinto, A. M., Salanova, M., \& Bakker, A. B. (2002). Burnout and engagement in university students: A cross-national study. Journal of Cross-Cultural Psychology, 33, 464-481.

Schaufeli, W. B., \& Salanova, M. (2007). Work engagement: an emerging psychological and its implications for organizations. In S. W. Gilliland, D. D. Steiner, \& D. P. Skarlicki (Eds.), Research in Social Issues in Management (Volume 5): Managing Social and Ethical Issues in Organizations. (pp. 135-177). Greenwich, CT: Information Age Publishers.

Schaufeli, W. B., Salanova, M., Gonzalez-Roma, V., \& Bakker, A. B. (2002). The measurement of engagement and burnout: A two sample confirmatory factor analytic approach. Journal of Happiness Studies, 3, 71-92.

Schmidt, W. C. (1997). World-Wide Web survey research: Benefits, potential problems, and solutions. Behavior Research Methods, Instruments, \& Computers, 29, 274279.

Schonlau, M., Fricker, R. D., \& Elliott, M. N. (2001). Conducting research surveys via email and the web. Retrieved April 5, 2008, from http://www.rand.org/publications/MR/MR1480/html

Sheehan, K. B., \& Hoy, M. G. (1999). Using email to survey Internet users in the United States: Methodology and assessment. Journal of Computer Mediated Communications, 4, 1-24. 
Shraga, O. (2007). Vigor at work: Its construct validity, and its relations with job satisfaction and job characteristics: Triangulating qualitative and quantitative methodologies. Unpublished doctoral dissertation, Tel Aviv University, Israel.

Shirom, A. (2003). Feeling vigorous at work? The construct of vigor and the study of positive affect in organizations. In D. Ganster \& P. L. Perrewe (Eds.), Research in organizational stress and well-being (Vol. 3, pp. 135-165). Greenwich, CN: JAI Press.

Shirom, A. (2007). Explaining vigor: On the antecedents and consequences of vigor as a positive affect at work. In C. L. Cooper \& D. Nelson (Eds.), Positive Organizational Behavior (pp. 86- 100). London: Sage.

Simsek, Z., \& Veiga, J. (2001). A primer on Internet organizational surveys. Organizational Research Methods, 4, 218-235.

Slater, P. E. (1966). Microcosms: Structural, psychological, and religious evolution in groups. New York: Wiley.

Smith, K. K., \& Berg, D. N. (1987). Paradoxes of group life. San Francisco: Jossey Bass.

Sonnentag, S. (2003). Recovery, work engagement, and proactive behavior: A new look at the interface between nonwork and work. Journal of Applied Psychology, 88, $518-528$.

Sprang, G., Clark, J. J., \& Whitt-Woosley, A. (2007). Compassion fatigue, compassion satisfaction, and burnout: Factors impacting a professional's quality of life. Journal of Loss and Trauma, 12, 259-280.

Stanton, J. M. (1998). An empirical assessment of data collection using the Internet. Personnel Psychology, 51, 709-725.

States, A. (2008, April 17). The rage to engage. Time. Retrieved June 14, 2008, from http://www.time.com/time/magazine/article/0,9171,1731893,00.html

Steel, R. P., \& Ovalle, N. K. (1984). A review of the meta-analysis of research on the relationship between behavioral intentions and employee turnover. Journal of Applied Psychology, 69, 673-686.

Tabachnick, B. G., \& Fidell, L. S. (2001). Using multivariable statistics (4 ${ }^{\text {th }}$ ed.). Boston: Allyn \& Bacon.

Taylor, S., \& Lynn, P. (1998). The effect of a preliminary notification letter to a postal survey of young people. Journal of the Market Research Society, 2, 165-178. 
The Gallup Organization. (2001, March 15). What your disaffected workers cost. Gallup Management Journal. Retrieved from http://gmj.gallup.com/content/439/WhatYour-Disaffected-Workers-Cost.aspx

The Ken Blanchard Companies. (2008). 2008 corporate issues survey. Guildford, United Kingdom: Author.

Thomas, C. H. (2007). A new measurement scale for employee engagement: Scale development, pilot test, and replication. Academy of Management Proceedings, 1 $6,6 \mathrm{p}$.

Thoits, P. A. (1991). On merging identity theory and stress research. Social Psychology Quarterly, 54, 101-112.

Towers Perrin. (2003). Working today: Understanding what drives employee engagement. Retrieved from http://www.towersperrin.com/tp/getwebcachedoc?webc=hrs/usa/2003/200309/tale nt_2003.pdf

Towers Perrin. (2007). Closing the engagement gap: A road map for driving superior business performance. Retrieved from http://www.biworldwide.com/info/pdf/Towers_Perrin_Global_Workforce_Study. pdf

Tsui, A. S., Pearce, J. L., Porter, L. W., \& Tripoli, A, M. (1997). Alternative approaches to the employee-organization relationship: Does investment in employees pay off? Academy of Management Journal, 40, 1089-1121.

Vance, R. J. (2006). Employee engagement and commitment: A guide to understanding, measuring, and increasing engagement in your organization. Alexandria, VA: The SHRM Foundation.

Verquer, M. L., Beehr, T. A., \& Wagner, S. H. (2003). A meta-analysis of relations between person-organization fit and work attitudes. Journal of Vocational Behavior, 63, 473-489.

Wagner, R., \& Harter, J. K. (2006). 12: The great elements of managing. Washington, DC: The Gallup Organization.

Waltman, G. H. (1990). New options in continuing education: Professional development for rural social workers. Human Services in the Rural Environment, 13, 16-20.

Watt, J. W., \& Kelly, M. J. (1996). Addressing practitioner's isolation through new technologies: Creating an electronic journal for students, practitioners, and educators via the internet. Human Services in the Rural Environment, 19, 10-15. 
Wefald, A. J., \& Downey, R. G. (in press). The construct dimensionality of engagement and its relationship with satisfaction. The Journal of Psychology: Interdisciplinary and Applied.

Welfad, A. (2008). An examination of job engagement, transformational leadership, and related psychological constructs. Unpublished doctoral dissertation, Kansas State University, Manhattan.

Xanthopoulou, D., Bakker, A. B., Demerouti, E., \& Schaufeli, W. B. (2007). The role of personal resources in the job demands-resources model. International Journal of Stress Management, 14, 121-141.

U.S. Department of Labor, Bureau of Labor Statistics. (2009, December 4). Total employment and the labor force (Household Survey data). Retrieved from http://www.bls.gov/news.release/pdf/empsit.pdf

Yaghi, A., Goodman, D., Holton, E. F., \& Bates, R. A. (2008). Validation of the Learning Transformation System Inventory. A study in the public sector in Jordan. Journal of Occupational Health Psychology, 19, 93-104.

Yildirim, I. (2008). Relationships between burnout, sources of social support and sociodemographic variables. Social Behavior and Personality, 36, 603-616.

Yin, R. K. (2003), Case study research: Design and methods (3rd ed.), London: Sage.

Yun, G. W., \& Trumbo, C. W. (2000). Comparative response to a survey executed by post, e-mail, \& web form. Journal of Computer Mediated Communication, 6(1). Retrieved from http://www.ascuse.org/jcmc/vol6/issue1/yun.html

Zigarmi, D., Nimon, K., Houson, D., Witt, D., \& Diehl, J. (2009). Beyond engagement: Toward a framework and operational definition for employee work passion. Human Resource Development Review, 8, 300-326. 


\section{Appendix}

Please rate the following questions using the scale below:

$1=$ Strongly Disagree

$2=$ Disagree

$3=$ Neutral

4= Agree

$5=$ Strongly Agree

Modified Meaningfulness Scale (May, Gibson, \& Harter, 2004)

1. The work I do on this job is very important to me.

2. My job activities are personally meaningful to me.

3. The work I do on this job is worthwhile.

4. My job activities are significant to me.

5. The work I do on this job is meaningful to me.

6. I feel that the work I do on this job is valuable.

\section{Modified Safety Scale (May et al., 2004)}

1. I can be myself at work.

2. At work I can bring up problems and tough issues without fear of being teased or made fun of.

3. I feel physically safe at work.

4. At work, I know is expected of me everyday.

5. Each day my work demands are consistent.

Modified Availability Scale (May et al., 2004)

1. At work, I have the support I need to complete my job.

2. At work, I have the resources I need to complete my job.

3. I am mentally and emotionally absorbed in my job when I am working.

4. I have the skills and training I need to complete my work at the level that is expected of me.

5. If I do not have the resources to complete my work, I am confident my organization would help me get them.

Modified Psychological Climate Measure (Brown \& Leigh, 1996)

Supportive management subscale

1. My boss is flexible about how I accomplish my job objectives.

2. My manager is supportive of my ideas and ways of getting things done.

3. My boss gives me the authority to do my job as I see fit.

4. I'm careful in taking responsibility because my boss is often critical of new ideas. [reverse scored]

5. I can trust my boss to back me up on decisions I make in the field. Contribution subscale

6. I feel very useful in my job.

7. Doing my job well really makes a difference. 
8. I feel like a key member of the organization.

9. The work I do is very valuable to the organization. Recognition subscale

10. I rarely feel my work is taken for granted.

11. My supervisors generally appreciate the way I do my job.

12. The organization recognizes the significance of the contributions I make. Challenge subscale

13. My job is very challenging.

14. It takes all my resources to complete my work objectives.

Person-Organization Fit Scale (Resick et al., 2007)

1. I feel my values "match" or fit this organization and the current employees in this organization.

2. I think the values and personality of this organization reflect my own values and personality.

3. The values of this organization are similar to my own values.

4. My values match those of current employees to this organization.

5. I feel my personality matches the "personality" or image of this organization.

Affective Commitment Scale (Rhoades et al., 2001)

1. I feel a strong sense of belonging to my organization.

2. I feel personally attached to my work organization.

3. I am proud to tell others I work at my organization.

4. Working at my organization has a great deal of personal meaning to me.

5. I would be happy to work at my organization until I retire.

6. I really feel that problems faced by my organization are also my problems.

Discretionary Effort Scale (Lloyd, 2008)

1. When I work, I really exert myself to the fullest, beyond that what is expected.

2. I finish a job even if it means sacrificing breaks or lunches.

3. I do more than is expected of me.

4. I voluntarily put in extra hours to achieve a result faster.

5. I persist in overcome obstacles to complete an important task.

6. I put in extra effort when I find it necessary.

7. I work harder that expected to help my organization be successful.

Intention to Turnover Scale (Colarelli, 1984)

1. I frequently think of quitting my job.

2. I am planning to search for a new job during the next 12 months

3. If I have my own way, I will be working for this organization one year from now. [reverse scored] 
VITA

\section{MICHAEL BRADLEY SHUCK}

Place of Birth

2002

2003-2005

2005

2005-2007

$2007-2008$

2007-2008

2007-Present

2008- 2010

2010

2010-Present
Louisville, Kentucky

Bachelor of Education \& Behavioral Sciences

Western Kentucky University, Bowling Green, Kentucky

Program Development Specialist

Leadership Strategies, Bowling Green, Kentucky

Master of Arts in Education,

Western Kentucky University, Bowling Green, Kentucky

Residence Life Coordinator

Florida Intentional University, Miami, Florida

Associate Director, Career Services Office

Florida Intentional University, Miami, Florida

Certified Lead Coach Training Consultant

National Association of College and Employers,

Bethlehem, Pennsylvania

Certified Myers Briggs Type Indicator Instructor

Center for Applications of Psychological Type,

Gainesville, Florida

Human Resource Development Specialist

Norwegian Cruise Line, Miami, Florida

Dissertation Evidence Acquisition Fellow

University Graduate School, Florida Intentional University, Miami, Florida

Assistant Professor

Educational Leadership, Foundations and Human Resource Education, University of Louisville, Louisville, Kentucky 


\section{PUBLICATIONS AND PRESENTATIONS}

Shuck, B., \& Wollard, K. (2010). Employee engagement \& HRD: A seminal review of the foundations. Human Resource Development Review, 9(1), 89-110.

Ghosh, R., Shuck, B., \& Petrosko, J. (2010). Group emotional intelligence and organizational learning and performance in work teams: Implications for HRD theory and practice. In C. Graham (Ed.), Proceedings of the Academy of Human Resource Development, 2010 Annual Conference (22-2). Knoxville, TN: AHRD.

Guitierrez, C. C., Baralt, S, \& Shuck , B. (2010). Engagement's role in adult learning: Implication for HRD practice. In S. M. Nielsen \& M. S. Plakhotnik (Eds.), Proceedings of the Ninth Annual College of Education Research Conference: Urban and International Education Section (xx-xx). Miami: Florida International University. http://coeweb.fiu.edu/research_conference/.

Shuck, B. (2009). Engagement leadership: A new developmental model. In S. M. Nielsen \& M. S. Plakhotnik (Eds.), Proceedings of the Eight Annual College of Education Research Conference: Urban and International Education Section (pp. 126-132). Miami: Florida International University. http://coeweb.fiu.edu/research_conference/.

Shuck, B., \& Wollard, K, (2009). A historical perspective of employee engagement: An emerging definition. In S. M. Nielsen \& M. S. Plakhotnik (Eds.), Proceedings of the Eight Annual College of Education Research Conference: Urban and International Education Section (pp. 133-139). Miami: Florida International University. http://coeweb.fiu.edu/research_conference/.

Montalvo, B. M., Shuck, B. (2008). The new worker economy: Trends and issues in retaining $21^{\text {st }}$ century talent $\&$ implications for practitioners. The Australian Career Practitioner, 19, 13-14. 